Portland State University

PDXScholar

1988

\title{
Voltage controlled resistance model for MOS transistors
}

Joey Zong-yi Jia

Portland State University

Follow this and additional works at: https://pdxscholar.library.pdx.edu/open_access_etds

Part of the Electrical and Computer Engineering Commons Let us know how access to this document benefits you.

Recommended Citation

Jia, Joey Zong-yi, "Voltage controlled resistance model for MOS transistors" (1988). Dissertations and Theses. Paper 3802.

https://doi.org/10.15760/etd.5686

This Thesis is brought to you for free and open access. It has been accepted for inclusion in Dissertations and Theses by an authorized administrator of PDXScholar. Please contact us if we can make this document more accessible: pdxscholar@pdx.edu. 
AN ABSTRACT OF THE THESIS OF Joey Zong-yi Jia for the Master of Science in Electrical Engineering presented May 16, 1988.

Title: Voltage Controlled Resistance Model for MOS transistors.

APPROVED BY THE MEMBERS OF THE THESIS COMMITTEE:

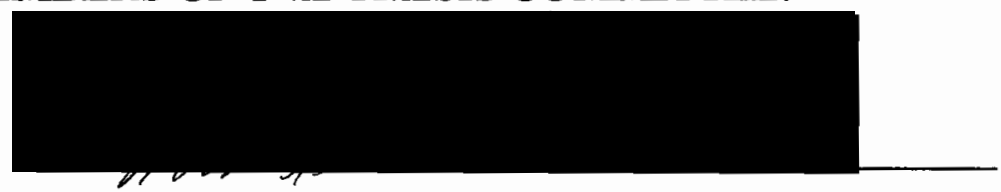

W. Robert Daasch, Chair

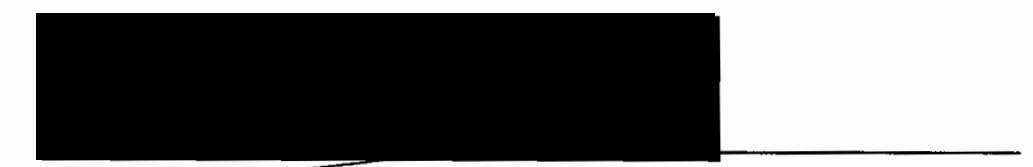

Paul Van Halen

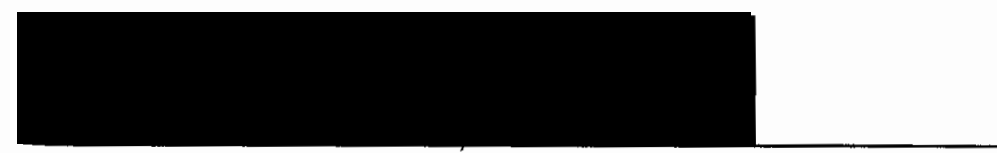

Rajinder P. Aggarwal

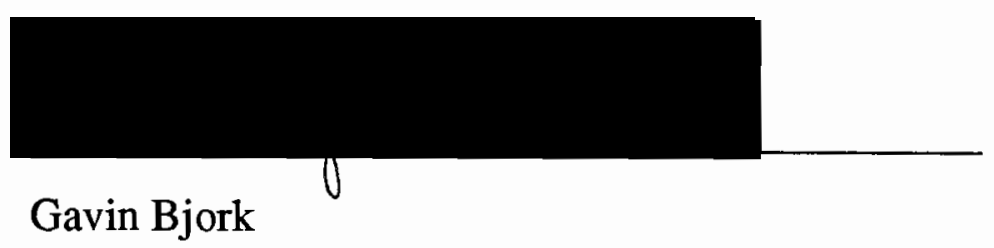

The voltage controlled resistance model is developed for a reliable MOS transistor resistance mapping. The model includes both system and local parameters, and incorporates the effect of rise and fall time variations on the gate delay. MOS transistor resistance mapping is applied in logic simulation and timing verification. Also, it can be used in automatic transistor sizing and critical path analysis. 


\title{
VOLTAGE CONTROLLED RESISTANCE MODEL FOR MOS TRANSISTORS
}

\author{
by
}

JOEY ZONG-YI JIA

A thesis submitted in partial fulfillment of the requirement for the degree of

\author{
MASTER OF SCIENCE \\ in \\ ELECTRICAL ENGINEERING
}

Portland State University

1988 
TO THE OFFICE OF GRADUATE STUDIES:

The members of the Committee approve the thesis of Joey Zong-yi Jia presented May 16, 1988.

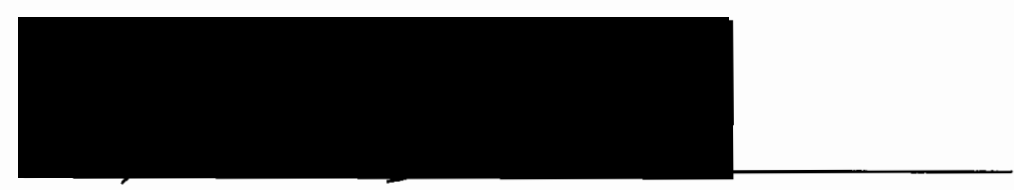

W. Robert Daasch, Chair

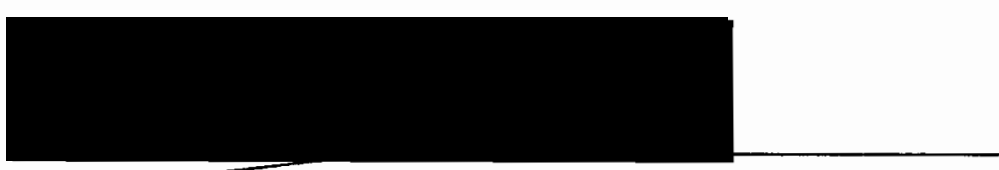

Paul Van Halen

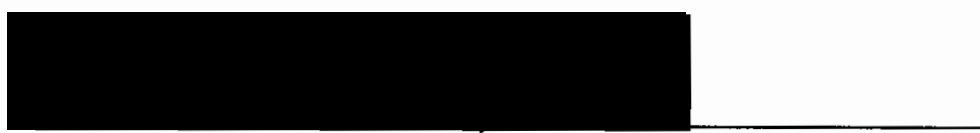

Rajinder P. Aggarwal

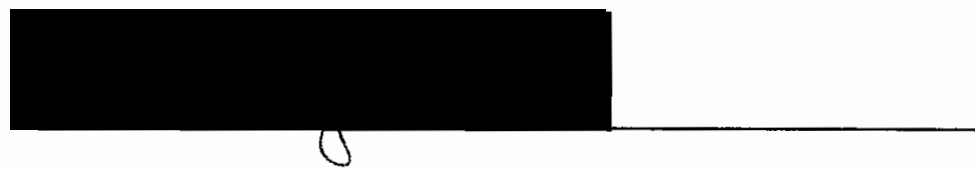

Gavin Bjork

APPROVED:

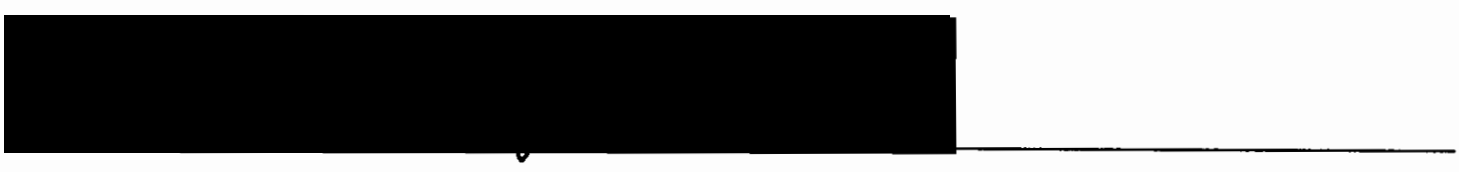

Lee W. Casperson, Chair, Department of Electrical and Computer Engineering

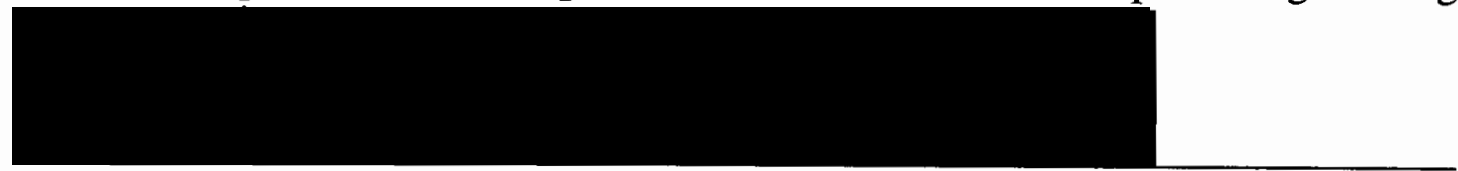

Bernard Ross, Vice Provost for Graduate Studies 


\section{ACKNOWLEDGEMENT}

I want to give the best regards to my advisor Dr. Robert Daasch who has been guiding and helping me all the time in the process of this research work. I would like to say thanks for his great confidence and persistence in the tremendous experimental work, also for his generous and enthusiastic suggestions whenever I needed them. Dr. Daasch's remarkable intelligence and serious working attitude have made a deep impression on me. It is really very informative and pleasant for me to work with him.

Besides, a number of people at Electrical and Computer Engineering Department gave instrumental helping for this research work. In particular, Ms. Shirley Clark, Mr. Janaka Jayawardena, and Mr. Daniel Greenfield are warmly appreciated for their help and convenience in using utility equipment.

Also I would like to acknowledge Mr. Arthur Chin and Mrs. Vivienne Chin for their long-term support, and to Mr. Dietmar Bornikel for his encouragement.

Many thanks to all my friends who have been helping, supporting, and encouraging me.

Portland, Oregon

J. J. 


\section{TABLE OF CONTENTS}

PAGE

ACKNOWLEDGEMENTS iii

LIST OF TABLES

$\mathrm{v}$

LIST OF FIGURES

vii

\section{CHAPTER}

I HISTORICAL

II MODEL FORMATION ............................................................ 17

Cutoff Region ................................................................... 19

Saturation Region .............................................................. 19

Linear Region .................................................................. 25

III MODEL COMPARISON AND ITS USAGE …………................ 31

Model Comparison .................................................................... 31

Positive and Negative Delay .................................................... $\quad 37$

New Event Driven RC Delay Algorithm ................................. $\quad 40$

IV TEST RESULTS ..................................................................... 46

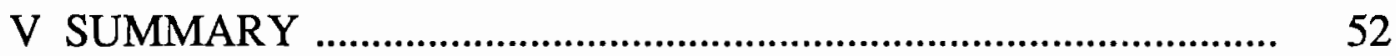

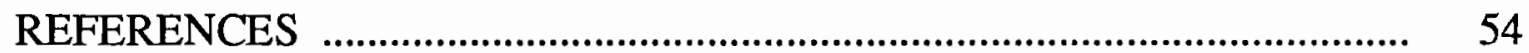

APPENDIX
A. TABLES OF COMPARISONS
B. SPICE DECKS ……........................................................... 73
C. PROGRAM CODE OF BISECTION METHOD ........................... 81 


\section{LIST OF TABLES}

TABLE

PAGE

I. The Terminal Voltage of a Single RC Circuit Is an Exponential Function of $t / R C$

II. A Comparison of SPICE Level 2, Level 1 Evaluated Resistances and the Model Resistance of an MOS Transistor with $\mathrm{W} / \mathrm{L}=8 / 3$ $(\mu \mathrm{m} / \mu \mathrm{m})$

III. A Comparison of SPICE Level 2, Level 1 Evaluated Resistances and the Model Resistance of an MOS Transistor with W/L $=16 / 3$ $(\mu \mathrm{m} / \mu \mathrm{m})$

IV. A Comparison of SPICE Level 2, Level 1 Evaluated Resistances and the Model Resistance of an MOS Transistor with $\mathrm{W} / \mathrm{L}=5 / 5$ $(\mu \mathrm{m} / \mu \mathrm{m})$

V. A Comparison of SPICE Level 2, Level 1 Evaluated Resistances and the Model Resistance of an MOS Transistor with $\mathrm{W} / \mathrm{L}=5 / 10$ $(\mu \mathrm{m} / \mu \mathrm{m})$

VI. A Comparison of $\Delta \mathrm{R}_{\mathrm{spc} 2}, \Delta \mathrm{R}_{\mathrm{spcl}}$ and $\Delta \mathrm{R}_{\text {mod }}$ of an NMOS Transistor with $\mathrm{W} / \mathrm{L}=8 / 3(\mu \mathrm{m} / \mu \mathrm{m})$

VII. A Comparison of $\Delta R_{s p c 2}, \Delta R_{s p c 1}$ and $\Delta R_{\bmod }$ of an NMOS Transistor with $\mathrm{W} / \mathrm{L}=16 / 3(\mu \mathrm{m} / \mu \mathrm{m})$

VIII. A Comparison of $\Delta \mathrm{R}_{\mathrm{spc} 2}, \Delta \mathrm{R}_{\mathrm{spc} 1}$ and $\Delta \mathrm{R}_{\mathrm{mod}}$ of an NMOS Transistor with $\mathrm{W} / \mathrm{L}=5 / 5(\mu \mathrm{m} / \mu \mathrm{m})$ 
IX. A Comparison of $\Delta R_{\text {spc2 }}, \Delta R_{\text {spc1 } 1}$ and $\Delta R_{\text {mod }}$ of an NMOS

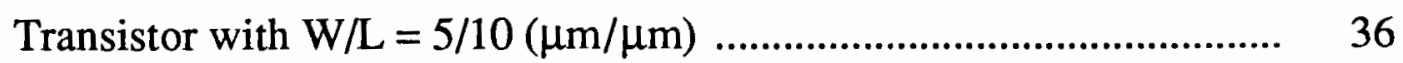

X. A Comparison of Two Different SPICE Deck Evaluated Results of an NMOS Transistor with $\mathrm{W} / \mathrm{L}=8 / 3(\mu \mathrm{m} / \mu \mathrm{m})$............................. 38

XI. A Comparison of Two Different SPICE Deck Evaluated Results of an NMOS Transistor with $\mathrm{W} / \mathrm{L}=16 / 3(\mu \mathrm{m} / \mu \mathrm{m})$............................ 38

XII. A Comparison of Two Different SPICE Deck Evaluated Results of an NMOS Transistor with $\mathrm{W} / \mathrm{L}=5 / 5(\mu \mathrm{m} / \mu \mathrm{m})$.............................. 39

XIII. A Comparison of Two Different SPICE Deck Evaluated Results

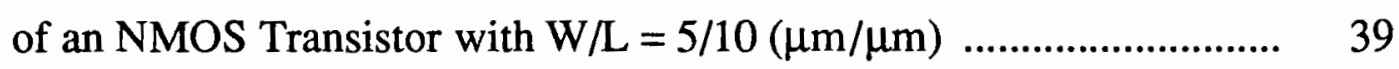

XIIII. The Test Result Table for a CMOS Three-input NAND Gate ............. $\quad 46$

XV. The Test Result Table for a CMOS Three-input NOR Gate ................. 48

XVI. The Test Result for a CMOS 3X2 PLA ……………………………..... 49

XVII. The Frequency Comparison Table for a Five-stage Ring Oscillator 


\section{LIST OF FIGURES}

FIGURE

PAGE

1-1. An MOS transistor is modeled as a switch with a series resistor in

the switch-level model

1-2. The circuit used to demonstrate RC time constant predicting the terminal voltage $\mathrm{V}_{\mathrm{C}}$

1-3(a).The circuit used for finding effective resistance of an n-type transistor

$1-3(b)$. Terminal voltage $V_{C}$ versus time $t$

1-4(a). The circuit used for finding effective resistance of a p-type

transistor

1-4(b).Terminal voltage $V_{C}$ versus time $t$

1-5. Element of an RC tree (a) A lumped capacitor (b) A lumped resistance (c) An $\mathrm{RC}$ line

1-6. The example of an $\mathrm{RC}$ tree network

1-7(a). The logic diagram of a four-stage inverter chain

1-7(b). The circuit diagram of a four-stage inverter chain

1-8. The switch-level model of the first stage of the four-stage inverter chain

1-9. The switch-level model of the second stage of the four-stage inverter chain 
1-10. The diagram of the event driven delay time

1-11. The circuit used to define an n-type transistor's quasi-static resistance

1-12. The circuit used to define a p-type transistor's quasi-static resistance

2-1. The experiment circuit used to develop the dynamic resistance model of an n-type MOS transistor

2-2. Distribution of $t_{\text {delay }}, t_{\text {off }}, t_{\text {sat }}$, and $t_{\text {lin }}$ in the time axis

2-3(a). The transition happens after $\mathrm{T}, \mathrm{t}_{\mathrm{sl}}>\mathrm{T}$

2-3(b). The transition happens at $\mathrm{T}, \mathrm{t}_{\mathrm{sl}}=\mathrm{T}$

2-3(c). The transition happens before $\mathrm{T}, \mathrm{t}_{\mathrm{sl}}<\mathrm{T}$

2-4. The experiment circuit with Miller capacitance included

3-1. The circuit used to specify three different delay cases

3-2(a). First delay case where $\tau>\mathrm{T}$

3-2(b). Second delay case where $\mathrm{T} / 2<\tau=\mathrm{T}$

3-2(c). Third case where $V_{\text {th }}<\tau \leq T / 2$

3-3. The diagram of the event delay time using the quasi-static resistance model

4-1. The logic diagram for the simulated three-input CMOS NAND gate

4-2. The logic diagram for the simulated three-input CMOS NOR gate

4-3. The logic diagram for the simulated five-stage ring oscillator 


\section{CHAPTER I}

\section{HISTORICAL}

In the modern MOS VLSI design, simulation is an important and necessary step in a digital circuit design process. Designers use simulation tools to predict and verify their designs' performance and function. Thus they are able to find errors early in the design cycle rather than after the expensive and time-consuming step of manufacturing. The design-simulation-redesign cycle has been substituted for the design-manufacture-redesign cycle, which efficiently reduces the design period and the cost of manufacturing prototypes. Simulation is significant in the design procedure. Therefore, well-designed computer simulation tools are extremely important. A good simulator (simulation program) should give a designer reliable close-to-real results.

Different simulators are applied in different design stages. In the function design stage, programs such as Adlib-Sable [01] verify the functional aspects of a design. But they are not able to supply time verifications to users. In the conventional circuit analysis stage, simulators such as ASTAP [02] and SPICE [03] give detailed analogic results of a circuit by solving coupled differential equations. The disadvantage is that they consume enormous computer CPU time when they simulate large size circuits. In between these two types of simulators, several logic level simulators $[04,05]$ have been developed for handling very large scale digital circuits. An example of the logic level simulator is RSIM [06], an MOS digital circuit simulator designed by Christopher Jay Terman at the Massachusetts Institute of Technology in 1983. A digital circuit can be described in terms of 
behavioral-level [07], register-transfer-level [07], gate-level [07], transistor-level [07], and switch-level models [01, 07, 08]. Various models might be used for different simulators. Among logic level simulators, the RC switch-level model has been widely adopted since the model uniformly represents MOS device circuits well and may predict the circuit delay time with acceptable accuracy. Also according to Tsao [07], simulation modes can be classified as unit-delay mode, multiple-delay mode [09], timing mode [10] and the mixture of these modes [11]. The unit-delay mode verifies the logic of a circuit only. It does not supply any timing information at all. The multiple-mode presents logic levels by 0,1 , and $X$ (unknown), with some precalculated rise and fall delays. The timing mode is a simplified form of a conventional circuit analysis program such as ASTAP and SPICE. The mixture-mode is the combination of the three modes described above. As in the example above, RSIM is the switch-level multiple-delay simulator. It uses the event-driven algorithm to simulate a digital circuit as a switch-level RC network, and it predicts the time delay using the effective resistance $R_{\text {eff }}$.

In a switch-level RC network, an MOS transistor can be modeled as a switch with a series resistor [06]. The switch has three states: open, closed, and unknown. All three states are controlled by a normalized gate voltage, $\mathrm{V}_{\mathrm{gs}}$. Voltage levels can be normalized by 1,0 , and X. 1 indicates the voltage level above a preset high logic threshold voltage and beyond 5 volts. 0 indicates the voltage level above 0 volt and beyond a preset low logic threshold voltage. $\mathrm{X}$ represents an unknown voltage level which is above the low logic threshold voltage and beyond the high logic threshold voltage. For instance, a single transistor with a load capacitor in Figure 1-1(a) can be modeled in Figure 1-1(b). When $\mathrm{V}_{\mathrm{gs}}=1$, the switch is closed and $R=R_{\text {eff }}$. When $V_{g s}=0$, the switch is open and $R=\infty$. The switch is in an unknown state if $\mathrm{V}_{\mathrm{gs}}=\mathrm{X}$, meaning that the $\mathrm{R}$ is in the range $\mathrm{R}_{\mathrm{eff}}<\mathrm{R}<\infty$. 


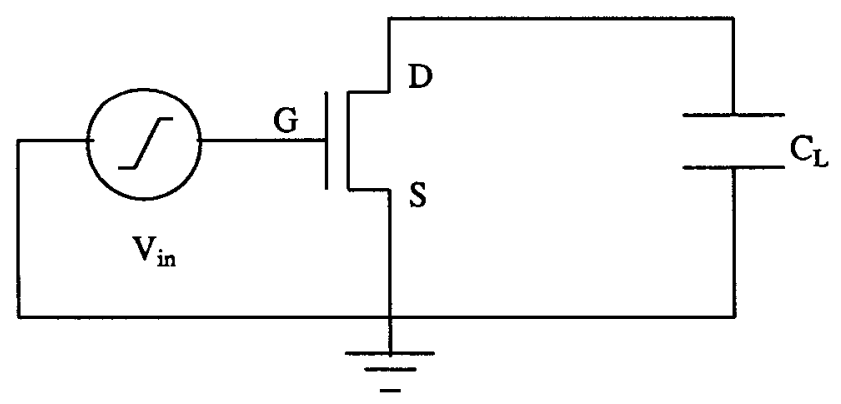

(a)

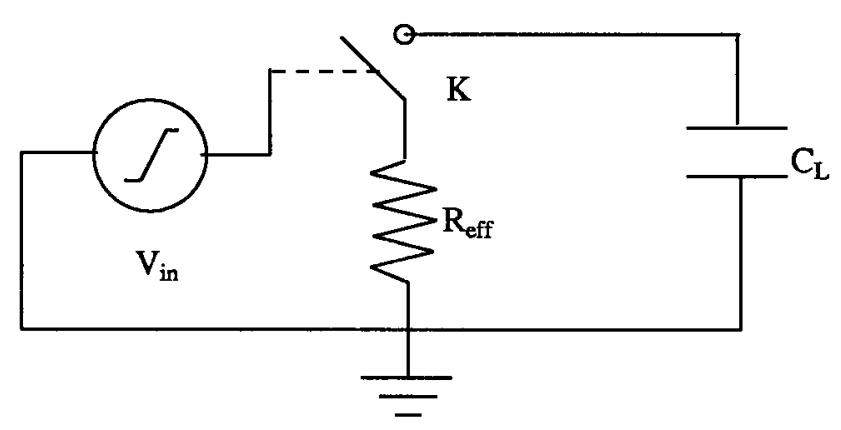

(b)

Figure 1-1. An MOS transistor is modeled as a switch with a series resistor in the switch-level model

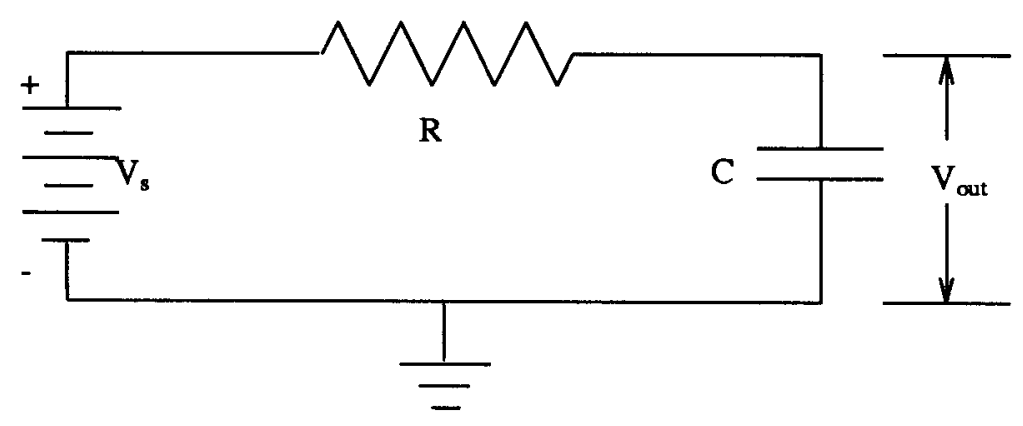

Figure 1-2. The circuit used to demonstrate RC time constant predicting the instantaneous terminal voltage $\mathrm{V}_{\mathrm{C}}$

$R_{\text {eff }}$ is called an effective resistance [06, 12], more accurately, an effective channel resistance. An effective resistance differs from the actual resistance since 
it is physically unmeasurable. For instance, the circuit in Figure 1-2 has a time constant RC. R and C are values of the physical resistor and capacitor in the circuit. The time constant $\mathrm{RC}$ is used to predict the instantaneous voltage value of $\mathrm{V}_{\text {out }}$.

\section{TABLE I}

THE TERMINAL VOLTAGE OF A SINGLE RC CIRCUIT IS AN EXPONENTIAL FUNCTION OF $\mathrm{t} / \mathrm{RC}$

\begin{tabular}{|c||c|}
\hline $\mathrm{t}=$ & $\mathrm{V}_{\text {out }}=$ \\
\hline \hline $\mathrm{RC}$ & $0.632 \mathrm{~V}_{\mathrm{s}}$ \\
\hline $2 \mathrm{RC}$ & $0.865 \mathrm{~V}_{\mathrm{s}}$ \\
\hline $3 \mathrm{RC}$ & $0.950 \mathrm{~V}_{\mathrm{s}}$ \\
\hline $4 \mathrm{RC}$ & $0.982 \mathrm{~V}_{\mathrm{s}}$ \\
\hline $5 \mathrm{RC}$ & $0.993 \mathrm{~V}_{\mathrm{s}}$ \\
\hline
\end{tabular}

If we define the time $\tau$ when $V_{\text {out }}$ reaches the value $0.865 \mathrm{~V}_{s}, \tau$ is equal to $2 \mathrm{RC}$. This time can be expressed by $\tau=R_{\text {eff }} * C$. In this case, $\tau=R_{\text {eff }} * C=2 R C$ and $R_{\text {eff }}=\tau / C=2 R$. $R_{\text {eff }}$ is defined by a user and used to predict delay times as multiple of the RC time constant. Of course, it could be a fraction of the RC time constant too.

$$
\tau_{\text {delay }}=\mathrm{R}_{\mathrm{eff}} * \mathrm{C}
$$

A digital circuit can map to a switch-level RC network by mapping MOS transistors to associated effective resistances. A look-up-table of effective resistance values, indexed by different sizes and types of transistors, is one method for calibrating such a model. The table is typically obtained from SPICE simulation of 
different sizes and types of transistors. The principle of calculating effective resistance is to measure a charge time $\tau_{c}$ or a discharge time $\tau_{d}$ of a capacitor $C_{L}$, charging or discharging through an MOS transistor. The effective resistance is the ratio of $\tau$ over $C_{L}$. To find the effective resistance for an $n$-type transistor, SPICE analyzes the transistor at $\mathrm{V}_{\mathrm{gs}}=5 \mathrm{~V}$ discharging a capacitor $\mathrm{C}_{\mathrm{L}}$ until the voltage across the capacitor $\mathrm{C}_{\mathrm{L}}$ drops down to a logic threshold voltage. Here the power supply $\mathrm{V}_{\mathrm{dd}}$ is $5 \mathrm{~V}$, and the logic threshold voltage is $2.5 \mathrm{~V}$. The capacitor $\mathrm{C}_{\mathrm{L}}$ is set to $5 \mathrm{~V}$ initially. The discharge time $\tau_{\mathrm{d}}$ is analyzed by SPICE, and the effective resistance $R_{\text {eff }}$ is defined as $R_{\text {eff }}=\tau_{d} / C_{L}$. Figure 1-3(a) shows the circuit used by SPICE to analyze the discharge time $\tau_{\mathrm{d}}$. Figure $1-3(\mathrm{~b})$ shows the plot of the terminal voltage $\mathrm{V}_{\mathrm{C}}$ versus time $\mathrm{t}$.

Similarly, SPICE analyzes a p-type transistor at $\mathrm{V}_{\mathrm{gs}}=0 \mathrm{~V}$ charging a load capacitor $C_{L}$ until the voltage across the $C_{L}$ rises up to a logic threshold voltage $2.5 \mathrm{~V}$. In the similar way as the n-type transistor analysis, the power supply is $\mathrm{V}_{\mathrm{dd}}$ $5 \mathrm{~V}$, and the $\mathrm{C}_{\mathrm{L}}$ is initially set to $0 \mathrm{~V}$. The charging time $\tau_{\mathrm{c}}$ is analyzed by SPICE. The effective resistance is $R_{\text {eff }}=\tau_{c} / C_{L}$. Figure 1-4(a) shows the circuit used by SPICE to find the charging time $\tau_{c}$. Figure 1-4(b) is the plot of $V_{C}$ versus time $t$.

Richman et. al. [12] have applied the effective resistance for automatic transistor sizing and critical delay path analysis. However, they obtained the effective resistance value by measuring pair delay of a different sized and loaded inverter chain.

An RC tree is the base structure of a switch-level RC network model. An RC tree [13] is a network which contains resistors and capacitors only and is defined as following:

(1) A lumped capacitor between ground and another node is an RC tree. 


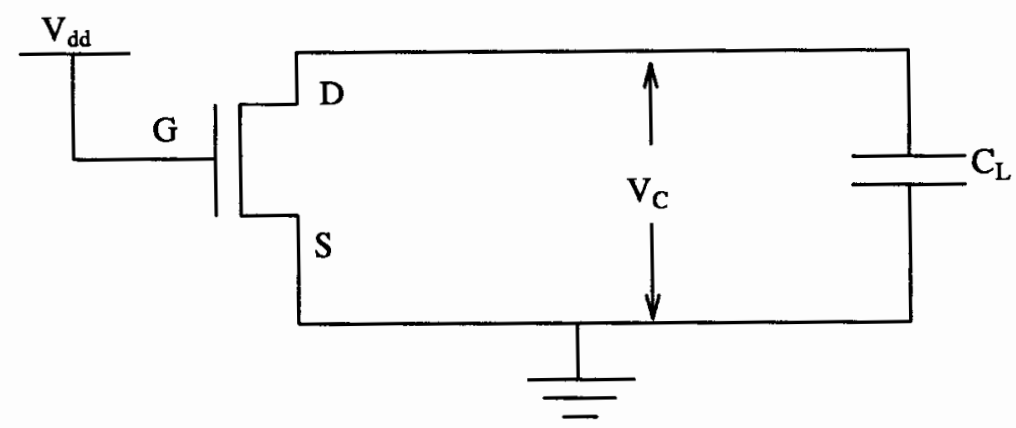

(a)

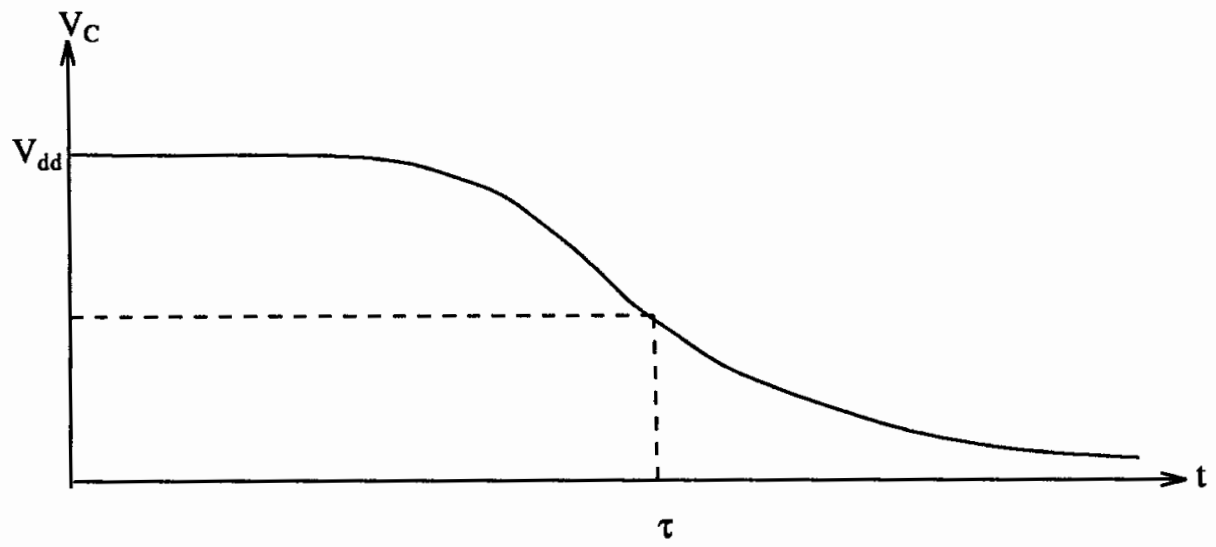

(b)

Figure 1-3. (a) The circuit used for finding effective resistance of an $\mathrm{n}$-type transistor. (b) Terminal voltage $\mathrm{V}_{\mathrm{C}}$ versus time $\mathrm{t}$

(2) A lumped resistor between two nonground nodes is an RC tree.

(3) An RC line with no de path to ground is an $\mathrm{RC}$ tree.

(4) Any two RC trees with common grounds and one nonground node from each tree connected together is a new RC tree.

(5) No resistor loop exists and all capacitors are grounded in an RC tree network. Three elements of an RC tree is shown in Figure 1-5.

Rubinstein et. al. [13], Lin et. al. [14] and Zukowski [15] have mapped the MOS circuit into an RC tree network to estimate a signal delay in the circuit. In the MOS transistor resistor mapping technique, an MOS transistor can map to dif- 


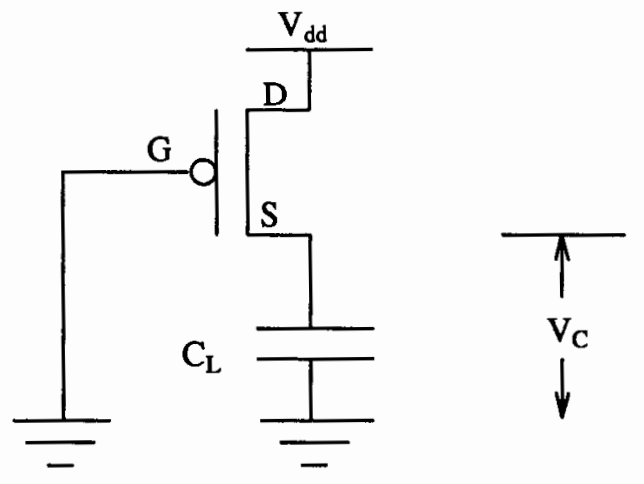

(a)

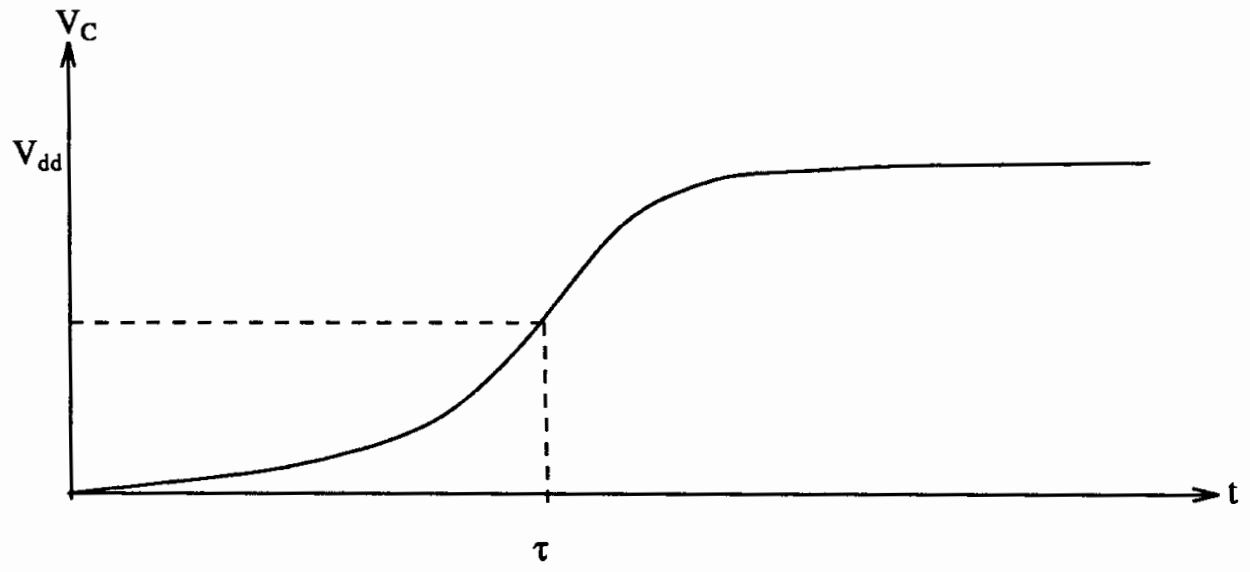

(b)

Figure 1-4. (a) The circuit used for finding effective resistance of a ptype transistor (b)Terminal voltage $V_{C}$ versus time $t$

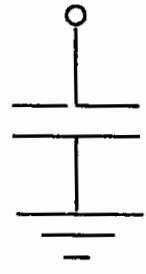

(a)

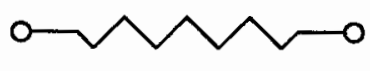

(b)

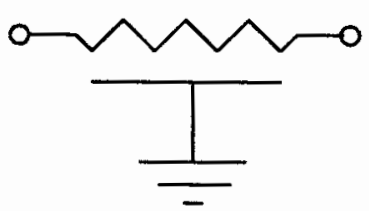

(c)

Figure 1-5. Elements of an RC tree (a) A lumped capacitor (b) A lumped resistor (c) An RC line 
ferent resistance values according to its operating states. When a transistor is turned on, it maps to a nonlinear resistor with the resistance $R=V_{d s} / I_{d s}$. When it is turned off, it maps to an infinity, $R=\infty$. The sum of gate and interconnect capacitances maps to the lumped capacitances of the RC network. For example, a long and wide poly wire contributes significant capacitance to an RC tree.

In an RC tree network, the delay time of any node can be found by adding certain RC values along an unique charging or discharging path [13].

$$
\mathrm{T}_{\mathrm{DI}}=\sum_{\mathbf{k}} \mathrm{R}_{\mathbf{k i}} \mathrm{C}_{\mathbf{k}}
$$

In the example of Figure 1-6, the delay time of the output node can be expressed as

$$
\tau_{\text {out }}=\left(R_{1}+R_{2}+R_{3}+R_{4}\right] C_{4}+\left[R_{1}+R_{2}+R_{3}\right) C_{3}+\left(R_{1}+R_{2}\right) C_{2}+R_{1} C_{1}
$$

However, in all cases the more accurate the $\mathrm{R}$ used, the more accurate the delay time will be.

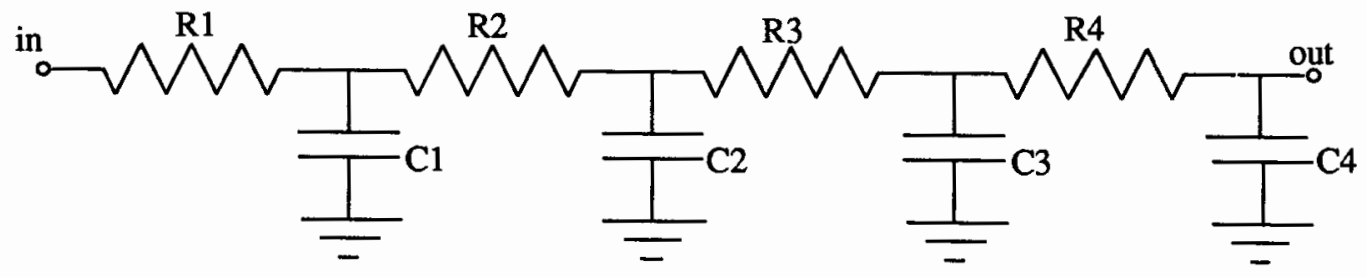

Figure 1-6. The example of an $\mathrm{RC}$ tree network

RSIM begins its logic network simulation when a user changes the value of an input node. In RSIM, any node given a value by a user is treated as an input node with zero impedance. Starting from an input node, RSIM analyzes a network stage by stage using MOS transistor's switch-resistor model. A stage, according to Terman [06], is a subnetwork where its inputs are isolated from its outputs, or a 
searching point reaches a zero impedance source or drain node. An example of a four stage network is shown in Figure 1-7. The change in a node's logic value causes RSIM to analyze a stage. RSIM calculates the transition or delay time by estimating the length of the time required to charge or discharge the node's capacitance.

Another term event is also used in the logic simulation. In RSIM [06], an event is defined as a packet which contains the name of a node, its new logic level, and the estimated time in which the transition to the new value occurs. RSIM keeps a list of pending events in a time sequence, with the earliest event first. A new event is generated and stored on the event list when processing new input values causes a node to change its value. After all inputs have been processed, RSIM returns to process events on the event list, starting with the earliest event first. For each event, the new value contained in the event packet is assigned to the specified node. Then, all stages affected by this node's new value are analyzed and new events are generated during the analysis. These new events are inserted into the event list. RSIM continues processing events until the event list is empty. The network, at this point, is said to have settled, and the new input values have been completely propagated through out the network.

The logic network in Figure 1-7 is used to demonstrate RSIM's logic simulation procedure. The network consists of four CMOS inverters in the series. Figure 1-7(a) presents this network's logic diagram. The network can be divided into four stages. Figure 1-7(b) shows its circuit diagram. In the diagram, $\mathbf{M}_{1}, \mathrm{M}_{3}, \mathrm{M}_{5}$, and $M_{7}$ are p-type transistors; $M_{2}, M_{4}, M_{6}$, and $M_{8}$ are n-type transistors. $C_{2}, C_{4}$, and $\mathrm{C}_{6}$ are gate capacitances, each of which is associated with a pair of $\mathrm{p}$ - and $\mathrm{n}$ type transistor gates; $\mathrm{C}_{1}, \mathrm{C}_{3}$, and $\mathrm{C}_{5}$ are interconnected capacitances distributed by poly or metal layers which connect the output of an inverter to the input of the 
following inverter. $\mathrm{C}_{7}$ is the load capacitance driven by the last inverter.

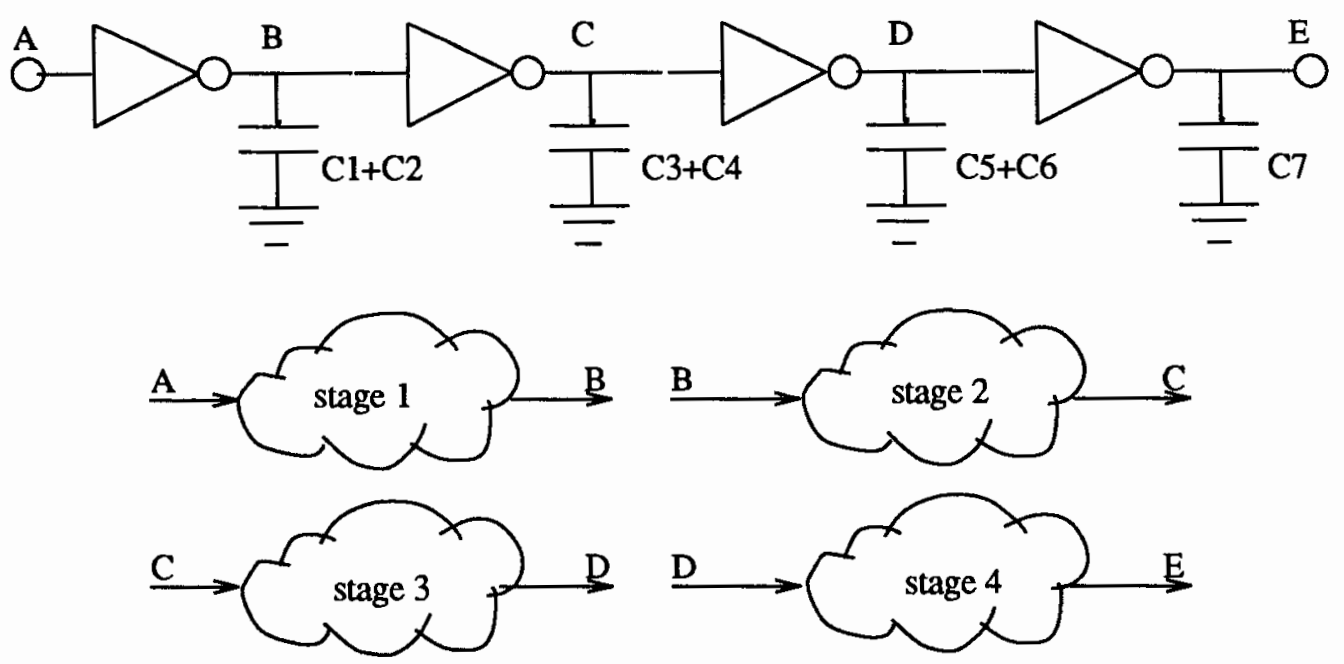

Figure 1-7(a). The logic diagram of a four-stage inverter chain

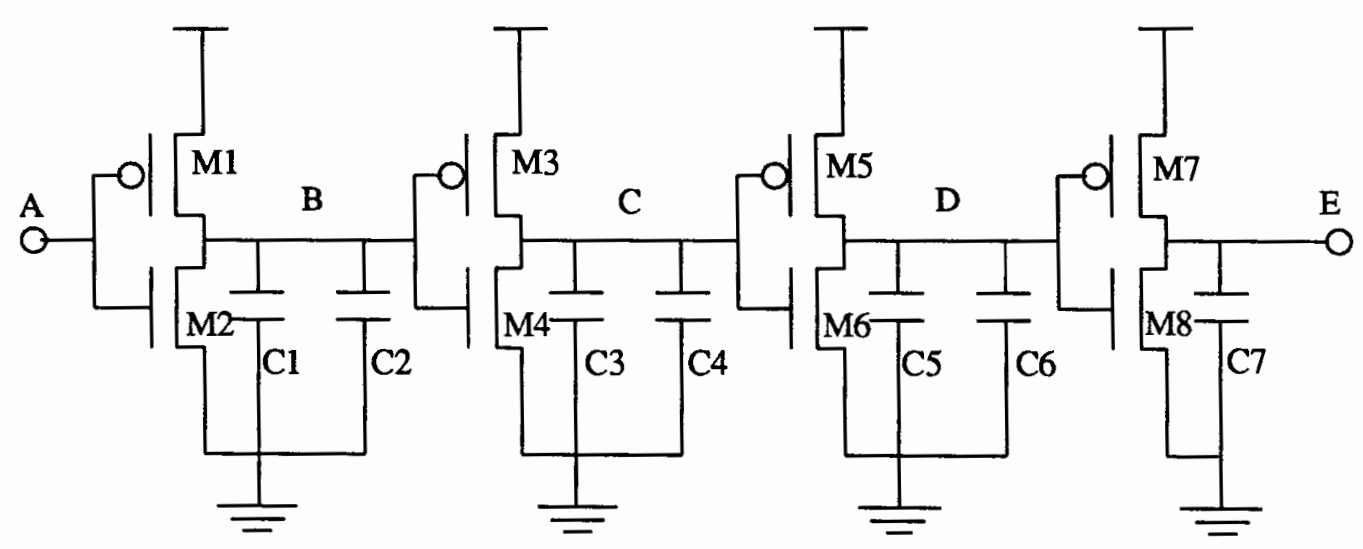

Figure 1-7(b). The circuit diagram of a four-stage inverter chain

If a logic 1 is applied to node A, node A has a logic transition. This new logic level will propagate to each node through out the entire network. Corresponding to this transition, RSIM schedules five events to set nodes A, B, C, D and E to new logic levels during the stage by stage analysis. In RSIM, the event delay time is defined as: 
event delay $=\mathrm{R}_{\mathrm{eff}} * \mathrm{C}_{\text {load }}$.

The following is RSIM's logic simulation procedure.

Event \#1: Node $A$ is set to 1 by a user. The simulator calculates all stages affected by $A$. In this case, only the stage containing node $B$ is effected.

In the first stage, node $\mathrm{A}$ is an input node since its new logic level 1 is set by the user. As this new level turns the transistor $M_{1}$ off, the switch $K_{1}$ opens. Conversely this new level turns the transistor $\mathrm{M}_{2}$ on while the switch $\mathrm{K}_{2}$ in the model closes. The logic level at node $B$ is pulled down by the transistor $\mathbf{M}_{2}$. A suitable resistance value $R_{2}$ is used to model the transistor $M_{2}$. The value $R_{2}$, according to the transistor's width, length, and type, is chosen from the calibrated resistance table. In this stage, node $B$ is the only node affected by the transition occurring at node A. Figure 1-8 shows the model of the first stage of the inverter chain. The logic level at node $B$ is pulled down to 0 by the transistor $M_{2}$, which causes event \#2 to happen.

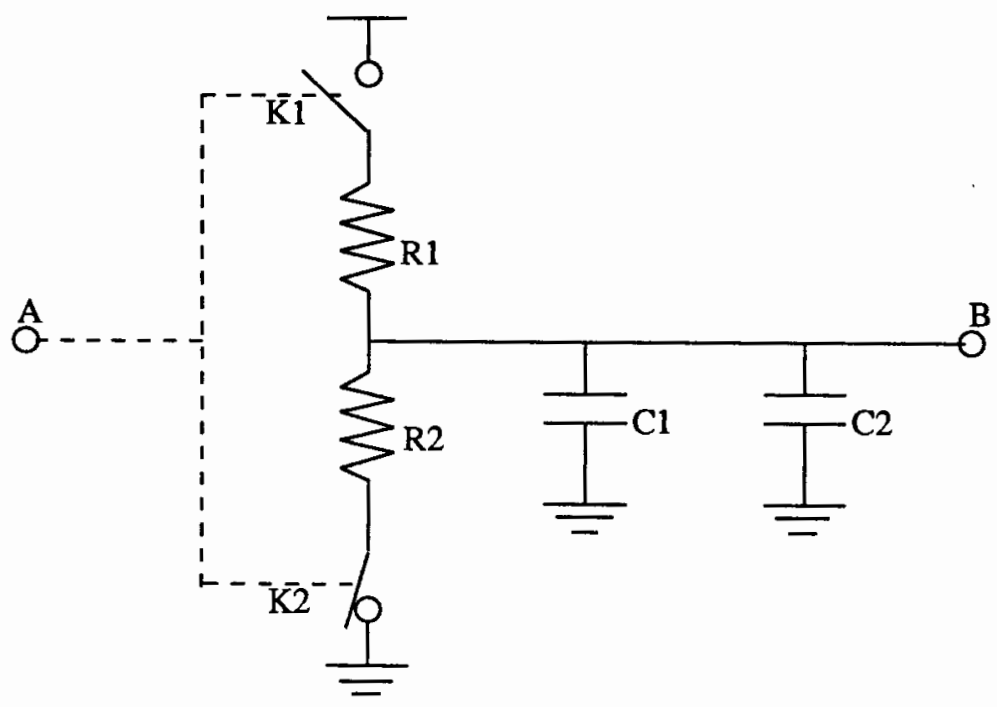

Figure 1-8. The switch-level model of the first stage of the four-stage inverter chain 
Event \#2: Node B changes level from 1 to 0 , causing the stage containing $C$ to be analyzed. $\mathrm{t}_{12}=\mathrm{R}_{\mathrm{eff} 2} *\left(\mathrm{C}_{1}+\mathrm{C}_{2}\right)$.

The logic level 0 appears at node $B$ which causes the transistors $M_{3}$ to be turned on and $\mathrm{M}_{4}$ to be turned off. The logic level at node $\mathrm{C}$ is pulled up by the transistor $M_{3}$. An effective resistance value $R_{3}$ is used to model the transistor $M_{3}$. Figure 1-9 shows the model for the second stage. The occurrence of event \#2 lags behind the occurrence of event \#1 by a time delay $t_{12}$. RSIM estimates this time delay by multiplying $\mathrm{R}_{2}$ by $\left(\mathrm{C}_{1}+\mathrm{C}_{2}\right)$ or $\mathrm{t}_{12}=\mathrm{R}_{2} *\left(\mathrm{C}_{1}+\mathrm{C}_{2}\right)$. Since the transistor $\mathrm{M}_{3}$ has been turned on, it pulls the logic level at node $C$ up to 1 which causes event \#3 to happen.

Event \#3: Node $C$ changes level from 0 to 1 , causing the stage containing $D$ to be analyzed. $\mathrm{t}_{23}=\mathrm{R}_{\mathrm{eff} 3} *\left(\mathrm{C}_{3}+\mathrm{C}_{4}\right)$.

Event \#4: Node D changes level from 1 to 0 , causing the stage containing E to be analyzed. $\mathrm{t}_{34}=\mathrm{R}_{\mathrm{eff} 6} *\left(\mathrm{C}_{5}+\mathrm{C}_{6}\right)$.

Event \#5: $E$ is set to 1. Node $E$ does not affect any more stages, so no more events are added to the event list. $\mathrm{t}_{45}=\mathrm{R}_{\mathrm{eff}} * \mathrm{C}_{7}$.

At this point, the event list is empty, and the network has settled. The time gap between event \#4 and \#5 is $t_{45}$. Figure 1-10 shows the waveforms for the simulation example.

The value of an effective resistance $R_{\text {eff }}$ is a function of the ratio of a transistor's width $\mathrm{W}$, length $\mathrm{L}$, the initial drain to source voltages $\mathrm{V}_{\mathrm{dsi}}$, and the final drain to source voltage $V_{d s f}$. The value is associated a step input which is applied to the transistor's gate. If the gate voltage does not switch instantly, the equivalent mapping the effective resistance to an MOS transistor is not sufficient. A linear ramp approximation to actual input waveform has been suggested [16]. An ramp input has been used instead of a step input to rerun the SPICE 


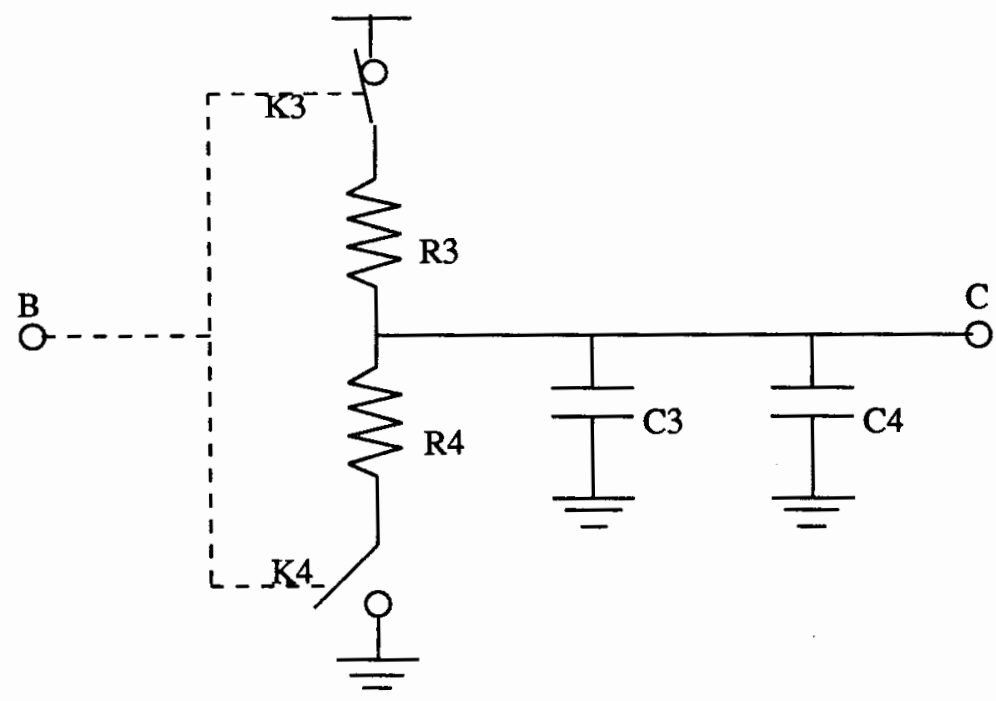

Figure 1-9. The switch-level model of the second stage of the fourstage inverter chain

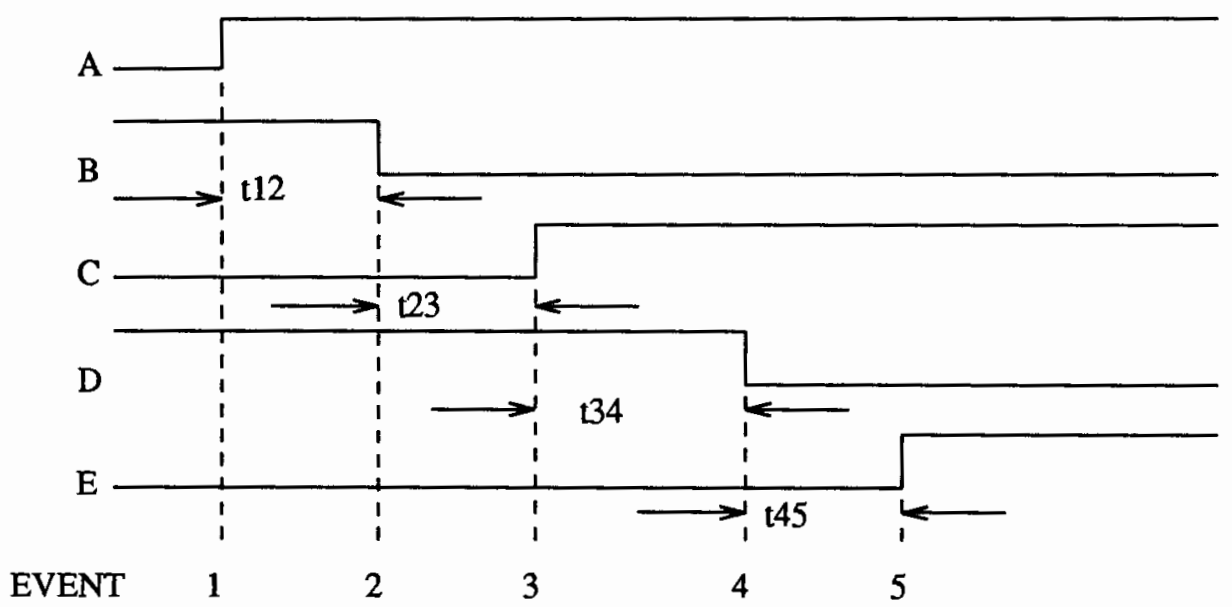

Figure 1-10. The diagram of the event delay time

simulation. The result shows that the equivalent channel resistance is larger than the effective channel resistance.

As Tsao pointed out, the switch-level multiple-delay simulation method "suffers from two major problems: linear resistance approximation and algo- 
rithmic limitation... In addition, the dynamic effects of the circuit, such as input state dependency and internal state history, are not modeled accordingly." [01] Also, Richman announced "the effect of variations in input rise and fall time on the gate delay must be incorporated..." [12]. Therefore, a reliable MOS transistor's resistance model which incorporates dynamic input effects is requested to be developed. We name our dynamic channel resistance model as quasi-static resistance. It is denoted by $R_{\text {quasi }}$. The slope of a ramp input is denoted by $1 / T$. Incidentally, we call all transistor parameters $\left(\mathrm{W}, \mathrm{L}, \mathrm{V}_{\mathrm{th}}\right.$, and $\mathrm{t}_{\mathrm{ox}}$, etc. as system parameters. In other hand, we call the ramp slope $1 / T$, load capacitance $\mathrm{C}_{\mathrm{L}}$, and final gate voltage as local parameters.

This thesis develops the MOS transistor's dynamic resistance model using the dc characteristic equations $1.3,1.4,1.5$, and 1.6 [17].

$$
\begin{aligned}
& \text { (1) when } V_{g s} \leq V_{t h} \\
& I_{d s}=0 \\
& \text { (2) when } V_{g s}-V_{t h} \geq V_{d s} \\
& I_{d s}=K\left[\left(V_{g s}-V_{t h}\right)-\frac{1}{2} V_{d s}\right] V_{d s} \\
& \text { (3) when } V_{g s}-V_{t h}<V_{d s} \\
& I_{d s}=\frac{K}{2}\left(V_{g s}-V_{t h}\right)^{2} \\
& K=\frac{W}{L} \mu_{n} C_{o x}
\end{aligned}
$$

The dynamic resistance model is developed from a simple $\mathrm{R}-\mathrm{C}$ discharging circuit shown in Figure 1-11. In this circuit, $C_{L}$ is a capacitor preset to the power supply voltage $V_{d d}$, and $R$ is a resistor with unknown value. The discharge current $I$ is a function of $d v / d t$, the change ratio of the capacitor terminal voltage. 


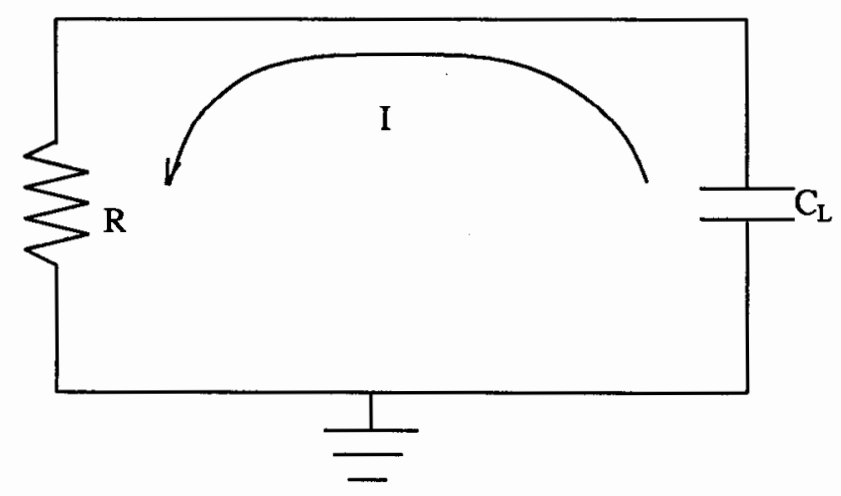

Figure 1-11. The circuit used to define an n-type transistor's quasistatic resistance

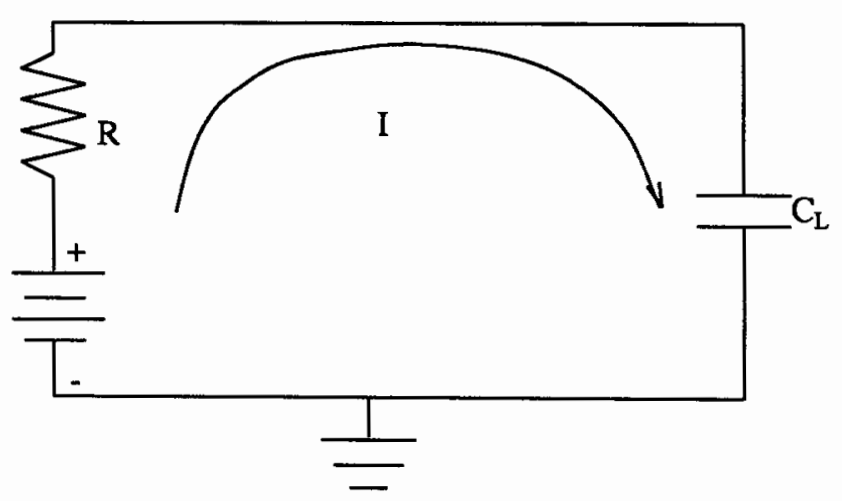

Figure 1-12. The circuit used to define a p-type transistor's quasi-static resistance

Thus we have the following fundamental equation:

$$
I=-C_{L} \frac{d v}{d t}
$$

If we vary 1.7 , we have the equivalent formula as in the following:

$$
d t=-C_{L} \frac{d v}{I}
$$

Integrating both sides of 1.8 with respected variables, we get 1.9 for time t.

$$
t=-C_{L} \int_{v_{1}}^{v_{2}} \frac{d v}{I}
$$


It is the delay time we defined earlier. The resistance $\mathrm{R}$ can be easily found by using the definition $R=t / C_{L}$. In the case of a charging circuit in Figure $1-12$, we can obtain the same result for the discharging case.

Since we have 1.9 for the delay time $t_{\text {delay }}$ and also the equations for $I$, which are MOS transistor's dc characteristic equations. This is the start of dynamic resistance model development. 


\section{CHAPTER II}

\section{MODEL FORMULATION}

The n-type MOS transistor resistance model is derived in this chapter. The same derivation also applies for the p-type MOS transistor. For simplicity, only n-type MOS transistors are considered below.

If we replace the resistor R in Figure 1-12 by an n-type MOS transistor M, we have a circuit shown in Figure 2-1. The capacitor $C_{L}$ is precharged up to the power supply voltage $V_{d d}$ and then conditionally discharged by the transistor $M$. The discharge current $I_{L}$ is controlled by the gate voltage $V_{\text {in }}$ which is a ramp input in our experiment. It obeys the MOS transistor's I-V characteristic equations for the region of the transistor's operation. We repeat the MOS transistor's dc equation here again for convenience.

$$
\begin{aligned}
& \text { (1) when } V_{g s}<V_{t h} \\
& I_{d s}=0 \\
& \text { (2) when } V_{g s}-V_{t h} \leq V_{d s} \\
& I_{d s}=\frac{K}{2}\left(V_{g s}-V_{t h}\right)^{2} \\
& \text { (3) when } V_{g s}-V_{t h}>V_{d s} \\
& I_{d s}=K\left(\left(V_{g s}-V_{t h}\right)-\frac{V_{d s}}{2}\right] V_{d s} \\
& K=\frac{W \mu_{n} C_{o x} *}{L}
\end{aligned}
$$

\footnotetext{
${ }^{*} \mathrm{C}_{\mathrm{ox}}$ is the gate capacitance per unit area.
} 


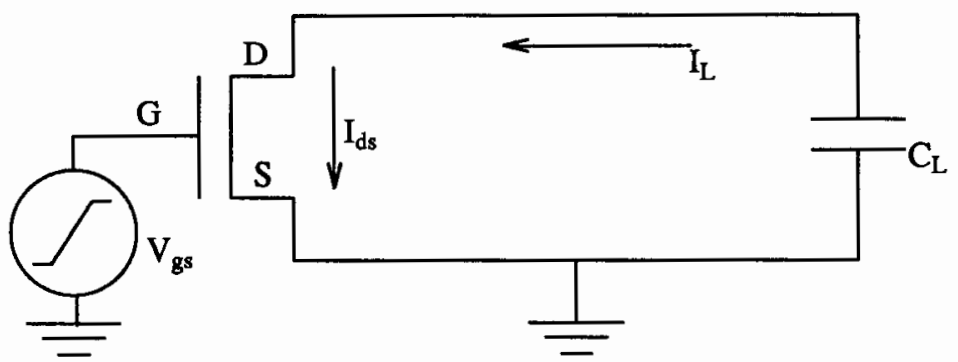

Figure 2-1. The experiment circuit used to develop the dynamic resistance model of an n-type MOS transistor

From Figure 2-1*, we can write the basic equation 2.5 for that circuit.

$$
\begin{aligned}
& I_{L}=I_{d s}=-C_{L} \frac{d V_{d s}}{d t} \\
& d t=-C_{L} \frac{d V_{d s}}{I_{d s}}
\end{aligned}
$$

Integrating both sides of $2.5 \mathrm{~b}$, we obtain 2.6 , the delay time which we have defined before.

$$
\begin{aligned}
& t_{s a t}=-C_{L} \int \frac{d V_{d s}}{I_{d s(s a t)}} \\
& t_{\text {lin }}=-C_{L} \int \frac{d V_{d s}}{I_{d s(l i n)}}
\end{aligned}
$$

$t_{\text {delay }}$ shown in Figure 2-2 is the sum of $t_{\text {off }}, t_{\text {sat }}$, and $t_{\text {lin }} .2 .7$ is the expression for $t_{\text {delay }}$. $t_{\text {off }}$ is the time period from zero to the time when $V_{g s}$ reaches $V_{\text {th }}$. $t_{\text {sat }}$ is the time period from $V_{g s}=V_{\text {th }}$ to $V_{g s}-V_{t h}=V_{d s}$. $t_{\text {lin }}$ is the time period from $V_{\mathrm{gs}}-\mathrm{V}_{\mathrm{th}}=\mathrm{V}_{\mathrm{ds}}$ to $\mathrm{V}_{\mathrm{ds}}=\mathrm{V}_{\mathrm{dsf}}$. $\quad \mathrm{V}_{\mathrm{dsf}}$ is defined as the end point voltage. The total delay time is $t_{\text {delay }}$ and the resistance is $R_{\text {quasi }}=\frac{t_{\text {delay }}}{C_{L}}$.

*The back-bias voltage is $\mathrm{V}_{\mathrm{BB}}=0$ in this experiment. 


$$
\begin{aligned}
t_{\text {delay }} & =t_{\text {off }}+t_{\text {sat }}+t_{\text {lin }} \\
& =t_{\text {off }}-C_{L} \int \frac{d V_{d s}}{I_{d s(s a t)}}-C_{L} \int \frac{d V_{d s}}{I_{d s(l i n)}}
\end{aligned}
$$

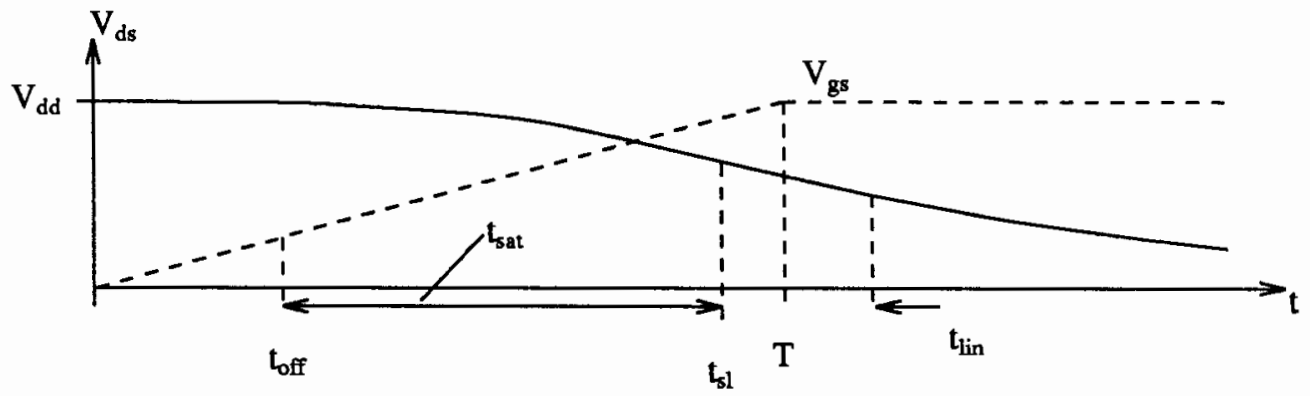

Figure 2-2. Distribution of $t_{\text {delay }}, t_{\text {off }}, t_{\text {sat }}$, and $t_{\text {lin }}$ in the time axis

$I_{d s}$ has different expressions in the different operational regions, each will be discussed separately.

\section{Cutoff Region}

In the cutoff region, the n-type transistor is turned off and $I_{d s}=0$. Since there is no discharge current, $I_{L}=0, V_{d s}$ remains a constant value, $V_{d d}$, through this region. The time for this period is $t_{\text {off }}$ and can be calculated using 2.8 .

$$
t_{\text {off }}=\frac{V_{\text {th }}}{V_{\text {dd }}} T
$$

\section{Saturation Region}

From $2-2$, in the saturation region, the drain to source current $I_{d s}$ is only dependent on the gate voltage. Since the $V_{g s}$ is a ramp input in our experiment, it can be expressed as in 2.9 .

$$
V_{g s}= \begin{cases}\frac{V_{d d}}{T} t & 0<t \leq T \\ V_{d d} & t>T\end{cases}
$$


We can rewrite 2.2 as the following:

$$
\begin{aligned}
& \text { when } V_{g s}-V_{t h} \geq V_{d s} \\
& I_{d s}= \begin{cases}\frac{K}{2}\left[\frac{V_{d d}}{T} t-V_{t h}\right]^{2} & 0<t \leq T \\
\frac{K}{2}\left(V_{d d}-V_{t h}\right)^{2} & t>T\end{cases}
\end{aligned}
$$

Substituting 2.10 into 2.7 , we obtain 2.11 as the second term of the right side of 2.7 .

$$
t_{\text {sat }}=\left\{\begin{array}{cc}
-\frac{2 C_{L}}{K} \int \frac{d V_{d s}}{\left[\frac{V_{d d}}{T} t-V_{t h}\right]^{2}} & 0<t \leq T \\
-\frac{2 C_{L}}{k} \int \frac{d V_{d s}}{\left(V_{d d}-V_{t h}\right)^{2}} &
\end{array}\right.
$$

Because 2.11 has a time variable $t$ in the right side of the equation, it is difficult to integrate. Charge analysis is used to estimate this integral.

Since there is always an existence of the intersection time $t_{\mathrm{sl}}$. At time $t_{\mathrm{sl}}$, the following condition is satisfied:

$$
\mathrm{V}_{\mathrm{gs}}-\mathrm{V}_{\mathrm{th}}=\mathrm{V}_{\mathrm{ds}}
$$

At this point, the transistor's operation region changes from saturation to linear at time $t_{s 1}$. Figure 2-3 shows this transition time. Three possible locations for $t_{s 1}$ in time are $0<t_{s l}<T, t_{s l}=T$, and $t_{s l}>T$ illustrated in Figure 2-3. If $t_{s l}$ can be found, then the time period $t_{\text {sat }}$ is the difference of $t_{s l}$ and $t_{\text {off }}$.

In the case of Figure 2-3(a), $0<t_{\mathrm{sl}}<\mathrm{T}, \mathrm{V}_{\mathrm{gs}}$ varies with time $\mathrm{t}$. At time $\mathrm{t}_{\mathrm{sl}}$, $\mathrm{V}_{\mathrm{ds}}$ has an expression in 2-12. 


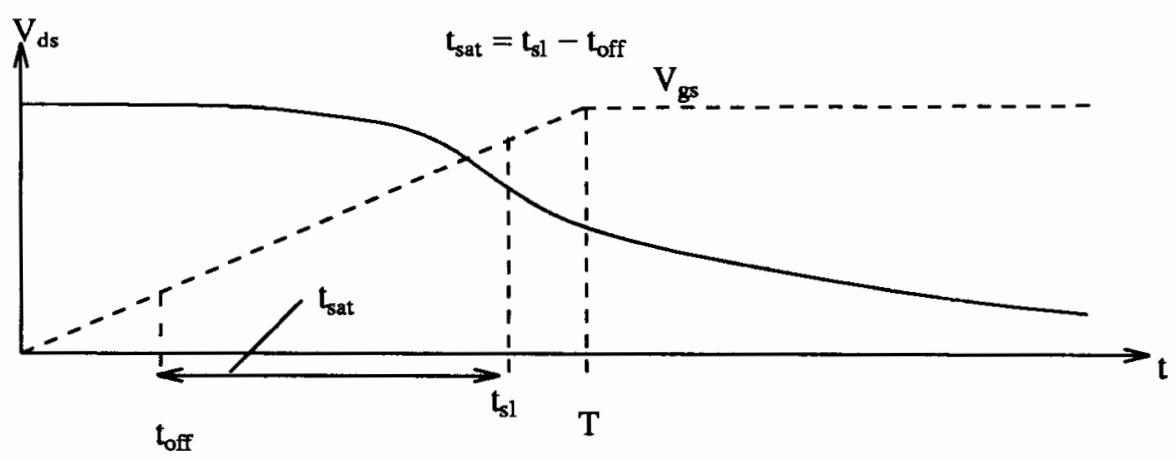

(a)

Figure 2-3(a). The transition happens before $\mathrm{T}, \mathrm{t}_{\mathrm{sl}}<\mathrm{T}$

$$
V_{d s}=V_{d d}-\frac{Q}{C_{L}}=V_{g s}-V_{t h}
$$

$\mathrm{Q}$ is the charge discharged from $\mathrm{C}_{\mathrm{L}}$ by the transistor $\mathrm{M}$ during the time from $\mathrm{t}_{\mathrm{off}}$ to $t_{\mathrm{sl}}$. $\mathrm{Q}$ can be calculated by using 2.13 .

$$
Q=\int_{t_{\text {off }}}^{t} I_{d s} d t=\frac{K}{2} \int_{t_{\text {off }}}^{t}\left(\frac{V_{d d}}{T} t-V_{t h}\right)^{2} d t
$$

Substituting 2.8 into 2.13 , which is 2.14 .

$$
\begin{aligned}
Q & =\frac{K}{2} \int_{t_{\text {off }}}^{t}\left[\frac{V_{d d}}{T} t-\frac{V_{d d}}{T} t_{\text {off }}\right]^{2} d t \\
& =\frac{K}{2}\left(\frac{V_{d d}}{T}\right)^{2} \int_{t_{\text {off }}}^{t}\left[t-t_{\text {off }}\right)^{2} d t \\
& =\frac{K}{6}\left(\frac{V_{d d}}{T}\right)^{2} \zeta^{3}
\end{aligned}
$$

Here $\zeta=\mathrm{t}-\mathrm{t}_{\text {off }}$. 
Combining 2.8, 2.12 and 2.14, we have a monotonic equation 2.15 . 2.15b can be solved by bisection method.*

$$
\begin{aligned}
& \frac{V_{d d}}{T} \zeta=V_{d d}-\frac{K}{6 C_{L}}\left[\frac{V_{d d}}{T}\right]^{2} \zeta^{3} \\
& \frac{K V_{d d}}{6 C_{L} T^{2}} \zeta^{3}+\frac{1}{T} \zeta-1=0
\end{aligned}
$$

Solving $2.15 b$, we obtain the time $t=t_{s l}$, also we obtain the drain to source voltage $\mathrm{V}_{\mathrm{dsi}}$ at time $\mathrm{t}_{\mathrm{sl}}$ using the value $\mathrm{t}_{\mathrm{sl}}$ and 2.16

$$
\mathrm{V}_{\mathrm{dsi}}=\mathrm{V}_{\mathrm{dd}}-\frac{\mathrm{Q}\left(\mathrm{t}_{\mathrm{sl}}\right)}{\mathrm{C}_{\mathrm{L}}}
$$

In this case,

$$
\begin{aligned}
t_{s a t} & =t_{s l}-t_{o f f} \\
V_{d s i} & =V_{d d}-\frac{Q\left(T_{s l}\right)}{C_{L}} \\
& =V_{d d}-\frac{K}{6 C_{L}}\left(\frac{V_{d d}}{T}\right)^{2}\left(t_{s l}-t_{o f f}\right)^{3}
\end{aligned}
$$

The second case in Figure 2-3(b) is a special situation of the first case. Which is

$$
\begin{aligned}
& t_{s l}=T \quad \text { where } t_{\text {sat }}=T-t_{\text {off }} \\
& V_{d s i}=V_{d d}-V_{t h}
\end{aligned}
$$

In the last case, $t_{s l}=T+\Delta t$ as shown in Figure 2-3(c). When $\Delta t \geq 0, V_{g s}$ is a constant $\left(\mathrm{V}_{\mathrm{gs}}=\mathrm{V}_{\mathrm{dd}}\right)$. During time $\Delta \mathrm{t}$, an amount of charge $\mathrm{Q}^{\prime}$ is discharged from

$\overline{\text { *A small program }}$ was written for solving $2.15 \mathrm{~b}$. See Appendix C. 


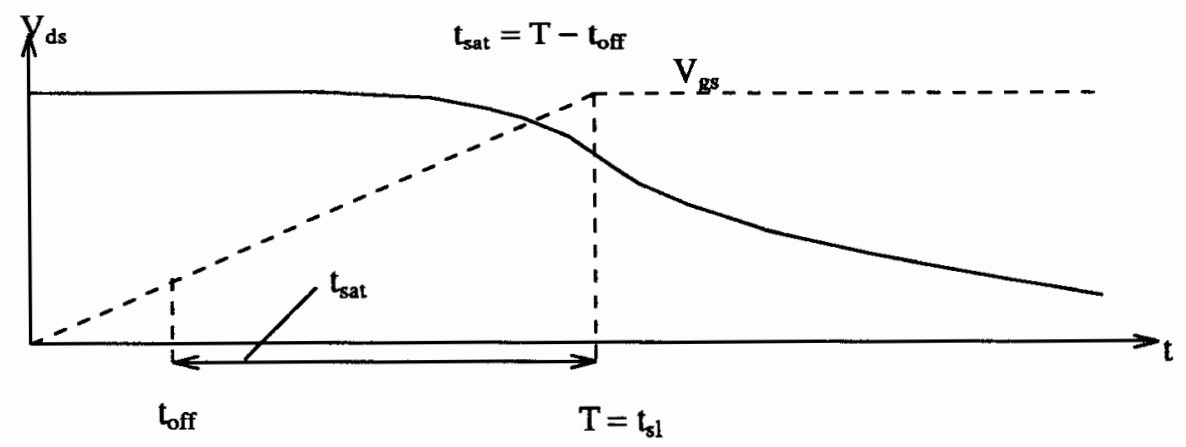

(b)

Figure 2-3(b). The transition happens at $\mathrm{T}, \mathrm{t}_{\mathrm{sl}}=\mathrm{T}$

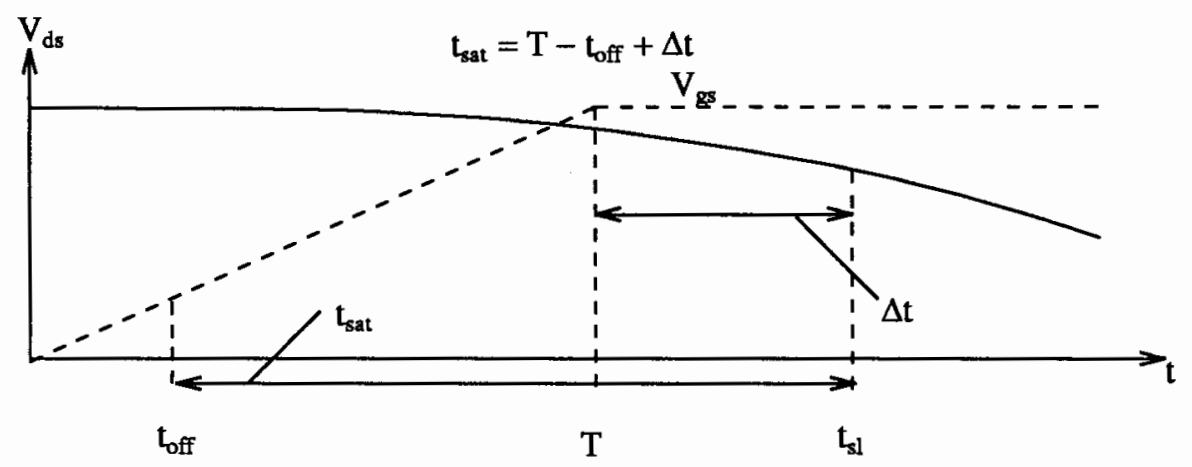

(c)

Figure 2-3(c). The transition happens before $\mathrm{T}, \mathrm{t}_{\mathrm{sl}}=\mathrm{T}$

the capacitance $C_{L}$. Since $Q=\Delta V_{d s} C_{L}, \quad V_{d s}\left(t_{s l}\right)=V_{d d}-V_{\text {th }} \quad$ and $\Delta \mathrm{V}_{\mathrm{ds}}=\mathrm{V}_{\mathrm{ds}}(\mathrm{T})-\mathrm{V}_{\mathrm{ds}}\left(\mathrm{t}_{\mathrm{sl}}\right)$, $\mathrm{Q}$, can be solved directly using 2.21 .

$$
Q^{\prime}=\left\{V_{d s}(T)-V_{d s}\left(t_{s 1}\right)\right\} C_{L}
$$




$$
\begin{aligned}
& =\left\{\left[V_{d d}-\frac{K}{6 C_{L}}\left[\frac{V_{d d}}{T}\right)^{2}\left(T-t_{\text {off }}\right)^{3}\right]-\left(V_{d d}-V_{\text {th }}\right)\right\} C_{L} \\
& =\left\{V_{\text {th }}-\frac{K}{6 C_{L}}\left(\frac{V_{d d}}{T}\right]^{2} \xi^{3}\right\} C_{L} \\
& =\left\{\frac{V_{d d}}{T} t_{\text {off }}-\frac{K}{6 C_{L}}\left(\frac{V_{d d}}{T}\right)^{2} \xi^{3}\right\} C_{L} \\
& =\frac{V_{d d}}{T}\left[t_{\text {off }}-\frac{K}{6 C_{L}} \frac{V_{d d}}{T} \xi^{3}\right] C_{L}
\end{aligned}
$$

Here $\xi=\mathrm{T}-\mathrm{t}_{\mathrm{off}}$. And the time $\Delta \mathrm{t}$ can be obtained by 2.22 .

$$
\begin{aligned}
\Delta t & =\frac{Q^{\prime}}{I_{d s}} \\
= & \frac{\frac{V_{d d}}{T}\left[t_{\text {off }}-\frac{K}{6 C_{L}} \frac{V_{d d}}{T} \xi^{3}\right] C_{L}}{\frac{K}{2}\left(V_{d d}-V_{t h}\right)^{2}} \\
= & \frac{\frac{V_{d d}}{T}\left[t_{o f f}-\frac{K}{6 C_{L}} \frac{V_{d d}}{T} \xi^{3}\right] C_{L}}{\frac{K}{2}\left[\frac{\left.V_{d d}\right)^{2}}{\xi^{2}}\right.} \\
= & \frac{2 T C_{L}}{K V_{d d}}\left[\frac{t_{o f f}-\frac{K}{6 C_{L}} \frac{V_{d d}}{\xi^{2}} \xi^{3}}{\xi^{2}}\right]
\end{aligned}
$$

Thus in this case,

$$
\mathrm{t}_{\mathrm{sat}}=\xi+\Delta \mathrm{t}=\mathrm{T}-\mathrm{t}_{\mathrm{off}}+\Delta \mathrm{t}
$$




$$
\mathrm{V}_{\mathrm{dsi}}=\mathrm{V}_{\mathrm{dd}}-\mathrm{V}_{\mathrm{th}}
$$

\section{Linear Region}

To find the time period $t_{\operatorname{lin}}$ in the linear region is more complex than in the other two regions. Miller capacitance across the drain and the gate is induced when a MOS transistor operates in this region. The circuit in Figure 2-1 is redrawn in Figure 2-4 with the Miller capacitance included. A model for the Miller capacitance $C_{m}$ is a function of $V_{g s}$ and $V_{d s}$, which is expressed by 2.25 [18].

$$
\begin{aligned}
C_{\mathrm{m}} & =\beta-\beta \frac{\left(\mathrm{V}_{\mathrm{gs}}-\mathrm{V}_{\mathrm{th}}\right)^{2}}{\left[2\left(\mathrm{~V}_{\mathrm{gs}}-\mathrm{V}_{\mathrm{th}}\right)-\mathrm{V}_{\mathrm{ds}}\right]^{2}} \\
& =\beta-\beta \frac{\mathrm{V}_{\mathrm{gs}}^{2}}{\chi^{2}}
\end{aligned}
$$

We define $V_{\text {gs }}=V_{g s}-V_{t h}$ and $\chi=2\left(V_{g s}-V_{t h}\right)-V_{d s}$ for simplicity. And 2.26 is its derivative form [18].

$$
\begin{aligned}
& \frac{\mathrm{d}}{\mathrm{dt}} \mathrm{C}_{\mathrm{m}}=-2 \beta \frac{\mathrm{V} \mathrm{g}_{\mathrm{gs}}^{2}}{\chi^{3}} \frac{\mathrm{dV} \mathrm{ds}}{\mathrm{dt}} \\
& \beta=\frac{2}{3} \mathrm{WLC}_{\mathrm{ox}}
\end{aligned}
$$

$\mathrm{C}_{\mathrm{m}}$ has a maximum value $\mathrm{WLC}_{\mathrm{ox}} / 2$ when $\mathrm{V}_{\mathrm{ds}}=0$ and a minimum value zero when $V_{d s}=V_{g s}-V_{t h}[18]$.

According to Kirchhoff's current law, currents in Figure 2-4 must satisfy 2.28 .

$$
I_{d s}+I_{m}=I_{L}=-C_{L} \frac{d V_{d s}}{d t}
$$




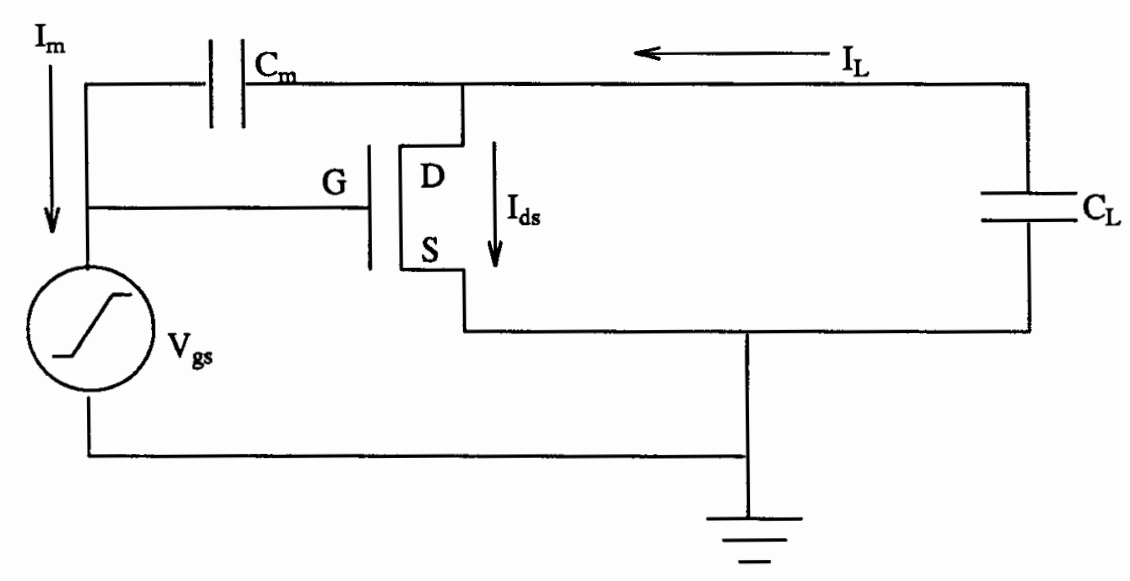

Figure 2-4. The experiment circuit with Miller capacitance included

Because of the nonlinear characteristic of the Miller capacitance, the current $I_{m}$ is not only dependent on the derivative of its terminal voltage $V_{C_{m}}$, and the derivative of $C_{m}$ as expressed by 2.26 .

$$
\begin{aligned}
I_{m} & =-\frac{d}{d t}\left[C_{m}\left(V_{g s}-V_{d s}\right)\right] \\
& =-\left[\frac{d}{d t} C_{m}\left(V_{g s}-V_{d s}\right)-C_{m} \frac{d}{d t} V_{d s}\right] \\
& =-\frac{d}{d t} C_{m} V_{g s}-\frac{d}{d t} C_{m} V_{d s}-C_{m} \frac{d}{d t} V_{d s}
\end{aligned}
$$

For simplicity, we assume $\mathrm{V}_{\mathrm{gs}}=5 \mathrm{~V}$ in the linear region. Therefore $\frac{\mathrm{d}}{\mathrm{dt}} \mathrm{V}_{\mathrm{gs}}=0$ in 2.29. But it is not always true. In the linear region, $\mathrm{V}_{\mathrm{gs}}$ may be still a part of a ramp as the case shown in Figure 2-3(a). Under our assumption, the ramp input jumps to $5 \mathrm{~V}$ at time $t_{\mathrm{sl}}$ as shown by the dashed line in Figure 2-3(a). Which causes the drain current $I_{d}$ to be overestimated. However, according to our experiments, $t_{s l}$ is very close to $T$ if the load capacitor $C_{L}$ is not extremely small. In 
another word, the introduced error is not significant if the load capacitor is not too small. Substituting $2.25,2.26$ into 2.29 , we have 2.30 .

$$
\begin{aligned}
I_{m} & =2 \beta \frac{V^{2}{ }_{g s} V_{g s}}{\chi^{3}} \frac{d V_{d s}}{d t}-2 \beta \frac{V^{2}{ }_{g s} V_{d s}}{\chi^{3}} \frac{d V_{d s}}{d v} \\
& +\beta \frac{d V_{d s}}{d t}-\beta \frac{V^{\prime}{ }_{g s}}{\chi^{2}} \frac{d V_{d s}}{d t}
\end{aligned}
$$

Substituting 2.3 and 2.30 into 2.28 , the discharge current $I_{L}$ has the following formula.

$$
\begin{aligned}
I_{L} & =-C_{L} \frac{d V_{d s}}{d t} \\
& =\frac{K}{2} \chi V_{d s}+2 \beta \frac{V^{2} V_{g s} g s}{\chi^{3}} \frac{d V_{d s}}{d t} \\
& -2 \beta \frac{V^{\prime}{ }_{g s} V_{d s}}{\chi^{3}} \frac{d V_{d s}}{d t}+\beta \frac{d V_{d s}}{d t}-\beta \frac{V^{\prime}{ }_{g s}}{\chi^{2}} \frac{d V_{d s}}{d t}
\end{aligned}
$$

Manipulating 2.31, we obtain 2.32 which is the differential form for the time period $t_{\text {lin }}$ in the linear region.

$$
\begin{aligned}
\mathrm{dt}_{\text {lin }}= & -\frac{2\left(\mathrm{C}_{\mathrm{L}}+\beta\right)}{\mathrm{K} \zeta \mathrm{V}_{\mathrm{ds}}} \mathrm{dV}_{\mathrm{ds}}+\frac{2 \beta \mathrm{V}_{\mathrm{gs}}^{2}}{\mathrm{~K} \chi^{3} \mathrm{~V}_{\mathrm{ds}}} \mathrm{dV}_{\mathrm{ds}} \\
& +\frac{4 \beta \mathrm{V}^{2}{ }_{\mathrm{gs}}}{\mathrm{K} \chi^{4}} \mathrm{dV}_{\mathrm{ds}}-\frac{4 \beta \mathrm{V}_{\mathrm{gs}}^{2} \mathrm{~V}_{\mathrm{gs}}}{\mathrm{K} \chi^{4} \mathrm{~V}_{\mathrm{ds}}} \mathrm{dV}_{\mathrm{ds}}
\end{aligned}
$$

Integrating 2.32 in four parts, we have the delay time $t_{\text {lin }}$ in integral formulas as $2.33,2.34,2.35,2.36$, and 2.37. In these formulas, $V_{d s i}$ is the drain to source voltage at time $t_{s l}$, and $V_{d s f}$ is the final drain to source voltage such as a logical 
threshold voltage chosen by designers. Also we define $\chi_{\mathrm{i}}=2\left(\mathrm{~V}_{\mathrm{gs}}-\mathrm{V}_{\mathrm{th}}\right)-\mathrm{V}_{\mathrm{dsi}}$ and $\chi_{\mathrm{f}}=2\left(\mathrm{~V}_{\mathrm{gs}}-\mathrm{V}_{\mathrm{th}}\right)-\mathrm{V}_{\mathrm{dsf}}$ for simplicity.

$$
\begin{aligned}
& \mathrm{t}_{\operatorname{lin}}=\mathrm{t}_{\operatorname{lin} 1}+\mathrm{t}_{\operatorname{lin} 2}+\mathrm{t}_{\operatorname{lin} 3}+\mathrm{t}_{\operatorname{lin} 4} \\
& t_{\text {lin } 1}=-\frac{2\left(\beta+C_{L}\right)}{K} \int_{V_{d s i}}^{V_{d s f}} \frac{d V_{d s}}{\chi V_{d s}} \\
& =-\frac{\beta+C_{L}}{2 K V^{\prime} g s}\left(\int_{V_{d s i}}^{V_{d s f}} \frac{d V_{d s}}{\chi}+\int_{V_{d s i}}^{V_{d s f}} \frac{d_{d s}}{V_{d s}}\right) \\
& =-\frac{\beta+C_{L}}{K V^{\prime} g s} \ln \left(\frac{\chi_{i} V_{d s f}}{\chi_{\mathrm{f}} V_{d s i}}\right) \\
& =-\left(\frac{L}{W \mu_{n} C_{o x}}\right]\left[\frac{2}{3} W_{L C} C_{0 x}+C_{L}\right]\left[\frac{1}{V_{g s}^{\prime}}\right] \ln \left(\frac{\chi_{i} V_{d s f}}{\chi_{\mathrm{f}} V_{d s i}}\right) \\
& t_{\operatorname{lin} 2}=\frac{2 \beta V^{\prime}}{K}{ }_{g s} \int_{V_{d s i}}^{V_{d s f}} \frac{d V_{d s}}{\chi^{3} V_{d s}} \\
& =\frac{\beta V_{\text {gs }}}{K}\left(\int_{V_{d s i}}^{V_{d s f}} \frac{d V_{d s}}{\chi^{3}}+\frac{1}{2 V_{\prime g s}} \int_{V_{d s i}}^{V_{d s f}} \frac{d V_{d s}}{\chi^{2}}\right. \\
& \left.+\frac{1}{4 \mathrm{~V}^{\prime}{ }_{\mathrm{gs}}^{2}} \int_{\mathrm{V}_{\mathrm{dsi}}}^{\mathrm{V}_{\mathrm{dsf}}} \frac{\mathrm{dV}_{\mathrm{ds}}}{\chi}+\frac{1}{4 \mathrm{~V},^{2}{ }_{\mathrm{gs}}} \int_{\mathrm{V}_{\mathrm{dsi}}}^{\mathrm{V}_{\mathrm{dsf}}} \frac{\mathrm{dV}_{\mathrm{ds}}}{\mathrm{V}_{\mathrm{ds}}}\right) \\
& =\frac{\mathrm{L}^{2} \mathrm{~V}_{\mathrm{gs}}}{3 \mu_{\mathrm{n}}}\left\{\left(\frac{1}{\chi_{\mathrm{f}}^{2}}-\frac{1}{\chi_{\mathrm{i}}^{2}}\right)+\frac{1}{\mathrm{~V}_{\mathrm{gs}}}\left(\frac{1}{\chi_{\mathrm{f}}}-\frac{1}{\chi_{\mathrm{i}}}\right)\right.
\end{aligned}
$$




$$
\left.+\frac{1}{2 \mathrm{~V}^{2}{ }_{\mathrm{gs}}} \ln \left(\frac{\chi_{\mathrm{i}} \mathrm{V}_{\mathrm{dsf}}}{\chi_{\mathrm{f}} \mathrm{V}_{\mathrm{sdi}}}\right)\right\}
$$

$$
\begin{aligned}
t_{\text {lin } 3} & =\frac{4 \beta V,^{2}{ }_{g s}}{K} \int_{V_{d s i}}^{V_{d s f}} \frac{\mathrm{dV}_{\mathrm{ds}}}{\chi^{4}} \\
& =\frac{4 \beta}{3 \mathrm{~K}} \mathrm{~V}^{2}{ }_{\mathrm{gs}}\left(\frac{1}{\chi_{\mathrm{f}}^{3}}-\frac{1}{\chi_{\mathrm{i}}^{3}}\right) \\
& =\frac{8 \mathrm{~L}^{2}}{9 \mu_{\mathrm{n}}} \mathrm{V}^{2}{ }_{\mathrm{gs}}\left(\frac{1}{\chi_{\mathrm{f}}{ }^{3}}-\frac{1}{\chi_{\mathrm{i}}{ }^{3}}\right)
\end{aligned}
$$

$$
\mathrm{t}_{\text {lin } 4}=-\frac{4 \beta}{\mathrm{K}} \mathrm{V},{ }_{\mathrm{gs}}^{2} \mathrm{~V}_{\mathrm{gs}} \int_{\mathrm{V}_{\mathrm{dsi}}}^{\mathrm{V}_{\mathrm{dsf}}} \frac{\mathrm{dV} \mathrm{ds}}{\chi^{4} \mathrm{~V}_{\mathrm{ds}}}
$$$$
=-\frac{2 \beta}{K} V_{\prime g s} V_{g s}\left\{\int_{V_{d s i}}^{V_{d s f}} \frac{d V_{d s}}{\chi^{4}}+\frac{1}{2 V^{\prime} g s} \int_{V_{d s i}}^{V_{d s f}} \frac{d V_{d s}}{\chi^{3}}\right.
$$$$
+\frac{1}{4 \mathrm{~V},^{3} \mathrm{gs}} \int_{\mathrm{V}_{\mathrm{dsi}}}^{\mathrm{V}_{\mathrm{dsf}}} \frac{\mathrm{dV}_{\mathrm{ds}}}{\chi^{2}}+\frac{1}{8 \mathrm{~V}^{3}{ }_{\mathrm{gs}}} \int_{\mathrm{V}_{\mathrm{dsi}}}^{\mathrm{V}_{\mathrm{dsf}}} \frac{\mathrm{dV} \mathrm{ds}}{\chi}
$$$$
\left.+\frac{1}{8 \mathrm{~V},^{3} \mathrm{gs}} \int_{\mathrm{V}_{\mathrm{dsi}}}^{\mathrm{V}_{\mathrm{dsf}}} \frac{\mathrm{dV}_{\mathrm{ds}}}{\mathrm{V}_{\mathrm{ds}}}\right\}
$$

$$
=-\frac{2 \beta}{K} V_{g s} V_{g s}\left\{\frac{1}{3}\left(\frac{1}{\chi_{f}^{3}}-\frac{1}{\chi_{i}^{3}}\right\}+\frac{1}{4 V_{g s}}\left(\frac{1}{\chi_{f}^{2}}-\frac{1}{\chi_{i}^{2}}\right)\right.
$$




$$
\begin{gathered}
\left.+\frac{1}{4 \mathrm{~V}^{2}{ }_{\mathrm{gs}}}\left(\frac{1}{\chi_{\mathrm{f}}}-\frac{1}{\chi_{\mathrm{i}}}\right)+\frac{1}{8 \mathrm{~V}^{3}{ }_{\mathrm{gs}}} \ln \left(\frac{\chi_{\mathrm{f}} \mathrm{V}_{\mathrm{dsf}}}{\chi_{\mathrm{i}} \mathrm{V}_{\mathrm{dsi}}}\right)\right\} \\
=-\frac{4}{3} \frac{\mathrm{L}^{2}}{\mu_{\mathrm{n}}} \mathrm{V}_{\mathrm{gs}} \mathrm{V}_{\mathrm{gs}}\left\{\frac{1}{3}\left[\frac{1}{\chi_{\mathrm{f}}^{3}}-\frac{1}{\chi_{\mathrm{i}}^{3}}\right)+\frac{1}{4 \mathrm{~V}_{\mathrm{gs}}}\left(\frac{1}{\chi_{\mathrm{f}}^{2}}-\frac{1}{\chi_{\mathrm{i}}^{2}}\right)\right. \\
\left.+\frac{3}{4 \mathrm{~V}^{2}{ }_{\mathrm{gs}}}\left(\frac{1}{\chi_{\mathrm{f}}}-\frac{1}{\chi_{\mathrm{i}}}\right)+\frac{1}{8 \mathrm{~V}_{\mathrm{ggs}}^{3}} \ln \left(\frac{\chi_{\mathrm{f}} \mathrm{V}_{\mathrm{dsf}}}{\chi_{\mathrm{i}} \mathrm{V}_{\mathrm{dsi}}}\right)\right\}
\end{gathered}
$$

Our dynamic resistance model is developed using the MOS transistor's dc characteristic equations. The resistance value is predicted by the integral of $\mathrm{dV}_{\mathrm{ds}} / \mathrm{I}_{\mathrm{ds}}$. The model includes both local and system parameters. Therefore, it reflects the dynamic input effects. 


\section{CHAPTER III}

\section{MODEL COMPARISON AND ITS USAGE}

This chapter compares our dynamic model resistance to the SPICE level 1 and level 2 evaluated resistances. In addition, the value of the quasi-static resistance is defined and the event driven RC timing verification algorithm using the quasi-static resistance is presented.

\section{Model Comparisons}

First, we compare our model resistance to the SPICE level 1 evaluated resistance. The comparison is listed in TABLE II through TABLE V. As we expected, the two types of resistances are in good agreement. In the SPICE level 1 evaluation, parameters $\mathrm{W}, \mathrm{L}, \mu$, and $\mathrm{V}_{\text {th }}$ are defined as constants as well as they are in our model. Therefore, nonlinear effects such as channel modulation [19], velocity saturation [19], etc. are excluded. As a result, neither our model nor the SPICE level 1 evaluation traces the MOS transistor's behavior well.

Secondly, we compare the SPICE level 1 evaluated resistance to the level 2's. The comparison is listed in TABLE II through TABLE $\mathrm{V}$ too. The level 2 evaluated resistance differs from the level 1's quite a bit. In the SPICE level 2 evaluation, systematic parameters are involved, and $\mathrm{W}, \mathrm{L}, \mu$, and $\mathrm{V}_{\text {th }}$ are involved as nonlinear parameters. Therefore, all effects neglected in the level 1 evaluation are included in the level 2 evaluation. Of course, the SPICE level 2 evaluation result traces the MOS transistor's nonlinear characteristic nicely. From our observations, the difference of the level 2's resistance and the level 1's resistance is a 
constant for a fixed SPICE deck, which states that the difference of the level 2's resistance and the level 1's resistance is a nonlinear part, and this part is a constant. Thus the level 1's resistance can trace the level 2's resistance closely by adding this constant. Meanwhile the comparison shows that the effect of a ramp input does not involve the parameter's nonlinearization in the SPICE level 2 evaluation, or the ramp input slope $1 / \mathrm{T}$ does not show the nonlinearity.

Next we compare our model's incremental resistances to the SPICE level 1's and level 2's. Comparison is listed in TABLE VI through TABLE IX. In this comparison, the difference between two resistance values (one associates with a ramp slope $1 / \mathrm{T}$ and the other associates with the ramp slope $1 / 0.01 \mathrm{~ns}$ ) is defined as the incremental resistance. From our observations, our model's incremental resistance, the SPICE level 1's, and level 2's incremental resistances are quite consistent.* In other words, the comparison results clarify that the ramp input slope $1 / \mathrm{T}$ has the prime effect on the incremental resistance regardless of the nonlinearity of the other parameters.

Finally, we conclude all comparison results. The fact shows that our model resistance traces the SPICE level 1 evaluated resistance well, and the level 1 evaluated resistance traces the level 2's resistance closely by adding a constant. Moreover, the incremental resistances of our model, the level 1's and the level 2's, are very much consistent. Therefore a resistance associated with a ramp slope $1 / \mathrm{T}$ can be calculated by summing a resistance associated with an infinitive slope and an incremental resistance associated with with the slope $1 / T$. Thus we define the quasi-static resistance is

\footnotetext{
*Exceptions for very small load capacitance $C_{L}$ and very long channel length $L$. See Appendix A.
} 
TABLE II

\section{A COMPARISON OF SPICE LEVEL 2, LEVEL 1 EVALUATED RESISTANCES AND THE MODEL RESISTANCE OF AN MOS TRANSISTOR WITH W/L $=8 / 3(\mu \mathrm{m} / \mu \mathrm{m})$}

\begin{tabular}{|c|c|c|c|c|c|}
\hline \multicolumn{7}{|c}{ M72M SPICE parameter } & $\mathrm{C}_{\mathrm{L}}=1 \mathrm{pf}$ & $\mathrm{W} / \mathrm{L}=8 / 3$ \\
\hline \hline $\mathrm{T}$ & $\mathrm{R}_{\mathrm{spc} 2}$ & $\mathrm{R}_{\mathrm{spc} 2}-\mathrm{R}_{\mathrm{spc} 1}$ & $\mathrm{R}_{\mathrm{spc} 1}$ & $\mathrm{R}_{\mathrm{mod}}-\mathrm{R}_{\mathrm{spc} 1}$ & $\mathrm{R}_{\mathrm{mod}}$ \\
& $(\mathrm{ns})$ & $(\mathrm{K} \Omega)$ & $(\mathrm{K} \Omega)$ & $(\mathrm{K} \Omega)$ & $(\mathrm{K} \Omega)$ \\
\hline 0.01 & 5.0 & 2.9 & 2.1 & 0.3 & 2.4 \\
\hline 0.05 & 5.0 & 2.9 & 2.1 & 0.3 & 2.4 \\
\hline 0.1 & 5.0 & 2.9 & 2.1 & 0.3 & 2.4 \\
\hline 0.5 & 5.3 & 2.9 & 2.4 & 0.3 & 2.7 \\
\hline 1.0 & 5.6 & 2.9 & 2.7 & 0.4 & 3.1 \\
\hline 5.0 & 8.2 & 2.6 & 5.6 & 0.3 & 5.9 \\
\hline 10.0 & 11.5 & 2.5 & 9.0 & 0.2 & 9.2 \\
\hline 15.0 & 14.7 & 2.7 & 12.0 & 0.3 & 12.3 \\
\hline
\end{tabular}

TABLE III

A COMPARISON OF SPICE LEVEL 2, LEVEL 1 EVALUATED RESISTANCES AND THE MODEL RESISTANCE OF AN MOS TRANSISTOR WITH W/L $=16 / 3(\mu \mathrm{m} / \mu \mathrm{m})$

\begin{tabular}{|c|c|c|c|c|c|}
\hline & \multicolumn{2}{|c|}{ M72M SPICE parameter } & $C_{L}=1 \mathrm{pf}$ & $\mathrm{W} / \mathrm{L}=16 / 3$ & \\
\hline $\begin{array}{c}\mathrm{T} \\
(\mathrm{ns})\end{array}$ & $\begin{array}{l}R_{\mathrm{spc} 2} \\
(\mathrm{~K} \Omega)\end{array}$ & $\begin{array}{c}R_{\mathrm{spc} 2}-R_{\mathrm{spc} 1} \\
(\mathrm{~K} \Omega)\end{array}$ & $\begin{array}{l}\mathrm{R}_{\mathrm{spc1}} \\
(\mathrm{K} \Omega)\end{array}$ & $\begin{array}{c}R_{\text {mod }}-R_{\text {spcl }} \\
(K \Omega)\end{array}$ & $\begin{array}{l}R_{\text {mod }} \\
(K \Omega)\end{array}$ \\
\hline 0.01 & 2.5 & 1.4 & 1.1 & 0.1 & 1.2 \\
\hline 0.05 & 2.5 & 1.4 & 1.1 & 0.1 & 1.2 \\
\hline 0.1 & 2.6 & 1.4 & 1.2 & 0.1 & 1.3 \\
\hline 0.5 & 2.8 & 1.4 & 1.4 & 0.1 & 1.5 \\
\hline 1.0 & 3.2 & 1.4 & 1.8 & 0.1 & 1.9 \\
\hline 5.0 & 5.8 & 1.3 & 4.5 & 0.1 & 4.6 \\
\hline 10.0 & 8.9 & 1.5 & 7.4 & 0.2 & 7.6 \\
\hline 15.0 & 11.7 & 1.7 & 10.0 & 0.4 & 10.4 \\
\hline
\end{tabular}


TABLE IV

A COMPARISON OF SPICE LEVEL 2, LEVEL 1 EVALUATED

RESISTANCES AND THE MODEL RESISTANCE OF AN

MOS TRANSISTOR WITH W/L $=5 / 5(\mu \mathrm{m} / \mu \mathrm{m})$

\begin{tabular}{|c|c|c|c|c|c|}
\hline \multicolumn{3}{|c|}{ M72M SPICE parameter } & \multirow{2}{*}{$\begin{array}{c}\mathrm{C}_{\mathrm{L}}=1 \mathrm{pf} \\
\mathrm{R}_{\mathrm{spc} 1} \\
(\mathrm{~K} \Omega)\end{array}$} & \multicolumn{2}{|l|}{$\mathrm{W} / \mathrm{L}=5 / 5$} \\
\hline $\begin{array}{c}\mathbf{T} \\
(\mathrm{ns})\end{array}$ & $\begin{array}{l}R_{\mathrm{spc} 2} \\
(\mathrm{~K} \Omega)\end{array}$ & $\begin{array}{c}R_{\mathrm{spc} 2}-R_{\mathrm{spc} 1} \\
(\mathrm{~K} \Omega)\end{array}$ & & $\begin{array}{c}\mathbf{R}_{\text {mod }}-\mathbf{R}_{\mathrm{spcl}} \\
(\mathrm{K} \Omega)\end{array}$ & $\begin{array}{l}R_{\text {mod }} \\
(\mathrm{K} \Omega)\end{array}$ \\
\hline 0.01 & 10.0 & 4.8 & 5.2 & 1.1 & 6.3 \\
\hline 0.05 & 10.1 & 4.8 & 5.3 & 1.0 & 6.3 \\
\hline 0.1 & 10.1 & 4.8 & 5.3 & 1.1 & 6.4 \\
\hline 0.5 & 10.4 & 4.8 & 5.6 & 1.0 & 6.6 \\
\hline 1.0 & 10.7 & 4.8 & 5.9 & 1.1 & 7.0 \\
\hline 5.0 & 13.4 & 4.6 & 8.8 & 1.1 & 9.9 \\
\hline 10.0 & 16.8 & 4.4 & 12.4 & 1.0 & 13.4 \\
\hline 15.0 & 20.2 & 4.3 & 15.9 & 1.0 & 16.9 \\
\hline
\end{tabular}

TABLE V

A COMPARISON OF SPICE LEVEL 2, LEVEL 1 EVALUATED

RESISTANCES AND THE MODEL RESISTANCE OF AN

MOS TRANSISTOR WITH W/L $=5 / 10(\mu \mathrm{m} / \mu \mathrm{m})$

\begin{tabular}{|c|c|c|c|c|c|}
\hline \multicolumn{6}{|c|}{ M72M SPICE parameter $\mathrm{C}_{\mathrm{L}}=1 \mathrm{pf} \quad \mathrm{W} / \mathrm{L}=5 / 10$} \\
\hline \hline $\mathrm{T}$ & $\mathrm{R}_{\mathrm{spc} 2}$ & $\mathrm{R}_{\mathrm{spc} 2}-\mathrm{R}_{\mathrm{spc} 1}$ & $\mathrm{R}_{\mathrm{spc} 1}$ & $\mathrm{R}_{\mathrm{mod}}-\mathrm{R}_{\mathrm{spc} 1}$ & $\mathrm{R}_{\mathrm{mod}}$ \\
$(\mathrm{ns})$ & $(\mathrm{K} \Omega)$ & $(\mathrm{K} \Omega)$ & $(\mathrm{K} \Omega)$ & $(\mathrm{K} \Omega)$ & $(\mathrm{K} \Omega)$ \\
& & & & & \\
\hline 0.01 & 15.7 & 5.4 & 10.3 & 2.3 & 12.6 \\
\hline 0.05 & 15.8 & 5.4 & 10.4 & 2.3 & 12.7 \\
\hline 0.1 & 15.8 & 5.4 & 10.4 & 2.3 & 12.7 \\
\hline 0.5 & 16.1 & 5.4 & 10.7 & 2.3 & 13.0 \\
\hline 1.0 & 16.4 & 5.4 & 11.0 & 2.3 & 13.3 \\
\hline 5.0 & 19.3 & 5.4 & 13.9 & 2.3 & 16.2 \\
\hline 10.0 & 22.8 & 5.3 & 17.5 & 2.3 & 19.8 \\
\hline 15.0 & 26.3 & 5.2 & 21.1 & 2.3 & 23.4 \\
\hline
\end{tabular}


TABLE VI

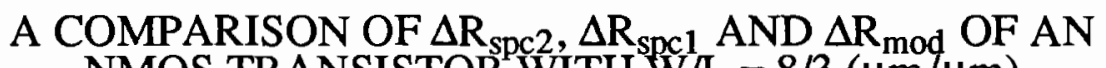

NMOS TRANSISTOR WITH W/L $=8 / 3(\mu \mathrm{m} / \mu \mathrm{m})$

\begin{tabular}{|c|c|c|c|}
\hline \multicolumn{3}{|c|}{ M72M SPICE parameter $\mathrm{C}_{\mathrm{L}}=1 \mathrm{pf} \quad \mathrm{W} / \mathrm{L}=8 / 3$} \\
\hline \hline $\mathrm{T}$ & $\Delta \mathrm{R}_{\mathrm{spc} 2}$ & $\Delta \mathrm{R}_{\mathrm{spcl}}$ & $\Delta \mathrm{R}_{\text {mod }}$ \\
& $(\mathrm{K} \Omega)$ & $(\mathrm{K} \Omega)$ & $(\mathrm{K} \Omega)$ \\
\hline 0.01 & - & - & - \\
\hline 0.05 & 0.0 & 0.0 & 0.0 \\
\hline 0.1 & 0.0 & 0.0 & 0.0 \\
\hline 0.5 & 0.3 & 0.3 & 0.3 \\
\hline 1.0 & 0.6 & 0.6 & 0.7 \\
\hline 5.0 & 3.2 & 3.5 & 3.5 \\
\hline 10.0 & 6.5 & 6.9 & 6.8 \\
\hline 15.0 & 9.7 & 9.9 & 9.9 \\
\hline
\end{tabular}

TABLE VII

A COMPARISON OF $\Delta R_{\mathrm{spc} 2}, \Delta \mathrm{R}_{\mathrm{spcl}}$ AND $\Delta \mathrm{R}_{\mathrm{mod}}$ OF AN

NMOS TRANSISTOR WITH W/L $=16 / 3(\mu \mathrm{m} / \mu \mathrm{m})$

\begin{tabular}{|c|c|c|c|}
\hline \multicolumn{3}{|c|}{ M72M SPICE parameter $\mathrm{C}_{\mathrm{L}}=1 \mathrm{pf} \quad \mathrm{W} / \mathrm{L}=16 / 3$} \\
\hline \hline $\mathrm{T}$ & $\Delta \mathrm{R}_{\mathrm{spc} 2}$ & $\Delta \mathrm{R}_{\text {spc1 }}$ & $\Delta \mathrm{R}_{\text {mod }}$ \\
& $(\mathrm{K} \Omega)$ & $(\mathrm{K} \Omega)$ & $(\mathrm{K} \Omega)$ \\
\hline$(\mathrm{ns})$ & & & - \\
\hline 0.01 & - & - & 0.0 \\
\hline 0.05 & 0.0 & 0.0 & 0.1 \\
\hline 0.1 & 0.1 & 0.1 & 0.3 \\
\hline 0.5 & 0.3 & 0.3 & 0.7 \\
\hline 1.0 & 0.7 & 0.7 & 3.4 \\
\hline 5.0 & 3.3 & 3.4 & 6.4 \\
\hline 10.0 & 6.4 & 6.3 & 9.2 \\
\hline 15.0 & 9.2 & 8.9 & \\
\hline
\end{tabular}


TABLE VIII

A COMPARISON OF $\Delta \mathrm{R}_{\mathrm{spc} 2}, \Delta \mathrm{R}_{\mathrm{spc1}}$ AND $\Delta \mathrm{R}_{\mathrm{mod}}$ OF AN

NMOS TRANSISTOR WITH W/L $=5 / 5(\mu \mathrm{m} / \mu \mathrm{m})$

\begin{tabular}{|c|c|c|c|}
\hline \multicolumn{3}{|c|}{ M72M SPICE parameter $\mathrm{C}_{\mathrm{L}}=1 \mathrm{pf} \quad \mathrm{W} / \mathrm{L}=5 / 5$} \\
\hline \hline$T$ & $\Delta \mathrm{R}_{\mathrm{spc} 2}$ & $\Delta \mathrm{R}_{\mathrm{spc} 1}$ & $\Delta \mathrm{R}_{\mathrm{mod}}$ \\
& $(\mathrm{K} \Omega)$ & $(\mathrm{K} \Omega)$ & $(\mathrm{K} \Omega)$ \\
\hline 0.01 & - & - & - \\
\hline 0.05 & 0.1 & 0.1 & 0.0 \\
\hline 0.1 & 0.1 & 0.1 & 0.1 \\
\hline 0.5 & 0.4 & 0.4 & 0.3 \\
\hline 1.0 & 0.7 & 0.7 & 0.7 \\
\hline 5.0 & 3.4 & 3.6 & 3.6 \\
\hline 10.0 & 6.8 & 7.2 & 7.1 \\
\hline 15.0 & 10.2 & 10.7 & 10.6 \\
\hline
\end{tabular}

TABLE IX

A COMPARISON OF $\Delta \mathrm{R}_{\text {spc } 2}, \Delta \mathrm{R}_{\text {spc1 }}$ AND $\Delta \mathrm{R}_{\mathrm{mod}}$ OF AN NMOS TRANSISTOR WITH W $/ \mathrm{L}=5 / 10(\mu \mathrm{m} / \mu \mathrm{m})$

\begin{tabular}{|c|c|c|c|}
\hline \multicolumn{3}{|c|}{ M72M SPICE parameter $\mathrm{C}_{\mathrm{L}}=1 \mathrm{pf} \quad \mathrm{W} / \mathrm{L}=5 / 10$} \\
\hline \hline $\mathrm{T}$ & $\Delta \mathrm{R}_{\mathrm{spc} 2}$ & $\Delta \mathrm{R}_{\mathrm{spc} 1}$ & $\Delta \mathrm{R}_{\text {mod }}$ \\
& $(\mathrm{K} \Omega)$ & $(\mathrm{K} \Omega)$ & $(\mathrm{K} \Omega)$ \\
\hline 0.01 & - & - & - \\
\hline 0.05 & 0.1 & 0.1 & 0.1 \\
\hline 0.1 & 0.1 & 0.1 & 0.1 \\
\hline 0.5 & 0.4 & 0.3 & 0.4 \\
\hline 1.0 & 0.7 & 0.7 & 0.7 \\
\hline 5.0 & 3.6 & 3.6 & 3.6 \\
\hline 10.0 & 7.1 & 7.2 & 7.2 \\
\hline 15.0 & 10.6 & 10.8 & 10.8 \\
\hline
\end{tabular}




$$
\mathrm{R}_{\text {quasi }}=\mathrm{R}_{\mathrm{eff}}+\Delta \mathrm{R}_{\bmod }(\mathrm{T}) .
$$

Where $R_{\text {eff }}$ is the effective resistance, $R_{\text {eff }}=R_{\text {spc2 }}$ when $T=0 . \Delta R_{\text {mod }}(T)$ is the incremental resistance calculated using our model.

To insure our model's generality, variant SPICE decks have been used for the SPICE evaluations and our model calculation. All results came out consistently. TABLE $X$ through TABLE XIII show the results using two different SPICE decks.*

\section{Positive and Negative Delay}

Three cases of delay must be considered in RC delay calculation. The circuit in Figure 3-1 is used to specify these cases. In the circuit, $C_{L}$ is set to $V_{d d}$ initially, and $V_{\text {in }}$ is a ramp input voltage with the slope $1 / T$. The first case is that the terminal voltage $V_{c}$ drops down to the logic threshold voltage, $V_{d d} / 2$, beyond the ramp input time $\mathrm{T}$ as shown in Figure 3-2(a). In the analog analysis, the delay is defined as $\tau-T / 2$. In the event driven simulation, the current time is $T$, and the next event is scheduled to happen with a time delay $R_{\text {quasi }}{ }^{*} C_{L}$. The second case is that the terminal voltage $V_{c}$ drops down to $V_{d d} / 2$ at the time range $T / 2<\tau \leq T$ as presented in Figure 3-2(b). In the analog analysis, the delay is $\tau-T / 2$. In the even driven simulation, the current time is $\mathrm{T}$. The next event can not be scheduled in backward in the time wheel, so it is scheduled with a zero time delay. Shoji named two types of delay as positive delay [20] because the output node switchs its logic level after the input voltage crosses the logic threshold voltage. At last, the terminal voltage $V_{d}$ reaches $V_{d d} / 2$ in the time $V_{t h}<\tau<T / 2$ as displayed in Figure 3-2(c). In the analog analysis, this delay is $\tau-T / 2$ which is less than zero.

\footnotetext{
*All SPICE decks used in our work are from MOSIS and are listed in Appendix B.
} 
TABLE X

A COMPARISON OF TWO DIFFERENT SPICE DECK EVALUATED RESULTS OF AN NMOS TRANSISTOR WITH W/L $=8 / 3(\mu \mathrm{m} / \mu \mathrm{m})$

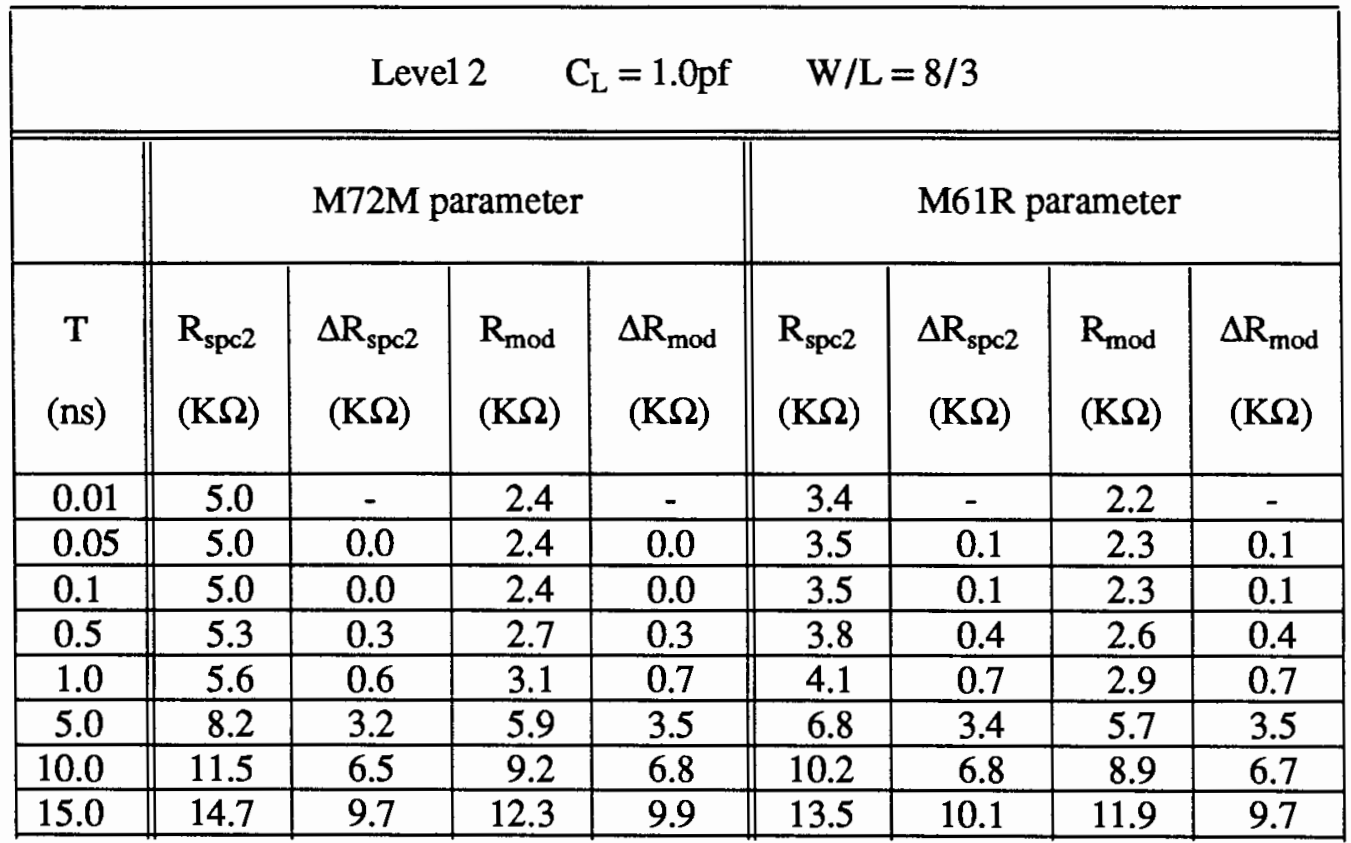

TABLE XI

A COMPARISON OF TWO DIFFERENT SPICE DECK EVALUATED RESULTS OF AN NMOS TRANSISTOR WITH W/L $=16 / 3(\mu \mathrm{m} / \mu \mathrm{m})$

\begin{tabular}{|c|c|c|c|c|c|c|c|c|}
\hline & \multicolumn{4}{|c|}{ Leve12 } & \multicolumn{4}{|c|}{$\mathrm{W} / \mathrm{L}=16 / 3$} \\
\hline & \multicolumn{4}{|c|}{ M72M parameter } & \multicolumn{4}{|c|}{ M61R parameter } \\
\hline $\begin{array}{c}\mathrm{T} \\
(\mathrm{ns})\end{array}$ & $\begin{array}{l}\mathrm{R}_{\mathrm{spc} 2} \\
(\mathrm{~K} \Omega)\end{array}$ & $\begin{array}{c}\overline{\Delta R_{\mathrm{spc} 2}} \\
(\mathrm{~K} \Omega)\end{array}$ & $\begin{array}{l}R_{\text {mod }} \\
(K \Omega)\end{array}$ & $\begin{array}{c}\Delta R_{\text {mod }} \\
(\mathrm{K} \Omega)\end{array}$ & $\begin{array}{l}R_{\mathrm{spc} 2} \\
(\mathrm{~K} \Omega)\end{array}$ & $\begin{array}{c}\Delta \mathrm{R}_{\mathrm{spc} 2} \\
(\mathrm{~K} \Omega)\end{array}$ & $\begin{array}{l}R_{\bmod } \\
(\mathrm{K} \Omega)\end{array}$ & $\begin{array}{r}\Delta \mathrm{R}_{\text {mod }} \\
(\mathrm{K} \Omega)\end{array}$ \\
\hline 0.01 & 2.5 & - & 1.2 & - & 1.8 & - & 1.1 & - \\
\hline 0.05 & 2.5 & 0.0 & 1.2 & 0.0 & 1.8 & 0.0 & 1.1 & 0.0 \\
\hline 0.1 & 2.6 & 0.1 & 1.3 & 0.1 & 1.8 & 0.0 & 1.2 & 0.1 \\
\hline 0.5 & 2.8 & 0.3 & 1.5 & 0.3 & 2.1 & 0.3 & 1.5 & 0.4 \\
\hline 1.0 & 3.2 & 0.7 & 1.9 & 0.7 & 2.4 & 0.6 & 1.8 & 0.7 \\
\hline 5.0 & 5.8 & 3.3 & 4.6 & 3.4 & 5.2 & 3.4 & 4.5 & 3.4 \\
\hline 10.0 & 8.9 & 6.4 & 7.6 & $\overline{6.4}$ & 8.3 & 6.5 & 7.4 & 6.3 \\
\hline 15.0 & 11.7 & 9.2 & 10.4 & 9.2 & 11.0 & $\overline{9.2}$ & 10.0 & 8.9 \\
\hline
\end{tabular}


TABLE XII

A COMPARISON OF TWO DIFFERENT SPICE DECK EVALUATED RESULTS OF AN NMOS TRANSISTOR WITH W/L $=5 / 5(\mu \mathrm{m} / \mu \mathrm{m})$

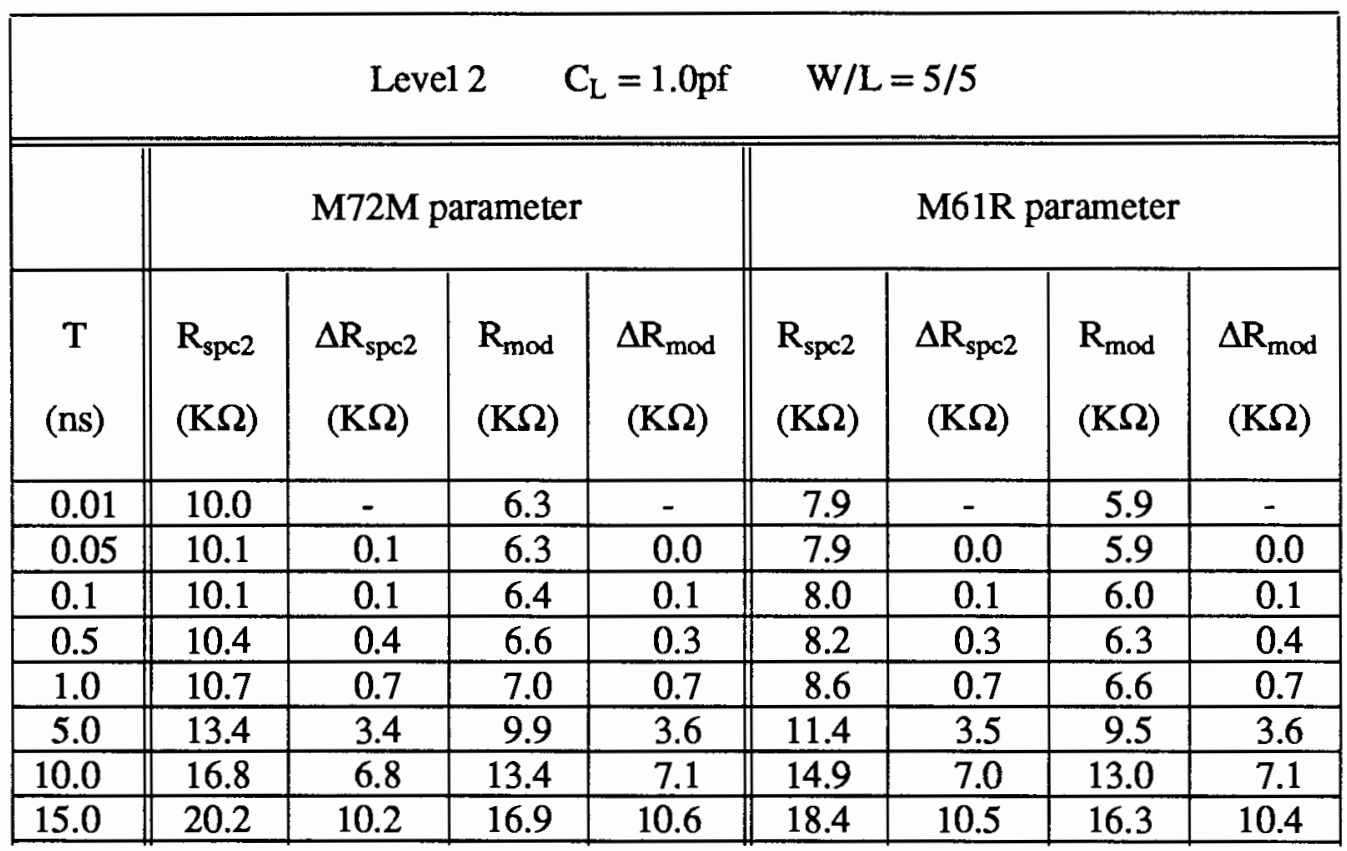

TABLE XIII

A COMPARISON OF TWO DIFFERENT SPICE DECK EVALUATED RESULTS OF AN NMOS TRANSISTOR WITH W/L $=5 / 10(\mu \mathrm{m} / \mu \mathrm{m})$

\begin{tabular}{|c|c|c|c|c|c|c|c|c|}
\hline & \multicolumn{4}{|c|}{ Level 2} & \multicolumn{4}{|c|}{$\mathrm{W} / \mathrm{L}=10 / 5$} \\
\hline & \multicolumn{4}{|c|}{ M72M parameter } & \multicolumn{4}{|c|}{ M61R parameter } \\
\hline $\begin{array}{c}\mathrm{T} \\
\text { (ns) }\end{array}$ & $\begin{array}{l}R_{\mathrm{spc} 2} \\
(\mathrm{~K} \Omega)\end{array}$ & $\begin{array}{c}\Delta R_{\mathrm{spc} 2} \\
(\mathrm{~K} \Omega)\end{array}$ & $\begin{array}{l}R_{\text {mod }} \\
(K \Omega)\end{array}$ & $\begin{array}{c}\Delta R_{\text {mod }} \\
(K \Omega)\end{array}$ & $\begin{array}{l}R_{\mathrm{spc} 2} \\
(\mathrm{~K} \Omega)\end{array}$ & $\begin{array}{c}\Delta \mathrm{R}_{\mathrm{spc} 2} \\
(\mathrm{~K} \Omega)\end{array}$ & $\begin{array}{l}R_{\text {mod }} \\
(K \Omega)\end{array}$ & $\begin{array}{r}\Delta R_{\text {mod }} \\
(K \Omega)\end{array}$ \\
\hline 0.01 & 5.7 & - & 12.6 & - & 14.7 & - & 11.9 & - \\
\hline 0.05 & 15.8 & 0.1 & 12.7 & 0.1 & 14.7 & 0.0 & 11.9 & 0.0 \\
\hline 0.1 & 15.8 & 0.1 & 12.7 & 0.1 & 14.7 & 0.0 & 11.9 & 0.0 \\
\hline 0.5 & 16.1 & 0.4 & 13.0 & 0.4 & 15.0 & 0.3 & 12.2 & 0.3 \\
\hline 1.0 & 16.4 & 0.7 & 13.3 & 0.7 & 15.3 & 0.6 & 12.6 & 0.7 \\
\hline 5.0 & 19.3 & 3.6 & 16.2 & 3.6 & 18.2 & 3.5 & 15.4 & 3.5 \\
\hline 10.0 & 22.8 & 7.1 & 19.8 & 7.2 & 21.7 & 7.0 & 19.0 & 7.1 \\
\hline 15.0 & 26.3 & 10.6 & 23.4 & 10.8 & 25.3 & 10.6 & 22.5 & 10.6 \\
\hline
\end{tabular}


In the event driven simulation, the current time is $T$. The next event is scheduled with a zero time delay. Shoji named this type delay as a negative delay [20] since the output node switchs its logic level before the input voltage crosses the logic threshold voltage.

The three cases described above form the backbone of the event driven $\mathrm{RC}$ delay algorithm used lately.

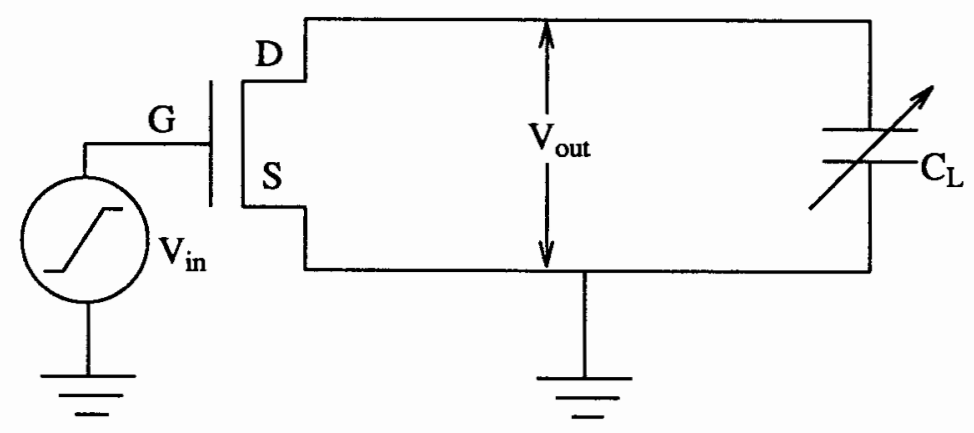

Figure 3-1. The circuit used to specify three different delay cases

\section{New Event Driven RC Delay Algorithm}

Terman has mentioned that "from a practical viewpoint, the success of RSIM depends to a large degree on the choice of the modeling resistance for each transistor." [06]. Using RSIM as a platform for event driven RC delay simulation, our model has been inserted into RSIM to simulate several test logic circuits. The algorithm used to estimate the event delay is:

$$
\begin{aligned}
& \text { if } V_{\text {in }}==I N P U T \\
& \text { event delay }=R_{\text {eff }}{ }^{*} C_{\text {load }} ; \\
& \text { else if } R_{\text {quasi }}{ }^{*} C_{\text {load }} \leq \text { previous event delay } \\
& \text { current event delay }=0 ; \\
& \text { else current event delay }=R_{\text {quasi }}{ }^{*} C_{\text {load }} .
\end{aligned}
$$

The same circuit shown in Figure 1-7 is used to demonstrate our RC time 


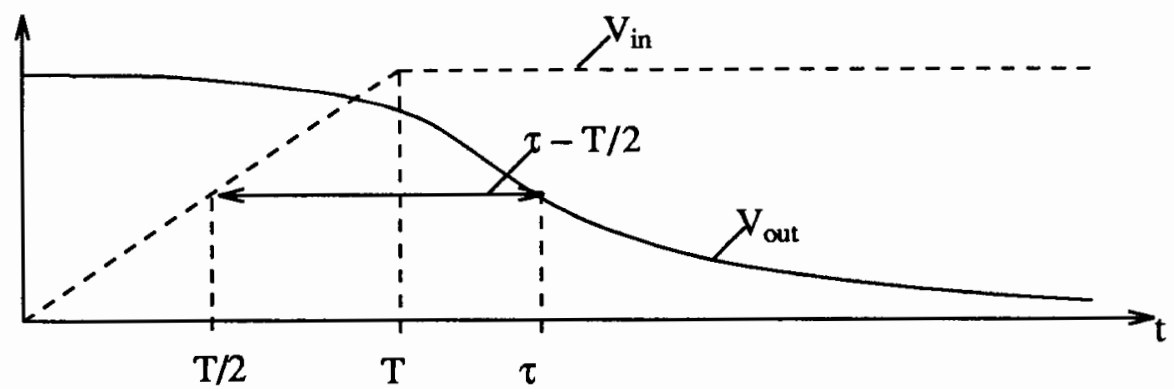

Delay defined in analog analysis

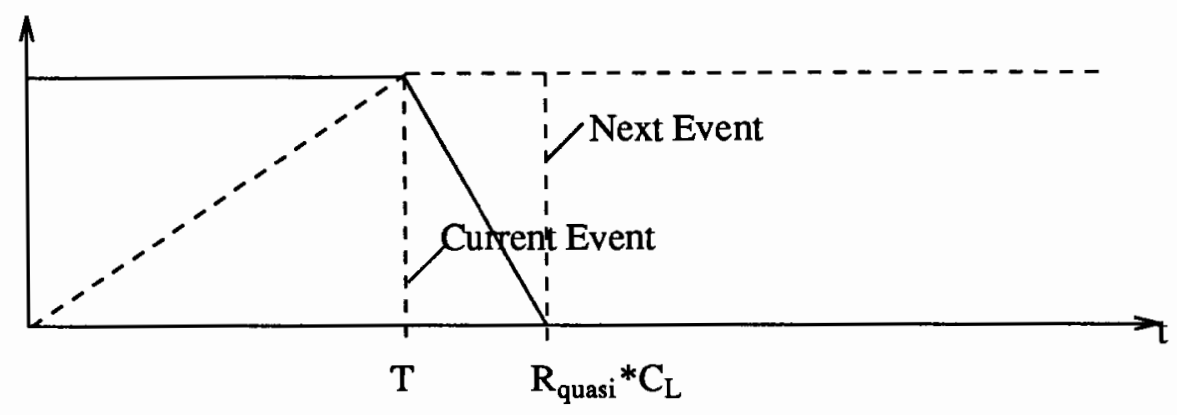

Delay defined in event driven algorithm

Figure 3-2(a). First delay case where $\tau>T$

variation. As a contrast, the waveforms presented in Figure 1-10 now have ramp shapes in our RC time variation as shown in Figure 3-3.

Again, node $\mathrm{A}$ is set to logic level 1 by a user. This stepped logic level transition causes the transistor $M_{1}$ to turn off and the the transistor $M_{2}$ to turn on. An effective resistance $R_{2}$ is used to model the transistor $M_{2}$ in the switch-resistor model as shown in Figure 1-8. The effective resistance is used in the first stage analysis because event \#1 is a step logic transition occurring at node $A$, and it is more properly to use the effective resistance to model the transistor $\mathrm{M}_{2}$.

Event \#1: Node $A$ is set to 1 by a user. This change is a stepped logic level transition. The simulator recalculates all stages affected by $A$, in this case, only the stage containing node $B$. 


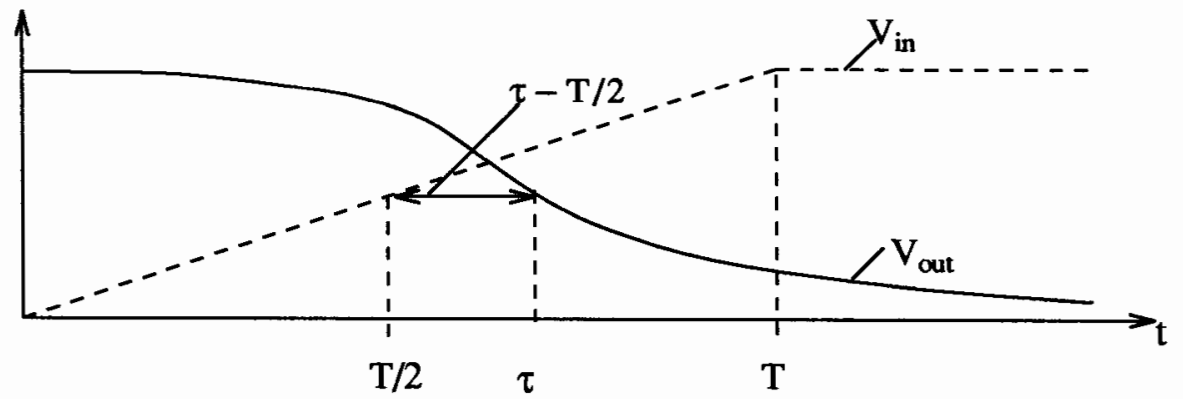

Delay defined in analog analysis

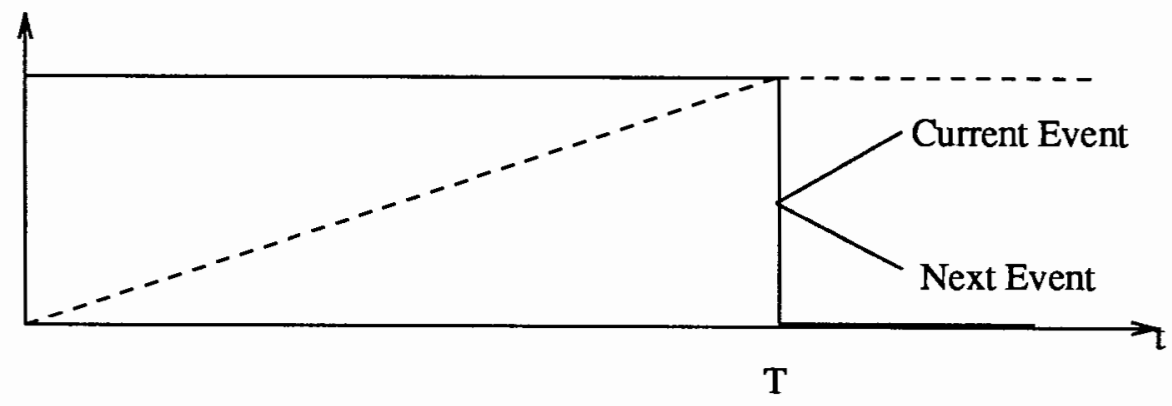

Delay defined in event driven algorithm

Figure 3-2(b). Second delay case where $\mathrm{T} / 2<\tau=\mathrm{T}$

The logic level at node $B$ is pulled down by the transistor $M_{2}$, which causes event $\# 2$ to happen. The event delay time between event \#1 and \#2 is $t_{12}$. $t_{12}=R_{2}\left(C_{1}+C_{2}\right)$. Event \#2 is a ramped logic level transition at node $B$. The ramp time is equal to $t_{12}$.

Event \#2: Node B changes level from 1 to 0 , causing the stage containing $C$ to be analyzed. The change is a ramped logic transition. $\mathrm{t}_{12}=\mathrm{R}_{\mathrm{eff2}} *\left(\mathrm{C}_{1}+\mathrm{C}_{2}\right)$.

The logic level 0 occurring at node $B$ turns the transistor $\mathrm{M}_{3}$ on and the transistor $\mathrm{M}_{4}$ off. Then the logic level at node $\mathrm{C}$ is pulled up by the transistor $\mathrm{M}_{3}$. See Figure 1-9. At this point, the quasi-static resistance $R_{\text {quasi3 }}$ is used to model the transistor $M_{3}$ because $M_{3}$ is affected by the ramp logic level change. The logic 


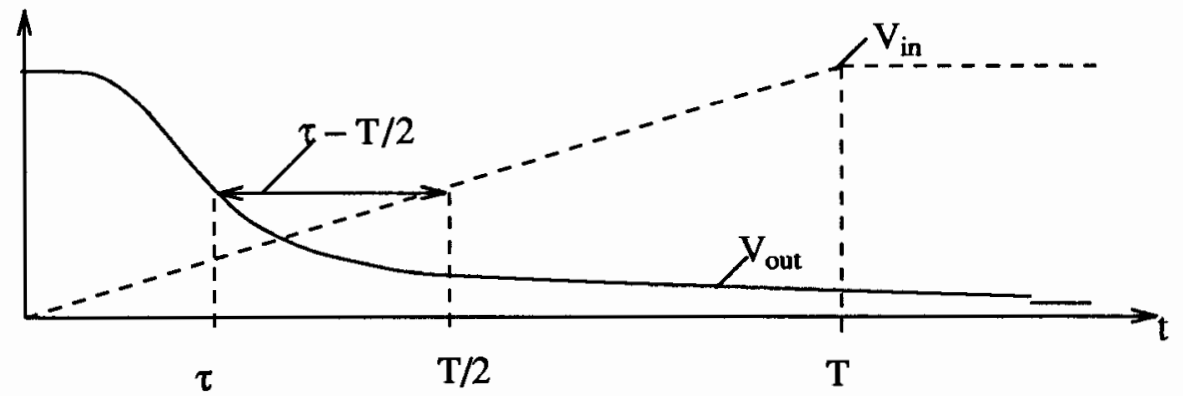

Delay defined in analog analysis

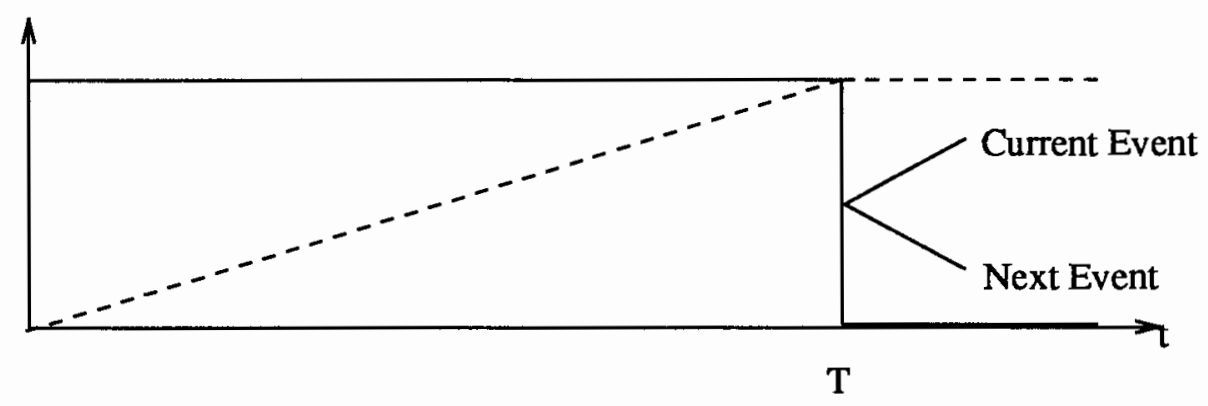

Delay defined in event driven algorithm

Figure 3-2(c). Third delay case where $\mathrm{V}_{\mathrm{th}}<\tau \leq \mathrm{T} / 2$

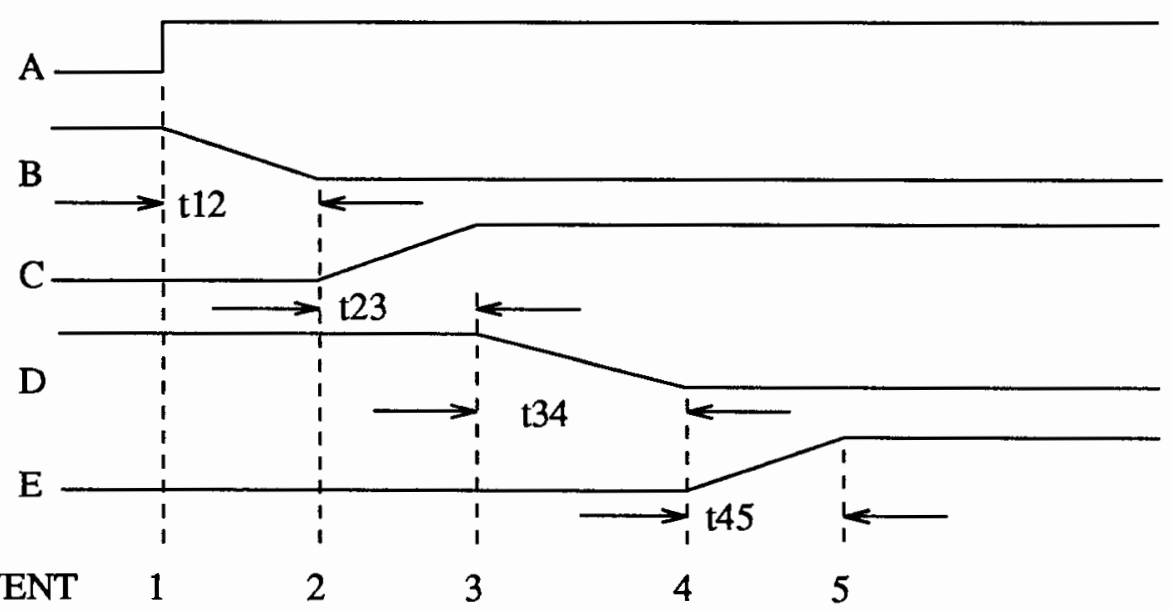

Figure 3-3. The diagram of the event delay time using quasi-static resistance model 
transition at node $C$ causes to event \#3 to occur. Event \#3 lags behind event \#2 by the delay time $t_{23} . t_{23}=R_{\text {quasi3 }} *\left(C_{3}+C_{4}\right)$. If $R_{\text {quasi3 }}=0$, the delay time $t_{23}=0$ which means that events \#2 and \#3 occur at same time.

Event \#3: Node C changes level from 0 to 1 , causing the stage containing D to be analyzed. The change is a ramped logic transition. $\mathrm{t}_{23}=\mathrm{R}_{\text {quasi3 }} *\left(\mathrm{C}_{3}+\mathrm{C}_{4}\right)$.

Similarly for the event \#4 and event \#5:

Event \#4: Node D changes level from 1 to 0 , causing the stage containing $E$ to be analyzed. The change is a ramped logic transition. $\mathrm{t}_{34}=\mathrm{R}_{\text {quasi6 }} *\left(\mathrm{C}_{5}+\mathrm{C}_{6}\right)$.

Event \#5: Node E is set to 1. Node E does not affect any stages, so no more events are added to the event list. $\mathrm{t}_{45}=\mathrm{R}_{\mathrm{quasi}} * \mathrm{C}_{7}$.

After event \#5, there are no more stages affected by the transition at node $E$. The network is said to have settled.

To all CMOS pass transistors, if linear ramp logic transitions are applied on their gates, they behave the same way. 


\section{CHAPTER IV}

\section{TEST RESULTS}

Four typical logic circuits have been simulated by SPICE, the quasi-static resistance model, and RSIM. These logic circuits are an NAND gate, an NOR gate, a 3X2 PLA and a ring oscillator. Also, RSIM is used as a platform to test the quasi-static resistance model.

\section{NAND Gate}

A CMOS three-input NAND gate has been simulated. In a CMOS NAND gate, all p-type transistors are tied in parallel, and all n-type transistors are tied in series. Figure 4-1 is the logic diagram for the simulated three-input NAND gate. Three inverters are used to generate ramp inputs for the NAND gate. Inputs for inverters are set by a user and are assumed to be step inputs. The size for the ntype transistors is $\mathrm{W}=5 \mu \mathrm{m}$ and $\mathrm{L}=5 \mu \mathrm{m}$, and the size for the p-type transistors is $\mathrm{W}=10 \mu \mathrm{m}$ and $\mathrm{L}=5 \mu \mathrm{m}$. Simulating the NAND gate is to examine the result of modeling series $n$-type transistors using the quasi-static resistance. In the simulation algorithm, the transistor, which is the last one turned on in the series, is modeled by the quasi-static resistance. In other words, the gate voltage variation effects the last turned on transistor only. Since there is no current flow through other transistors before the last transistor is turned on, the voltage variation on the other transistor gates is regardless. These transistors are modeled by effective resistances. The test results are listed in TABLE XIIII. The quasi-static resistance model has a maximum $3 \%$ overestimated delay time. 


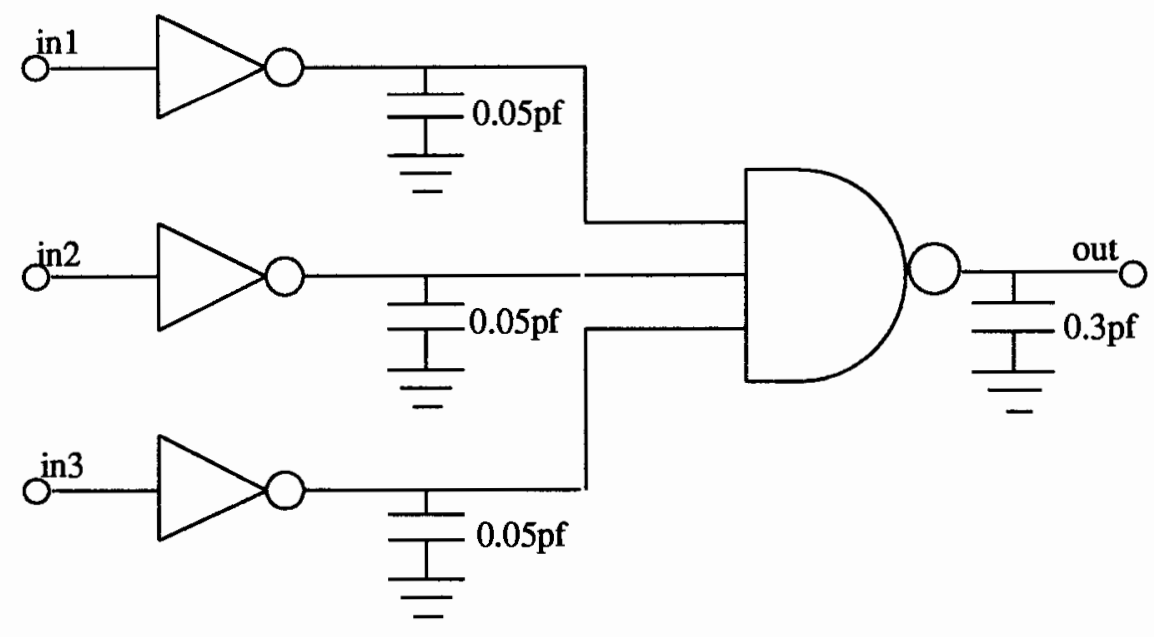

Figure 4-1. The logic diagram for the simulated CMOS three-input NAND gate

TABLE XIIII

THE TEST RESULT TABLE FOE A CMOS THREE-INPUT NAND

\begin{tabular}{|c|c|c|c|c|c|c|}
\hline inputs & output & $\begin{array}{c}\text { SPICE } \\
\text { delay } \\
(\mathrm{ns})\end{array}$ & $\begin{array}{c}\mathrm{R}_{\text {quasi model }} \\
\text { delay } \\
(\mathrm{ns})\end{array}$ & $\begin{array}{c}\text { error } \\
(\%)\end{array}$ & $\begin{array}{c}\text { RSIM } \\
\text { delay } \\
(\mathrm{ns})\end{array}$ & error \\
$(\%)$ \\
\hline \hline 000 & 0 & - & - & - & - & - \\
\hline 001 & 1 & 4.85 & 5.01 & +3 & 5.20 & +7 \\
\hline 000 & 0 & 10.77 & 10.97 & +2 & 11.40 & +6 \\
\hline 010 & 1 & 4.95 & 5.01 & +1 & 5.20 & +5 \\
\hline 000 & 0 & 10.91 & 10.97 & +0 & 11.40 & +5 \\
\hline 001 & 1 & 5.03 & 5.01 & -0 & 5.2 & +3 \\
\hline 000 & 0 & 10.96 & 10.97 & +0 & 11.40 & -4 \\
\hline
\end{tabular}

\section{NOR Gate}

A three-input CMOS NOR gate is simulated too. The CMOS NOR gate's structure is the complement of the CMOS NAND gate's. Three p-type transistors are tied in series, and three n-type transistors are tied in parallel. Figure 4-2 is the logic diagram of the simulated NOR gate circuit. As same as the NAND gate, 
three inverters are used to generate ramp inputs for the NOR gate. To obtain different slope ramp inputs, three different $\mathrm{C}_{\mathrm{L}} \mathrm{s}$ are attached at the outputs of the inverters. The size for the p-type transistors is $\mathrm{W}=10 \mu \mathrm{m}$ and $\mathrm{L}=5 \mu \mathrm{m}$, and the size for the n-type transistors is $\mathrm{W}=5 \mu \mathrm{m}$ and $\mathrm{L}=5 \mu \mathrm{m}$. Similarly, simulating the NOR gate is to examine the result of modeling series p-type transistors using the quasi-static resistance model. The result is listed in TABLE XV. For some critical pathes, the quasi-static resistance model underestimates delay time up to $12 \%$. If the pair-effect is incorporated in the quasi-static resistance model, this kind of error will be improved. On the other hand, RSIM has a worse case of $22 \%$ underestimated delay time.

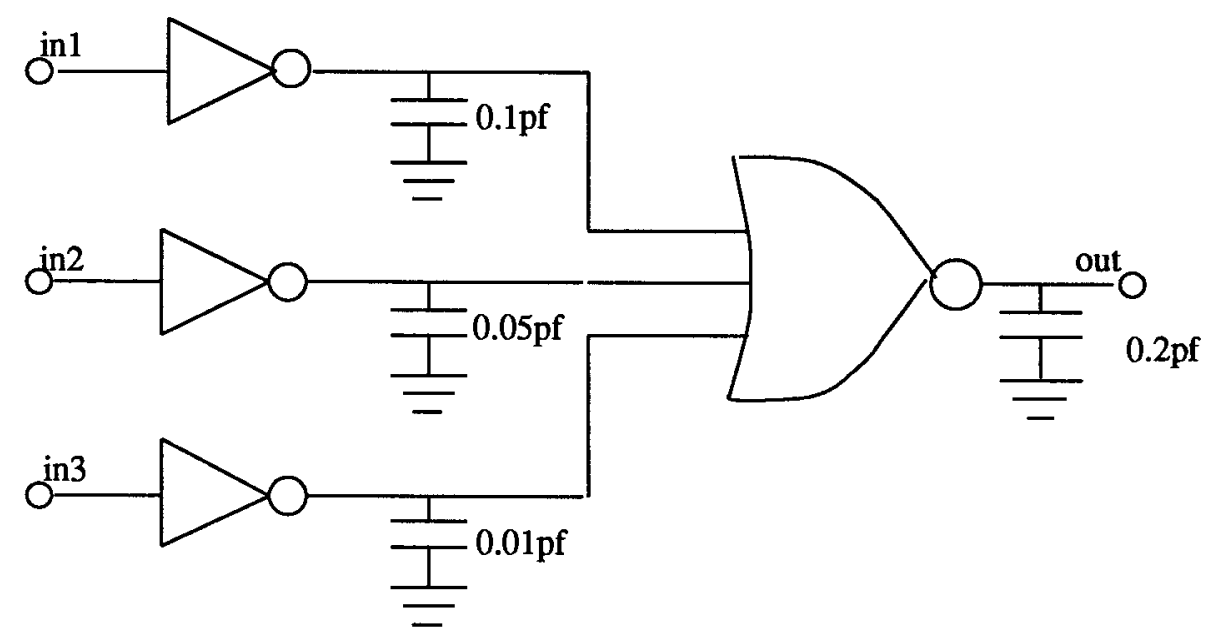

Figure 4-2. The logic diagram of the simulated CMOS three-input NOR gate

\section{3X2 PLA}

The 3X2 PLA is generated by PLAC [21]. It is a static CMOS PLA. All pull-up transistors are p-type transistors and remain on state all the time. These transistors can not be modeled by the quasi-static resistance model. All pull-down transistors are n-type transistors. They are modeled by the quasi-static resistance if ramp inputs are applied on their gates. The PLA structure contains NOR gate 


\section{TABLE XV}

THE TEST RESULT TABLE FOR A CMOS

THREE-INPUT NOR GATE

\begin{tabular}{|c|c|c|c|c|c|c|}
\hline inputs & output & $\begin{array}{c}\text { SPICE } \\
\text { delay } \\
(\mathrm{ns})\end{array}$ & $\begin{array}{c}\mathrm{R}_{\text {quasi model }} \\
\text { delay } \\
(\mathrm{ns})\end{array}$ & $\begin{array}{c}\text { error } \\
(\%)\end{array}$ & $\begin{array}{c}\text { RSIM } \\
\text { delay } \\
(\mathrm{ns})\end{array}$ & $\begin{array}{c}\text { error } \\
(\%)\end{array}$ \\
\hline \hline 111 & 1 & - & - & - & - & - \\
\hline 110 & 0 & 4.92 & 4.31 & -12 & 4.1 & -17 \\
\hline 111 & 1 & 8.55 & 8.49 & -1 & 9.4 & +10 \\
\hline 101 & 0 & 4.47 & 3.90 & -12 & 3.5 & -22 \\
\hline 111 & 1 & 8.55 & 8.12 & -1 & 8.9 & +4 \\
\hline 011 & 0 & 4.00 & 3.54 & -11 & 3.1 & -21 \\
\hline 111 & 1 & 8.33 & 7.86 & -5 & 8.6 & +3 \\
\hline
\end{tabular}

only. This simulation examines the quasi-static resistance modeling NOR gate properly. Also, it examines the algorithm how to handle the fast and slow delay cases. The simulation result is listed in TABLE XVI. The quasi-static resistance model has a worse case of $33 \%$ underestimated delay time. To investigate the cause of the underestimated delay time, hand debugging was used to trace the simulation process. The debugging showed that RSIM program, which we used it as a platform, could not execute the new event driven algorithm properly. Some of RSIM's subroutines need to be modified to use the quasi-static resistance model.

\section{Ring Oscillator}

A ring oscillator frequency measurement was a gate delay test experiment in which we are most interested. A ring oscillator is a sequential automaton and its frequency measurement is often used to determine gate delay of CMOS circuits. It is composed by $\mathrm{N}$ stages of cascaded CMOS inverters. Each inverter is uniquely sized and loaded. After a ring oscillator has been initialized, all gates in 
TABLE XVI-A

THE TEST RESULT TABLE FOR

A CMOS 3X2 PLA

OUTPUT-1

\begin{tabular}{|c|c|c|c|c|c|c|}
\hline inputs & output-1 & $\begin{array}{c}\text { SPICE } \\
\text { delay } \\
\text { (ns) }\end{array}$ & $\begin{array}{c}\mathrm{R}_{\text {quasi model }} \\
\text { delay } \\
\text { (ns) }\end{array}$ & error & $\begin{array}{c}\text { RSIM } \\
\text { delay } \\
\text { (ns) }\end{array}$ & error \\
$(\%)$
\end{tabular}

TABLE XVI-B

THE TEST RESULT TABLE OF

A 3X2 PLA

OUTPUT-2

\begin{tabular}{|c|c|c|c|c|c|c|}
\hline inputs & output-2 & $\begin{array}{c}\text { SPICE } \\
\text { delay } \\
\text { (ns) }\end{array}$ & $\begin{array}{l}\mathbf{R}_{\text {quasi model }} \\
\text { delay } \\
\text { (ns) }\end{array}$ & $\begin{array}{l}\text { error } \\
(\%)\end{array}$ & $\begin{array}{c}\text { RSIM } \\
\text { delay } \\
\text { (ns) }\end{array}$ & $\begin{array}{l}\text { error } \\
(\%)\end{array}$ \\
\hline$\overline{0000}$ & $\overline{1}$ & - & - & $=$ & - & $=$ \\
\hline 001 & 0 & 30.4 & 30.2 & 0 & 26.6 & -12 \\
\hline 010 & 1 & 26.9 & 20.4 & -24 & 20.8 & -23 \\
\hline 011 & 0 & 30.26 & 30.2 & 0 & 26.6 & -12 \\
\hline 100 & 1 & 28.1 & 20.4 & -27 & 20.8 & -26 \\
\hline 101 & 0 & 30.7 & 30.2 & -2 & 26.6 & -13 \\
\hline 110 & 1 & 26.9 & 20.4 & -24 & 20.8 & -23 \\
\hline 111 & 0 & 30.1 & 30.2 & 0 & 26.6 & -12 \\
\hline
\end{tabular}

the ring oscillator have same pull-up time and pull-down time. $\mathrm{N}$, the number of inverters, must be an odd number to keep a ring oscillator being unstable in state. The frequency of a ring oscillator is given by 4.1 [20]. 


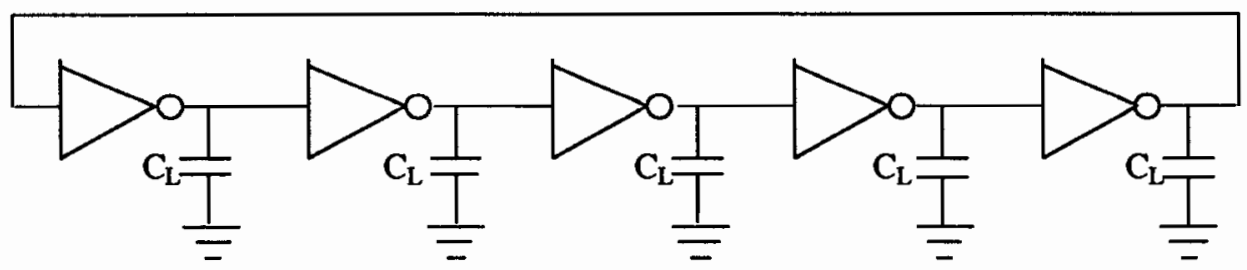

Figure 4-3. The logic diagram of a five-stage ring oscillator

TABLE XVII

THE FREQUENCY COMPARISON OF A

FIVE-STAGE RING OSCILLATOR

\begin{tabular}{|c|c|c|c|c|}
\hline$C_{\text {load }}$ & $\frac{\mathrm{R}_{\text {quasi }} \text { Model }}{S P I C E}$ & error(\%) & $\frac{\text { RSIM }}{\text { SPICE }}$ & error(\%) \\
\hline \hline $0.01 \mathrm{pf}$ & 1.59 & +59 & 1.38 & +38 \\
\hline $0.05 \mathrm{pf}$ & 1.47 & +47 & 1.47 & +47 \\
\hline $0.1 \mathrm{pf}$ & 1.41 & +41 & 1.47 & +47 \\
\hline $0.5 \mathrm{pf}$ & 1.33 & +33 & 1.45 & +45 \\
\hline
\end{tabular}

$$
\mathrm{f} \approx \frac{\mathrm{g}_{\mathrm{m}}}{2 \mathrm{CN}}
$$

Parameters $g_{m}, C$ and $\mathrm{N}$ are transistor conductance, the load resistance and the number of the stages. Those parameters determine the frequency of a ring oscillator. The period of oscillation is proportional to the number of cascaded stages. If the period of oscillation is divided by $\mathrm{N}$, the pair delay of a gate (sum of pull-up and pull-down delays) is determined. In our test experiment, a five-stage ring oscillator was used. In the ring oscillator, the size of the n-type transistor is $\mathrm{W}=5 \mu \mathrm{m}$ and $\mathrm{L}=5 \mu \mathrm{m}$; the size of the p-type transistor is $\mathrm{W}=10 \mu \mathrm{m}$ and $\mathrm{L}=5 \mu \mathrm{m}$. The logic diagram is shown in Figure 4-3. $\mathrm{C}_{\mathrm{L}} \mathrm{s}$ are loaded capacitances. The SPICE simulated oscillation frequency is normalized to 1 . The quasi-static resistance model and RSIM simulated oscillation frequencies, being the ratios of the 
SPICE simulated oscillation frequency, are listed in TABLE XVII. As shown in the table, the model overestimates the oscillation frequency quite a bit. This is because the same RSIM program problem happens here as happened in the $3 \mathrm{X} 2$ PLA.

Through all the test experiments, the quasi-static resistance model maps MOS transistors well in the dynamic simulation. But the algorithm exposes the shortage in simulating some critical delay pathes. 


\section{CHAPTER V}

\section{SUMMARY}

RC switch-level model has been successfully used for the MOS digital circuit time verification. In this model, MOS transistors are mapped by equivalent resistances. An accurate resistance leads to a better time verification result. Our resistance model is mathematically derived from the MOS transistor's dc characteristic equations. The model includes both system and local parameters. The integral of $\mathrm{dV}_{\mathrm{ds}} / \mathrm{I}_{\mathrm{ds}}$ predicts the model's resistance value. The resistance is dynamically evaluated, and it includes the effects of variations in input rise and fall time on the gate delay.

The quasi-static resistance is defined as $R_{\text {quasi }}=R_{\text {eff }}+\Delta R_{\text {mod }}(T) . \quad R_{\text {eff }}$ is defined by the experiment of the single transistor charging/discharging its load capacitor. The value is evaluated by the SPICE level 2 simulation in our case. $\Delta R_{\text {mod }}(T)$ is the incremental resistance associated with the ramp input slope $1 / T$ and the load capacitance $\mathrm{C}_{\mathrm{L}}$. The value is calculated using our model. The MOS transistor's system parameter variation is modeled in the SPICE level 2 evaluation. Our model reflects the variation in $\mu, \mathrm{V}_{\mathrm{th}}, \mathrm{t}_{\mathrm{ox}}, \mathrm{W}$, and $\mathrm{L}$. Also, it reflects the local parameter variation. Therefore, the quasi-static resistance reflects both system and local parameter variations.

As the advantage of using the quasi-static resistance, the time verification result includes the effects of input rise and fall time on the gate delay. Furthermore, users need not predefine all possible resistance values for simulating a logic circuit. Only a circuit independent effective resistance look-up-table is required. 
Moreover, the event driven algorithm using the quasi-static resistance takes care of both slow and fast delay cases. In the slow delay case, the next event is scheduled to happen with a RC time delay, where $\mathrm{R}$ is the quasi-static resistance. On the other hand, the next event is scheduled with a zero time delay in the fast delay case. The algorithm may be applicable for critical path searching and transistor sizing. Also, it may be used for estimating RC time delay in a bound limit.

Further research work can be extensively done in improving the resistance model and the estimation of RC time delay. For doing this, other MOS transistor's charge models may be chosen for evaluating quasi-static resistance. The $\mathrm{p}-\mathrm{n}$-channel transistor pair effect may be included in the model. The algorithm can be more improved. In the slow delay case, if a certain $\mathrm{R}_{\text {quasi }} \mathrm{C}$ value replaces a zero for the next stage input, a better result may be obtained. Therefore, a more accurate dynamic resistance model with its various applications can be built in the near future. 


\section{REFERENCES}

[01] Chong-Yeong Chu and Mark Alan Horowitz, "Charge-sharing Models for Switch-Level Simulation", IEEE Trans, Computer-aided Design, Vol. CAD-6, No. 6, Nov. 1987, pp. 1053-1061.

[02] W. Weeks et. al., "Algorithms for ASTAP -- A Network Analysis Program", IEEE Trans. Circuit Theory, Vol. CT-20, pp. 628-634, Nov. 1973.

[03] A. Vladimirescu et. al. "SPICE User's Guide", Department of Electrical Engineering and Computer Science, University of California, Berkeley, May 1975.

[04] D. Holt and D. Hutchings, "A MOS/LSI Oriented Logic Simulator", in 18th ACM/IEEE Design Automation Conf., June 1981, pp. 280-287.

[05] W. Sherwood, "A MOS Modeling Technique for 4-state True-Value Hierarchical Logic Simulation", in 18th ACMIIEEE Design Automation Conf., June 1981, pp. 775-785.

[06] Chistopher J. Terman, "Simulation Tools for Digital LSI Design", Ph.D. dissertation, Massachusetts Institute of Technology, 1983.

[07] David Tsao and Chin-Fu Chen, "A Fast-Timing Simulator for Digital MOS Circuits", IEEE Trans. Computer-aided Design, Vol. CAD-5 No. 4, Oct. 1986, pp. 536-540.

[08] Randal E. Bryant, "A Switch-Level Model and Simulation for MOS Digital Systems", IEEE Trans. Computers, Vol. C-33, No. 2, Feb. 1984, pp. 160-177.

[09] H. N. Nham and A. K. Bose, " A Multiple Delay Simulator for MOS LSI Circuits", in Proc. 17th Design Automation Conf., (Minneapolis, MN), June 1980 , pp. 610-617.

[10] B. R. Chawla, H. K. Gummel and P. Kozak, "MOSTIS--An MOS Timing Simulator", IEEE Trans. Circuits Syst., Dec. 1975, pp. 901-910. 
[11] C. F. Chen, C. Y. Lo, H. N. Nham and P. Subramaniam, "The Second Generation MOSTIS Mixed-mode Simulator", in Proc. 21st Design Automation Conf., 1984, pp. 10-17.

[12] Bruce A. Richman at. el. "A Deterministic Algorithm for Automatic CMOS Transistor Sizing", IEEE J. Solid-State Circuit Vol. 23, No. 2, April 1988.

[13] J. Rubinstein, P. Penfield and M. A. Horowitz, "Signal Delay in RC Tree Networks", IEEE Trans. Computer-aided design, Vol. CAD-2, No. 3, July 1983, pp. 202-211.

[14] Tzu-Mu Lin and Carver A. Mead "Signal Delay in General RC Networks", IEEE Trans. Computer-Aided Design, Vol. CAD-3, No. 4, Oct. 1984.

[15] Charles Alber Zukowski "Relaxing Bounds for Linear RC Mesh Circuits", IEEE Trans. Computer-Aided Design, Vol. CAD-5, No. 2, Apr. 1986.

[16] Takeshi Tokuda, et al. "Delay-Time Modeling for ED MOS Logic LSI", IEEE Trans. Computer-Aided Design, Vol. CÅD-2. No. 3, July 1983, pp. 129-134.

[17] Mohamed I. Elmasry "Digital MOS Intergrated Circuits", IEEE press: 1981, Section 1.2.

[18] Lance A. Glasser and Daniel W. Dobberpuhl, "The Design and Analysis of VLSI Circuits", Addison-Wesley Publishing Company, 1985.

[19] Yannis P. Tsividis, "Operation and Modeling of the MOS Transistor", McGraw-Hill Book Company, 1987.

[20] Masakazu Shoji, "CMOS Digital Circuit Technology", Prentice-Hall Inc., 1988.

[21] Akhilesh Tyagi, "Berkeley CAD Tools Manual", University of California, Berkeley, 1985. 
APPENDIX A

TABLES OF COMPARISONS 


\begin{tabular}{|c||c|c|c|c|}
\hline \multicolumn{5}{|c|}{$\mathrm{C}_{\mathrm{L}}=0.1 \mathrm{pf} \quad \frac{\mathrm{W}}{\mathrm{L}}=\frac{4}{3}$} \\
\hline \hline $\mathrm{T}(\mathrm{ns})$ & $\mathrm{R}_{\mathrm{spc} 2}(\mathrm{~K} \Omega)$ & $\Delta \mathrm{R}_{\mathrm{spc} 2}(\mathrm{~K} \Omega)$ & $\mathrm{R}_{\bmod }(\mathrm{K} \Omega)$ & $\Delta \mathrm{R}_{\bmod }(\mathrm{K} \Omega)$ \\
\hline 0.01 & 11.0 & - & 4.8 & - \\
\hline 0.05 & 11.0 & 0.0 & 5.1 & 0.3 \\
\hline 0.1 & 12.0 & 1.0 & 5.5 & 0.7 \\
\hline 0.5 & 14.0 & 3.0 & 8.4 & 3.6 \\
\hline 1.0 & 17.0 & 6.0 & 11.9 & 7.1 \\
\hline 5.0 & 43.0 & 32.0 & 36.0 & 31.2 \\
\hline 10.0 & 68.0 & 57.0 & 62.0 & 57.2 \\
\hline 15.0 & 91.0 & 80.0 & 85.9 & 81.1 \\
\hline
\end{tabular}

\begin{tabular}{|c||c|c|c|c|}
\hline \multicolumn{5}{|c|}{$\mathrm{C}_{\mathrm{L}}=0.1 \mathrm{pf} \quad \frac{\mathrm{W}}{\mathrm{L}}=\frac{4}{12}$} \\
\hline \hline $\mathrm{T}(\mathrm{ns})$ & $\mathrm{R}_{\mathrm{spc} 2}(\mathrm{~K} \Omega)$ & $\Delta \mathrm{R}_{\mathrm{spc} 2}(\mathrm{~K} \Omega)$ & $\mathrm{R}_{\bmod }(\mathrm{K} \Omega)$ & $\Delta \mathrm{R}_{\bmod }(\mathrm{K} \Omega)$ \\
\hline 0.01 & 24.0 & - & 20.0 & - \\
\hline 0.05 & 25.0 & 1.0 & 20.3 & 0.3 \\
\hline 0.1 & 25.0 & 1.0 & 20.6 & 0.6 \\
\hline 0.5 & 28.0 & 4.0 & 23.5 & 3.5 \\
\hline 1.0 & 31.0 & 7.0 & 27.1 & 7.1 \\
\hline 5.0 & 60.0 & 36.0 & 55.1 & 35.8 \\
\hline 10.0 & 95.0 & 71.0 & 86.8 & 66.8 \\
\hline 15.0 & 127.0 & 103.0 & 116.3 & 96.3 \\
\hline
\end{tabular}

\begin{tabular}{|c||c|c|c|c|}
\hline \multicolumn{5}{|c|}{$\mathrm{C}_{\mathrm{L}}=0.1 \mathrm{pf} \quad \frac{\mathrm{W}}{\mathrm{L}}=\frac{8}{3}$} \\
\hline \hline $\mathrm{T}(\mathrm{ns})$ & $\mathrm{R}_{\mathrm{spc} 2}(\mathrm{~K} \Omega)$ & $\Delta \mathrm{R}_{\mathrm{spc} 2}(\mathrm{~K} \Omega)$ & $\mathrm{R}_{\bmod }(\mathrm{K} \Omega)$ & $\Delta \mathrm{R}_{\bmod }(\mathrm{K} \Omega)$ \\
\hline 0.01 & 6.0 & - & 2.5 & - \\
\hline 0.05 & 6.0 & 0.0 & 2.8 & 0.3 \\
\hline 0.1 & 6.0 & 0.0 & 3.1 & 0.6 \\
\hline 0.5 & 9.0 & 3.0 & 6.0 & 3.5 \\
\hline 1.0 & 12.0 & 6.0 & 9.3 & 6.8 \\
\hline 5.0 & 34.0 & 28.0 & 31.0 & 28.5 \\
\hline 10.0 & 55.0 & 49.0 & 54.1 & 51.6 \\
\hline 15.0 & 75.0 & 69.0 & 74.9 & 72.4 \\
\hline
\end{tabular}




\begin{tabular}{|c||c|c|c|c|}
\hline \multicolumn{5}{|c|}{$C_{\mathrm{L}}=0.1 \mathrm{pf} \quad \frac{\mathrm{W}}{\mathrm{L}}=\frac{16}{3}$} \\
\hline \hline $\mathrm{T}(\mathrm{ns})$ & $\mathrm{R}_{\mathrm{spc} 2}(\mathrm{~K} \Omega)$ & $\Delta \mathrm{R}_{\mathrm{spc} 2}(\mathrm{~K} \Omega)$ & $\mathrm{R}_{\bmod }(\mathrm{K} \Omega)$ & $\Delta \mathrm{R}_{\bmod }(\mathrm{K} \Omega)$ \\
\hline 0.01 & 3.0 & - & 1.3 & - \\
\hline 0.05 & 3.0 & 0.0 & 1.6 & 0.3 \\
\hline 0.1 & 4.0 & 1.0 & 2.0 & 0.7 \\
\hline 0.5 & 6.0 & 3.0 & 4.7 & 3.4 \\
\hline 1.0 & 10.0 & 7.0 & 7.6 & 6.3 \\
\hline 5.0 & 28.0 & 25.0 & 27.1 & 25.8 \\
\hline 10.0 & 46.0 & 43.0 & 47.2 & 45.9 \\
\hline 15.0 & 63.0 & 60.0 & 65.4 & 64.1 \\
\hline
\end{tabular}

\begin{tabular}{|c||c|c|c|c|}
\hline \multicolumn{5}{|c|}{$\mathrm{C}_{\mathrm{L}}=0.1 \mathrm{pf} \quad \frac{\mathrm{W}}{\mathrm{L}}=\frac{5}{5}$} \\
\hline \hline$T(\mathrm{~ns})$ & $\mathrm{R}_{\mathrm{spc} 2}(\mathrm{~K} \Omega)$ & $\Delta \mathrm{R}_{\mathrm{spc} 2}(\mathrm{~K} \Omega)$ & $\mathrm{R}_{\bmod }(\mathrm{K} \Omega)$ & $\Delta \mathrm{R}_{\bmod }(\mathrm{K} \Omega)$ \\
\hline 0.01 & 11.0 & - & 6.5 & - \\
\hline 0.05 & 11.0 & 0.0 & 6.8 & 0.3 \\
\hline 0.1 & 11.0 & 0.0 & 7.2 & 0.7 \\
\hline 0.5 & 14.0 & 3.0 & 10.0 & 3.5 \\
\hline 1.0 & 18.0 & 7.0 & 13.6 & 7.1 \\
\hline 5.0 & 44.0 & 33.0 & 38.7 & 32.2 \\
\hline 10.0 & 72.0 & 61.0 & 65.6 & 59.1 \\
\hline 15.0 & 96.0 & 85.0 & 90.9 & 84.4 \\
\hline
\end{tabular}

\begin{tabular}{|c||c|c|c|c|}
\hline \multicolumn{5}{|c|}{$C_{\mathrm{L}}=0.1 \mathrm{pf} \quad \frac{\mathrm{W}}{\mathrm{L}}=\frac{5}{10}$} \\
\hline \hline $\mathrm{T}(\mathrm{ns})$ & $\mathrm{R}_{\mathrm{spc} 2}(\mathrm{~K} \Omega)$ & $\Delta \mathrm{R}_{\mathrm{spc} 2}(\mathrm{~K} \Omega)$ & $\mathrm{R}_{\bmod }(\mathrm{K} \Omega)$ & $\Delta \mathrm{R}_{\bmod }(\mathrm{K} \Omega)$ \\
\hline 0.01 & 17.0 & - & 13.4 & - \\
\hline 0.05 & 17.0 & 0.0 & 13.7 & 0.3 \\
\hline 0.1 & 18.0 & 1.0 & 14.0 & 0.6 \\
\hline 0.5 & 20.0 & 3.0 & 16.9 & 3.5 \\
\hline 1.0 & 24.0 & 7.0 & 20.5 & 7.1 \\
\hline 5.0 & 52.0 & 35.0 & 47.5 & 34.1 \\
\hline 10.0 & 84.0 & 67.0 & 77.6 & 64.2 \\
\hline 15.0 & 114.0 & 97.0 & 105.2 & 91.8 \\
\hline
\end{tabular}




\begin{tabular}{|c||c|c|c|c|}
\hline \multicolumn{5}{|c|}{$C_{L}=0.1 \mathrm{pfr} \quad \frac{\mathrm{W}}{\mathrm{L}}=\frac{10}{5}$} \\
\hline \hline $\mathrm{T}(\mathrm{ns})$ & $\mathrm{R}_{\mathrm{spc} 2}(\mathrm{~K} \Omega)$ & $\Delta \mathrm{R}_{\mathrm{spc} 2}(\mathrm{~K} \Omega)$ & $\mathrm{R}_{\bmod }(\mathrm{K} \Omega)$ & $\Delta \mathrm{R}_{\bmod }(\mathrm{K} \Omega)$ \\
\hline 0.01 & 6.0 & - & 3.4 & - \\
\hline 0.05 & 6.0 & 0.0 & 3.7 & 0.3 \\
\hline 0.1 & 6.0 & 0.0 & 4.0 & 0.6 \\
\hline 0.5 & 9.0 & 3.0 & 6.9 & 3.5 \\
\hline 1.0 & 12.0 & 6.0 & 10.3 & 6.9 \\
\hline 5.0 & 36.0 & 30.0 & 32.8 & 29.2 \\
\hline 10.0 & 59.0 & 53.0 & 57.3 & 53.9 \\
\hline 15.0 & 79.0 & 73.0 & 79.3 & 75.9 \\
\hline
\end{tabular}

\begin{tabular}{|c|c|c|c|c|}
\hline \multicolumn{3}{|r|}{$C_{L}=0.1 p f$} & \multicolumn{2}{|c|}{$\frac{V}{10}$} \\
\hline $\mathrm{T}(\mathrm{ns})$ & $\mathrm{R}_{\mathrm{spc} 2}(\mathrm{~K} \Omega)$ & $\Delta \mathrm{R}_{\mathrm{spc} 2}(\mathrm{~K} \Omega)$ & $\mathrm{R}_{\bmod }(\mathrm{K} \Omega)$ & $\Delta \mathrm{R}_{\bmod }(\mathrm{K} \Omega)$ \\
\hline 0.01 & 9.0 & - & 7.1 & - \\
\hline 0.05 & 9.0 & 0.0 & 7.4 & 0.3 \\
\hline 0.1 & 9.0 & 0.0 & 7.7 & 0.6 \\
\hline 0.5 & 12.0 & 3.0 & 10.6 & 3.5 \\
\hline 1.0 & 16.0 & 7.0 & 14.2 & 7.1 \\
\hline 5.0 & 42.0 & 33.0 & 39.0 & 31.9 \\
\hline 10.0 & 70.0 & 61.0 & 65.7 & 58.6 \\
\hline 15.0 & 94.0 & 85.0 & 90.9 & 83.8 \\
\hline & \multicolumn{2}{|r|}{$C_{L}=0.1 p f$} & \multicolumn{2}{|c|}{$V=\frac{16}{16}$} \\
\hline $\mathrm{T}(\mathrm{ns})$ & $\mathrm{R}_{\mathrm{spc} 2}(\mathrm{~K} \Omega)$ & $\Delta \mathrm{R}_{\mathrm{spc} 2}(\mathrm{~K} \Omega)$ & $\mathrm{R}_{\bmod }(\mathrm{K} \Omega)$ & $\Delta \mathrm{R}_{\bmod }(\mathrm{K} \Omega)$ \\
\hline 0.01 & 8.0 & - & 8.3 & - \\
\hline 0.05 & 9.0 & 1.0 & 8.6 & 0.3 \\
\hline 0.1 & 9.0 & 1.0 & 8.9 & 0.6 \\
\hline 0.5 & 12.0 & 4.0 & 11.8 & 3.5 \\
\hline 1.0 & 15.0 & 7.0 & 15.4 & 7.1 \\
\hline 5.0 & 42.0 & 34.0 & 39.6 & 31.3 \\
\hline 10.0 & 70.0 & 62.0 & 65.7 & 57.4 \\
\hline 15.0 & 93.0 & 85.0 & 90.9 & 82.6 \\
\hline
\end{tabular}




\begin{tabular}{|c||c|c|c|c|}
\hline \multicolumn{5}{|c|}{$\mathrm{C}_{\mathrm{L}}=0.1 \mathrm{pf} \quad \frac{\mathrm{W}}{\mathrm{L}}=\frac{16}{32}$} \\
\hline \hline $\mathrm{T}(\mathrm{ns})$ & $\mathrm{R}_{\mathrm{spc} 2}(\mathrm{~K} \Omega)$ & $\Delta \mathrm{R}_{\mathrm{spc} 2}(\mathrm{~K} \Omega)$ & $\mathrm{R}_{\bmod }(\mathrm{K} \Omega)$ & $\Delta \mathrm{R}_{\bmod }(\mathrm{K} \Omega)$ \\
\hline 0.01 & 15.0 & - & & \\
\hline 0.05 & 16.0 & 1.0 & 20.4 & - \\
\hline 0.1 & 16.0 & 1.0 & 21.0 & 0.3 \\
\hline 0.5 & 19.0 & 4.0 & 23.9 & 0.6 \\
\hline 1.0 & 23.0 & 8.0 & 27.5 & 3.5 \\
\hline 5.0 & 51.0 & 36.0 & 53.6 & 33.1 \\
\hline 10.0 & 88.0 & 73.0 & 81.2 & 60.8 \\
\hline 15.0 & 112.0 & 97.0 & 106.9 & 86.5 \\
\hline
\end{tabular}

\begin{tabular}{|c||c|c|c|c|}
\hline \multicolumn{5}{|c|}{$\mathrm{C}_{\mathrm{L}}=0.1 \mathrm{pf} \quad \frac{\mathrm{W}}{\mathrm{L}}=\frac{32}{16}$} \\
\hline \hline $\mathrm{T}(\mathrm{ns})$ & $\mathrm{R}_{\mathrm{spc} 2}(\mathrm{~K} \Omega)$ & $\Delta \mathrm{R}_{\mathrm{spc} 2}(\mathrm{~K} \Omega)$ & $\mathrm{R}_{\bmod }(\mathrm{K} \Omega)$ & $\Delta \mathrm{R}_{\bmod }(\mathrm{K} \Omega)$ \\
\hline 0.01 & 5.0 & - & 5.1 & - \\
\hline 0.05 & 5.0 & 0.0 & 5.4 & 0.3 \\
\hline 0.1 & 5.0 & 0.0 & 5.8 & 0.7 \\
\hline 0.5 & 8.0 & 3.0 & 8.7 & 3.6 \\
\hline 1.0 & 12.0 & 7.0 & 11.9 & 6.8 \\
\hline 5.0 & 35.0 & 30.0 & 32.9 & 29.8 \\
\hline 10.0 & 59.0 & 54.0 & 57.3 & 52.2 \\
\hline 15.0 & 79.0 & 74.0 & 79.3 & 74.2 \\
\hline
\end{tabular}

\begin{tabular}{|c||c|c|c|c|}
\hline \multicolumn{5}{|c|}{$\mathrm{C}_{\mathrm{L}}=0.1 \mathrm{pf} \quad \frac{\mathrm{W}}{\mathrm{L}}=\frac{32}{32}$} \\
\hline $\mathrm{T}(\mathrm{ns})$ & $\mathrm{R}_{\mathrm{spc} 2}(\mathrm{~K} \Omega)$ & $\Delta \mathrm{R}_{\mathrm{spc} 2}(\mathrm{~K} \Omega)$ & $\mathrm{R}_{\bmod }(\mathrm{K} \Omega)$ & $\Delta \mathrm{R}_{\bmod }(\mathrm{K} \Omega)$ \\
\hline 0.01 & 9.0 & - & 14.1 & - \\
\hline 0.05 & 9.0 & 0.0 & 14.4 & 0.3 \\
\hline 0.1 & 9.0 & 0.0 & 14.7 & 0.6 \\
\hline 0.5 & 12.0 & 3.0 & 17.6 & 3.5 \\
\hline 1.0 & 15.0 & 6.0 & 21.5 & 7.4 \\
\hline 5.0 & 45.0 & 36.0 & 42.6 & 28.5 \\
\hline 10.0 & 70.0 & 61.0 & 65.7 & 51.6 \\
\hline 15.0 & 95.0 & 90.0 & 90.9 & 76.8 \\
\hline
\end{tabular}




\begin{tabular}{|c||c|c|c|c|}
\hline \multicolumn{5}{|c|}{$\mathrm{C}_{\mathrm{L}}=0.1 \mathrm{pf} \quad \frac{\mathrm{W}}{\mathrm{L}}=\frac{50}{50}$} \\
\hline \hline $\mathrm{T}(\mathrm{ns})$ & $\mathrm{R}_{\mathrm{spc} 2}(\mathrm{~K} \Omega)$ & $\Delta \mathrm{R}_{\mathrm{spc} 2}(\mathrm{~K} \Omega)$ & $\mathrm{R}_{\bmod }(\mathrm{K} \Omega)$ & $\Delta \mathrm{R}_{\bmod }(\mathrm{K} \Omega)$ \\
\hline 0.01 & 2.0 & - & 25.3 & - \\
\hline 0.05 & 3.0 & 1.0 & 25.6 & 0.3 \\
\hline 0.1 & 3.0 & 1.0 & 25.9 & 0.6 \\
\hline 0.5 & 6.0 & 4.0 & 28.8 & 3.5 \\
\hline 1.0 & 10.0 & 8.0 & 33.1 & 7.8 \\
\hline 5.0 & 28.0 & 26.0 & 48.3 & 23.0 \\
\hline 10.0 & 46.0 & 44.0 & 66.2 & 40.9 \\
\hline 15.0 & 63.0 & 61.0 & 90.9 & 65.6 \\
\hline
\end{tabular}

\begin{tabular}{|c||c|c|c|c|}
\hline \multicolumn{5}{|c|}{$\mathrm{C}_{\mathrm{L}}=0.1 \mathrm{pf} \quad \frac{\mathrm{W}}{\mathrm{L}}=\frac{50}{100}$} \\
\hline \hline $\mathrm{T}(\mathrm{ns})$ & $\mathrm{R}_{\mathrm{spc} 2}(\mathrm{~K} \Omega)$ & $\Delta \mathrm{R}_{\mathrm{spc} 2}(\mathrm{~K} \Omega)$ & $\mathrm{R}_{\bmod }(\mathrm{K} \Omega)$ & $\Delta \mathrm{R}_{\bmod }(\mathrm{K} \Omega)$ \\
\hline 0.01 & 4.0 & - & 88.4 & - \\
\hline 0.05 & 5.0 & 1.0 & 88.7 & 0.3 \\
\hline 0.1 & 5.0 & 1.0 & 89.0 & 0.6 \\
\hline 0.5 & 8.0 & 4.0 & 91.9 & 3.5 \\
\hline 1.0 & 12.0 & 8.0 & 95.5 & 7.1 \\
\hline 5.0 & 34.0 & 30.0 & 112.1 & 23.7 \\
\hline 10.0 & 56.0 & 52.0 & 116.0 & 27.6 \\
\hline 15.0 & 74.0 & 70.0 & 123.3 & 34.9 \\
\hline
\end{tabular}

\begin{tabular}{|c||c|c|c|c|}
\hline \multicolumn{5}{|c|}{$C_{\mathrm{L}}=0.1 \mathrm{pf} \quad \frac{\mathrm{W}}{\mathrm{L}}=\frac{100}{50}$} \\
\hline \hline $\mathrm{T}(\mathrm{ns})$ & $\mathrm{R}_{\mathrm{spc} 2}(\mathrm{~K} \Omega)$ & $\Delta \mathrm{R}_{\mathrm{spc} 2}(\mathrm{~K} \Omega)$ & $\mathrm{R}_{\bmod }(\mathrm{K} \Omega)$ & $\Delta \mathrm{R}_{\mathrm{mod}}(\mathrm{K} \Omega)$ \\
\hline 0.01 & 3.0 & - & 22.1 & - \\
\hline 0.05 & 3.0 & 0.0 & 22.4 & 0.3 \\
\hline 0.1 & 4.0 & 1.0 & 22.8 & 0.7 \\
\hline 0.5 & 8.0 & 5.0 & 26.4 & 4.3 \\
\hline 1.0 & 10.0 & 7.0 & 27.9 & 5.8 \\
\hline 5.0 & 28.0 & 25.0 & 33.4 & 11.3 \\
\hline 10.0 & 46.0 & 43.0 & 57.3 & 35.2 \\
\hline 15.0 & 63.0 & 60.0 & 79.3 & 57.2 \\
\hline
\end{tabular}




\begin{tabular}{|c||c|c|c|c|}
\hline \multicolumn{5}{|c|}{$C_{L}=0.1 \mathrm{pf} \quad \frac{\mathrm{W}}{\mathrm{L}}=\frac{100}{100}$} \\
\hline \hline $\mathrm{T}(\mathrm{ns})$ & $\mathrm{R}_{\mathrm{spc} 2}(\mathrm{~K} \Omega)$ & $\Delta \mathrm{R}_{\mathrm{spc} 2}(\mathrm{~K} \Omega)$ & $\mathrm{R}_{\text {mod }}(\mathrm{K} \Omega)$ & $\Delta \mathrm{R}_{\text {mod }}(\mathrm{K} \Omega)$ \\
\hline 0.01 & 5.0 & - & 82.1 & - \\
\hline 0.05 & 5.0 & 0.0 & 82.4 & 0.3 \\
\hline 0.1 & 6.0 & 1.0 & 82.7 & 0.6 \\
\hline 0.5 & 9.0 & 4.0 & 85.6 & 3.5 \\
\hline 1.0 & 22.0 & 17.0 & 92.1 & 10.0 \\
\hline 5.0 & 35.0 & 30.0 & 77.4 & -4.7 \\
\hline 10.0 & 56.0 & 51.0 & 67.9 & -14.2 \\
\hline 15.0 & 75.0 & 70.0 & 90.9 & 8.8 \\
\hline
\end{tabular}

$$
\mathrm{C}_{\mathrm{L}}=0.5 \mathrm{pf} \quad \frac{\mathrm{W}}{\mathrm{L}}=\frac{4}{3}
$$

\begin{tabular}{|c||c|c|c|c|}
\hline \hline$T(n s)$ & $R_{\text {spc } 2}(K \Omega)$ & $\Delta R_{\text {spc2 }}(K \Omega)$ & $R_{\text {mod }}(K \Omega)$ & $\Delta R_{\text {mod }}(K \Omega)$ \\
\hline 0.01 & 10.2 & - & 4.7 & - \\
\hline 0.05 & 10.2 & 0.0 & 4.8 & 0.1 \\
\hline 0.1 & 10.2 & 0.0 & 4.9 & 0.2 \\
\hline 0.5 & 10.8 & 0.6 & 5.4 & 0.7 \\
\hline 1.0 & 11.4 & 1.2 & 6.1 & 1.4 \\
\hline 5.0 & 16.8 & 6.6 & 11.8 & 7.1 \\
\hline 10.0 & 23.2 & 13.0 & 18.4 & 13.7 \\
\hline 15.0 & 29.8 & 19.6 & 24.5 & 19.8 \\
\hline
\end{tabular}

$$
\mathrm{C}_{\mathrm{L}}=0.5 \mathrm{pf} \quad \frac{\mathrm{W}}{\mathrm{L}}=\frac{4}{12}
$$

\begin{tabular}{|c||c|c|c|c|}
\hline \hline $\mathrm{T}(\mathrm{ns})$ & $\mathrm{R}_{\mathrm{spc} 2}(\mathrm{~K} \Omega)$ & $\Delta \mathrm{R}_{\mathrm{spc} 2}(\mathrm{~K} \Omega)$ & $\mathrm{R}_{\mathrm{mod}}(\mathrm{K} \Omega)$ & $\Delta \mathrm{R}_{\mathrm{mod}}(\mathrm{K} \Omega)$ \\
\hline 0.01 & 23.2 & - & 19.0 & - \\
\hline 0.05 & 23.4 & 0.2 & 19.1 & 0.1 \\
\hline 0.1 & 23.4 & 0.2 & 19.2 & 0.2 \\
\hline 0.5 & 24.0 & 0.8 & 19.7 & 0.7 \\
\hline 1.0 & 24.8 & 1.6 & 20.5 & 1.5 \\
\hline 5.0 & 30.4 & 7.2 & 26.2 & 7.2 \\
\hline 10.0 & 37.4 & 14.2 & 33.4 & 14.4 \\
\hline 15.0 & 44.6 & 21.4 & 40.5 & 21.5 \\
\hline
\end{tabular}




\begin{tabular}{|c||c|c|c|c|}
\hline \multicolumn{5}{|c|}{$\mathrm{C}_{\mathrm{L}}=0.5 \mathrm{pf} \quad \frac{\mathrm{W}}{\mathrm{L}}=\frac{8}{3}$} \\
\hline \hline $\mathrm{T}(\mathrm{ns})$ & $\mathrm{R}_{\mathrm{spc} 2}(\mathrm{~K} \Omega)$ & $\Delta \mathrm{R}_{\mathrm{spc} 2}(\mathrm{~K} \Omega)$ & $\mathrm{R}_{\bmod }(\mathrm{K} \Omega)$ & $\Delta \mathrm{R}_{\bmod }(\mathrm{K} \Omega)$ \\
\hline 0.01 & 5.0 & - & 2.4 & - \\
\hline 0.05 & 5.2 & 0.2 & 2.4 & 0.0 \\
\hline 0.1 & 5.2 & 0.2 & 2.5 & 0.1 \\
\hline 0.5 & 5.6 & 0.6 & 3.1 & 0.7 \\
\hline 1.0 & 6.4 & 1.4 & 3.8 & 1.4 \\
\hline 5.0 & 11.6 & 6.6 & 9.2 & 6.8 \\
\hline 10.0 & 17.8 & 12.8 & 15.2 & 12.8 \\
\hline 15.0 & 23.4 & 18.4 & 20.7 & 18.3 \\
\hline
\end{tabular}

\begin{tabular}{|c||c|c|c|c|}
\hline \multicolumn{5}{|c|}{$C_{\mathrm{L}}=0.5 \mathrm{pf} \quad \frac{\mathrm{W}}{\mathrm{L}}=\frac{16}{3}$} \\
\hline \hline $\mathrm{T}(\mathrm{ns})$ & $\mathrm{R}_{\mathrm{spc} 2}(\mathrm{~K} \Omega)$ & $\Delta \mathrm{R}_{\mathrm{spc} 2}(\mathrm{~K} \Omega)$ & $\mathrm{R}_{\text {mod }}(\mathrm{K} \Omega)$ & $\Delta \mathrm{R}_{\mathrm{mod}}(\mathrm{K} \Omega)$ \\
\hline 0.01 & 2.6 & - & 1.2 & - \\
\hline 0.05 & 2.6 & 0.0 & 1.3 & 0.1 \\
\hline 0.1 & 2.8 & 0.2 & 1.3 & 0.1 \\
\hline 0.5 & 3.2 & 0.6 & 1.9 & 0.7 \\
\hline 1.0 & 3.8 & 1.2 & 2.6 & 1.4 \\
\hline 5.0 & 9.0 & 6.4 & 7.6 & 6.4 \\
\hline 10.0 & 14.2 & 11.6 & 13.0 & 11.8 \\
\hline 15.0 & 19.0 & 16.4 & 18.0 & 16.8 \\
\hline
\end{tabular}

\begin{tabular}{|c||c|c|c|c|}
\hline \multicolumn{5}{|c|}{$\mathrm{C}_{\mathrm{L}}=0.5 \mathrm{pf} \quad \frac{\mathrm{W}}{\mathrm{L}}=\frac{5}{5}$} \\
\hline \hline $\mathrm{T}(\mathrm{ns})$ & $\mathrm{R}_{\mathrm{spc} 2}(\mathrm{~K} \Omega)$ & $\Delta \mathrm{R}_{\mathrm{spc} 2}(\mathrm{~K} \Omega)$ & $\mathrm{R}_{\bmod }(\mathrm{K} \Omega)$ & $\Delta \mathrm{R}_{\bmod }(\mathrm{K} \Omega)$ \\
\hline 0.01 & 10.2 & - & 6.3 & - \\
\hline 0.05 & 10.2 & 0.0 & 6.4 & 0.1 \\
\hline 0.1 & 10.2 & 0.0 & 6.5 & 0.2 \\
\hline 0.5 & 10.8 & 0.6 & 7.0 & 0.7 \\
\hline 1.0 & 11.4 & 1.2 & 7.7 & 1.4 \\
\hline 5.0 & 17.0 & 6.8 & 13.5 & 7.2 \\
\hline 10.0 & 23.8 & 13.6 & 20.3 & 14.0 \\
\hline 15.0 & 30.6 & 20.4 & 26.6 & 20.3 \\
\hline
\end{tabular}




\begin{tabular}{|c||c|c|c|c|}
\hline \multicolumn{5}{|c|}{$\mathrm{C}_{\mathrm{L}}=0.5 \mathrm{pf} \quad \frac{\mathrm{W}}{\mathrm{L}}=\frac{5}{10}$} \\
\hline \hline $\mathrm{T}(\mathrm{ns})$ & $\mathrm{R}_{\mathrm{spc} 2}(\mathrm{~K} \Omega)$ & $\Delta \mathrm{R}_{\mathrm{spc} 2}(\mathrm{~K} \Omega)$ & $\mathrm{R}_{\bmod }(\mathrm{K} \Omega)$ & $\Delta \mathrm{R}_{\bmod }(\mathrm{K} \Omega)$ \\
\hline 0.01 & 15.8 & - & 12.7 & - \\
\hline 0.05 & 16.0 & 0.2 & 12.8 & 0.1 \\
\hline 0.1 & 16.0 & 0.2 & 12.8 & 0.1 \\
\hline 0.5 & 16.6 & 0.6 & 13.4 & 0.7 \\
\hline 1.0 & 17.2 & 1.4 & 14.1 & 1.4 \\
\hline 5.0 & 22.8 & 7.0 & 19.9 & 7.2 \\
\hline 10.0 & 30.0 & 14.2 & 27.0 & 14.3 \\
\hline 15.0 & 37.0 & 21.2 & 33.9 & 21.2 \\
\hline
\end{tabular}

\begin{tabular}{|c||c|c|c|c|}
\hline \multicolumn{5}{|c|}{$\mathrm{C}_{\mathrm{L}}=0.5 \mathrm{pf} \quad \frac{\mathrm{W}}{\mathrm{L}}=\frac{10}{5}$} \\
$\mathrm{~T}(\mathrm{~ns})$ & $\mathrm{R}_{\mathrm{spc} 2}(\mathrm{~K} \Omega)$ & $\Delta \mathrm{R}_{\mathrm{spc} 2}(\mathrm{~K} \Omega)$ & $\mathrm{R}_{\bmod }(\mathrm{K} \Omega)$ & $\Delta \mathrm{R}_{\bmod }(\mathrm{K} \Omega)$ \\
\hline 0.01 & 5.0 & - & 3.2 & - \\
\hline 0.05 & 5.0 & 0.0 & 3.2 & 0.0 \\
\hline 0.1 & 5.2 & 0.2 & 3.3 & 0.1 \\
\hline 0.5 & 5.6 & 0.6 & 3.9 & 0.7 \\
\hline 1.0 & 6.4 & 1.4 & 4.6 & 1.4 \\
\hline 5.0 & 11.8 & 6.8 & 10.1 & 6.9 \\
\hline 10.0 & 18.4 & 13.4 & 16.4 & 13.2 \\
\hline 15.0 & 24.4 & 19.4 & 22.2 & 19.0 \\
\hline
\end{tabular}

\begin{tabular}{|c||c|c|c|c|}
\hline \multicolumn{5}{|c|}{$\mathrm{C}_{\mathrm{L}}=0.5 \mathrm{pf} \quad \frac{\mathrm{W}}{\mathrm{L}}=\frac{10}{10}$} \\
\hline \hline $\mathrm{T}(\mathrm{ns})$ & $\mathrm{R}_{\mathrm{spc} 2}(\mathrm{~K} \Omega)$ & $\Delta \mathrm{R}_{\mathrm{spc} 2}(\mathrm{~K} \Omega)$ & $\mathrm{R}_{\bmod }(\mathrm{K} \Omega)$ & $\Delta \mathrm{R}_{\bmod }(\mathrm{K} \Omega)$ \\
\hline 0.01 & 7.8 & - & 6.4 & - \\
\hline 0.05 & 7.8 & 0.0 & 6.5 & 0.1 \\
\hline 0.1 & 7.8 & 0.0 & 6.6 & 0.2 \\
\hline 0.5 & 8.4 & 0.6 & 7.1 & 0.7 \\
\hline 1.0 & 9.2 & 1.4 & 7.9 & 1.5 \\
\hline 5.0 & 14.8 & 7.0 & 13.6 & 7.2 \\
\hline 10.0 & 21.8 & 14.0 & 20.4 & 14.0 \\
\hline 15.0 & 28.8 & 21.0 & 26.7 & 20.3 \\
\hline
\end{tabular}




\begin{tabular}{|c||c|c|c|c|}
\hline \multicolumn{5}{|c|}{$\mathrm{C}_{\mathrm{L}}=0.5 \mathrm{pf} \quad \frac{\mathrm{W}}{\mathrm{L}}=\frac{16}{16}$} \\
\hline \hline $\mathrm{T}(\mathrm{ns})$ & $\mathrm{R}_{\mathrm{spc} 2}(\mathrm{~K} \Omega)$ & $\Delta \mathrm{R}_{\mathrm{spc} 2}(\mathrm{~K} \Omega)$ & $\mathrm{R}_{\mathrm{mod}}(\mathrm{K} \Omega)$ & $\Delta \mathrm{R}_{\mathrm{mod}}(\mathrm{K} \Omega)$ \\
\hline 0.01 & 7.2 & - & 6.7 & - \\
\hline 0.05 & 7.2 & 0.0 & 6.7 & 0.0 \\
\hline 0.1 & 7.4 & 0.2 & 6.8 & 0.1 \\
\hline 0.5 & 7.8 & 0.6 & 7.4 & 0.7 \\
\hline 1.0 & 8.6 & 1.4 & 8.1 & 1.4 \\
\hline 5.0 & 14.2 & 7.0 & 13.8 & 7.1 \\
\hline 10.0 & 21.4 & 14.2 & 20.6 & 13.9 \\
\hline 15.0 & 28.4 & 21.2 & 26.9 & 20.2 \\
\hline
\end{tabular}

\begin{tabular}{|c||c|c|c|c|}
\hline \multicolumn{5}{|c|}{$C_{L}=0.5 p f \quad \frac{\mathrm{W}}{\mathrm{L}}=\frac{16}{32}$} \\
\hline \hline $\mathrm{T}(\mathrm{ns})$ & $\mathrm{R}_{\mathrm{spc} 2}(\mathrm{~K} \Omega)$ & $\Delta \mathrm{R}_{\mathrm{spc} 2}(\mathrm{~K} \Omega)$ & $\mathrm{R}_{\mathrm{mod}}(\mathrm{K} \Omega)$ & $\Delta \mathrm{R}_{\mathrm{mod}}(\mathrm{K} \Omega)$ \\
\hline 0.01 & 13.6 & - & 14.1 & - \\
\hline 0.05 & 13.4 & -0.2 & 14.2 & 0.1 \\
\hline 0.1 & 13.6 & 0.0 & 14.2 & 0.1 \\
\hline 0.5 & 14.2 & 0.6 & 14.8 & 0.7 \\
\hline 1.0 & 15.0 & 1.4 & 15.5 & 1.4 \\
\hline 5.0 & 20.6 & 7.0 & 21.3 & 7.2 \\
\hline 10.0 & 27.8 & 14.2 & 28.4 & 14.3 \\
\hline 15.0 & 35.0 & 21.4 & 35.3 & 21.2 \\
\hline
\end{tabular}

\begin{tabular}{|c||c|c|c|c|}
\hline \multicolumn{6}{|c|}{$\mathrm{C}_{\mathrm{L}}=0.5 \mathrm{pf} \quad \frac{\mathrm{W}}{\mathrm{L}}=\frac{32}{16}$} \\
\hline \hline $\mathrm{T}(\mathrm{ns})$ & $\mathrm{R}_{\mathrm{spc} 2}(\mathrm{~K} \Omega)$ & $\Delta \mathrm{R}_{\mathrm{spc} 2}(\mathrm{~K} \Omega)$ & $\mathrm{R}_{\mathrm{mod}}(\mathrm{K} \Omega)$ & $\Delta \mathrm{R}_{\mathrm{mod}}(\mathrm{K} \Omega)$ \\
\hline 0.01 & 3.8 & - & 3.5 & - \\
\hline 0.05 & 3.8 & 0.0 & 3.6 & 0.1 \\
\hline 0.1 & 3.8 & 0.0 & 3.7 & 0.2 \\
\hline 0.5 & 4.4 & 0.6 & 4.2 & 0.7 \\
\hline 1.0 & 5.0 & 1.2 & 5.0 & 1.5 \\
\hline 5.0 & 10.8 & 7.0 & 10.5 & 7.0 \\
\hline 10.0 & 17.6 & 13.8 & 16.6 & 13.1 \\
\hline 15.0 & 23.4 & 19.6 & 22.3 & 18.8 \\
\hline
\end{tabular}




$$
\mathrm{C}_{\mathrm{L}}=0.5 \mathrm{pf} \quad \frac{\mathrm{W}}{\mathrm{L}}=\frac{32}{32}
$$

\begin{tabular}{|c||c|c|c|c|}
\hline \hline $\mathrm{T}(\mathrm{ns})$ & $\mathrm{R}_{\mathrm{spc} 2}(\mathrm{~K} \Omega)$ & $\Delta \mathrm{R}_{\mathrm{spc} 2}(\mathrm{~K} \Omega)$ & $\mathrm{R}_{\mathrm{mod}}(\mathrm{K} \Omega)$ & $\Delta \mathrm{R}_{\mathrm{mod}}(\mathrm{K} \Omega)$ \\
\hline 0.01 & 7.2 & - & 7.8 & - \\
\hline 0.05 & 7.0 & -0.2 & 7.9 & 0.1 \\
\hline 0.1 & 7.0 & -0.2 & 8.0 & 0.2 \\
\hline 0.5 & 7.6 & 0.4 & 8.5 & 0.7 \\
\hline 1.0 & 8.2 & 1.0 & 9.3 & 1.5 \\
\hline 5.0 & 14.0 & 6.8 & 15.0 & 7.2 \\
\hline 10.0 & 21.2 & 14.0 & 21.7 & 13.9 \\
\hline 15.0 & 28.6 & 21.4 & 27.8 & 20.0 \\
\hline
\end{tabular}

$$
\mathrm{C}_{\mathrm{L}}=0.5 \mathrm{pf} \quad \frac{\mathrm{W}}{\mathrm{L}}=\frac{50}{50}
$$

\begin{tabular}{|c||c|c|c|c|}
\hline \hline $\mathrm{T}(\mathrm{ns})$ & $\mathrm{R}_{\mathrm{spc} 2}(\mathrm{~K} \Omega)$ & $\Delta \mathrm{R}_{\mathrm{spc} 2}(\mathrm{~K} \Omega)$ & $\mathrm{R}_{\mathrm{mod}}(\mathrm{K} \Omega)$ & $\Delta \mathrm{R}_{\mathrm{mod}}(\mathrm{K} \Omega)$ \\
\hline 0.01 & 6.8 & - & 10.1 & - \\
\hline 0.05 & 7.0 & 0.2 & 10.1 & 0.0 \\
\hline 0.1 & 7.0 & 0.2 & 10.2 & 0.1 \\
\hline 0.5 & 7.6 & 0.8 & 10.8 & 0.7 \\
\hline 1.0 & 8.4 & 1.6 & 11.5 & 1.4 \\
\hline 5.0 & 14.4 & 7.6 & 17.3 & 7.2 \\
\hline 10.0 & 21.6 & 14.8 & 23.8 & 13.7 \\
\hline 15.0 & 28.4 & 21.6 & 29.6 & 19.5 \\
\hline
\end{tabular}

\begin{tabular}{|c||c|c|c|c|}
\hline \multicolumn{6}{|c|}{$C_{L}=0.5 p f \quad \frac{\mathrm{W}}{\mathrm{L}}=\frac{50}{100}$} \\
\hline \hline $\mathrm{T}(\mathrm{ns})$ & $\mathrm{R}_{\mathrm{spc} 2}(\mathrm{~K} \Omega)$ & $\Delta \mathrm{R}_{\mathrm{spc} 2}(\mathrm{~K} \Omega)$ & $\mathrm{R}_{\mathrm{mod}}(\mathrm{K} \Omega)$ & $\Delta \mathrm{R}_{\mathrm{mod}}(\mathrm{K} \Omega)$ \\
\hline 0.01 & 13.6 & - & 27.7 & - \\
\hline 0.05 & 13.6 & 0.0 & 27.8 & 0.1 \\
\hline 0.1 & 13.6 & 0.0 & 27.8 & 0.1 \\
\hline 0.5 & 14.2 & 0.6 & 28.4 & 0.7 \\
\hline 1.0 & 15.0 & 1.4 & 29.1 & 1.4 \\
\hline 5.0 & 22.6 & 9.0 & 34.9 & 7.2 \\
\hline 10.0 & 29.8 & 16.2 & 42.6 & 14.9 \\
\hline 15.0 & 37.4 & 23.8 & 49.0 & 21.3 \\
\hline
\end{tabular}




\begin{tabular}{|c||c|c|c|c|}
\hline \multicolumn{5}{|c|}{$\mathrm{C}_{\mathrm{L}}=0.5 \mathrm{pf} \quad \frac{\mathrm{W}}{\mathrm{L}}=\frac{100}{50}$} \\
\hline \hline $\mathrm{T}(\mathrm{ns})$ & $\mathrm{R}_{\mathrm{spc} 2}(\mathrm{~K} \Omega)$ & $\Delta \mathrm{R}_{\mathrm{spc} 2}(\mathrm{~K} \Omega)$ & $\mathrm{R}_{\bmod }(\mathrm{K} \Omega)$ & $\Delta \mathrm{R}_{\bmod }(\mathrm{K} \Omega)$ \\
\hline 0.01 & 3.8 & - & 6.9 & - \\
\hline 0.05 & 3.8 & 0.0 & 7.0 & 0.1 \\
\hline 0.1 & 4.0 & 0.2 & 7.1 & 0.2 \\
\hline 0.5 & 4.4 & 0.6 & 7.6 & 0.7 \\
\hline 1.0 & 5.2 & 1.4 & 8.4 & 1.5 \\
\hline 5.0 & 11.4 & 7.6 & 13.7 & 6.8 \\
\hline 10.0 & 17.8 & 14.0 & 18.8 & 11.9 \\
\hline 15.0 & 23.8 & 20.0 & 23.6 & 16.7 \\
\hline
\end{tabular}

$$
\mathrm{C}_{\mathrm{L}}=0.5 \mathrm{pf} \quad \frac{\mathrm{W}}{\mathrm{L}}=\frac{100}{100}
$$

\begin{tabular}{|c||c|c|c|c|}
\hline \hline$T(n s)$ & $R_{\mathrm{spc} 2}(\mathrm{~K} \Omega)$ & $\Delta \mathrm{R}_{\mathrm{spc} 2}(\mathrm{~K} \Omega)$ & $\mathrm{R}_{\mathrm{mod}}(\mathrm{K} \Omega)$ & $\Delta \mathrm{R}_{\mathrm{mod}}(\mathrm{K} \Omega)$ \\
\hline 0.01 & 7.4 & - & 21.4 & - \\
\hline 0.05 & 7.4 & 0.0 & 21.5 & 0.1 \\
\hline 0.1 & 7.4 & 0.0 & 21.6 & 0.1 \\
\hline 0.5 & 8.0 & 0.6 & 22.1 & 0.7 \\
\hline 1.0 & 8.8 & 1.4 & 22.9 & 1.5 \\
\hline 5.0 & 14.6 & 7.2 & 29.2 & 7.8 \\
\hline 10.0 & 23.0 & 15.6 & 34.4 & 13.0 \\
\hline 15.0 & 29.0 & 21.6 & 38.5 & 17.1 \\
\hline
\end{tabular}

\begin{tabular}{|c||c|c|c|c|}
\hline \multicolumn{5}{|c|}{$\mathrm{C}_{\mathrm{L}}=1 \mathrm{pf} \quad \frac{\mathrm{W}}{\mathrm{L}}=\frac{4}{3}$} \\
\hline \hline $\mathrm{T}(\mathrm{ns})$ & $\mathrm{R}_{\mathrm{spc} 2}(\mathrm{~K} \Omega)$ & $\Delta \mathrm{R}_{\mathrm{spc} 2}(\mathrm{~K} \Omega)$ & $\mathrm{R}_{\text {mod }}(\mathrm{K} \Omega)$ & $\Delta \mathrm{R}_{\bmod }(\mathrm{K} \Omega)$ \\
\hline 0.01 & 10.1 & - & 4.7 & - \\
\hline 0.05 & 10.1 & 0.0 & 4.7 & 0.0 \\
\hline 0.1 & 10.1 & 0.0 & 4.8 & 0.1 \\
\hline 0.5 & 10.4 & 0.3 & 5.1 & 0.4 \\
\hline 1.0 & 10.7 & 0.6 & 5.4 & 0.7 \\
\hline 5.0 & 13.3 & 3.2 & 8.3 & 3.6 \\
\hline 10.0 & 16.6 & 6.5 & 11.8 & 7.1 \\
\hline 15.0 & 19.9 & 9.8 & 15.2 & 10.5 \\
\hline
\end{tabular}




\begin{tabular}{|c||c|c|c|c|}
\hline \multicolumn{5}{|c|}{$\mathrm{C}_{\mathrm{L}}=1 \mathrm{pf} \quad \frac{\mathrm{W}}{\mathrm{L}}=\frac{4}{12}$} \\
\hline \hline $\mathrm{T}(\mathrm{ns})$ & $\mathrm{R}_{\mathrm{spc} 2}(\mathrm{~K} \Omega)$ & $\Delta \mathrm{R}_{\mathrm{spc} 2}(\mathrm{~K} \Omega)$ & $\mathrm{R}_{\bmod }(\mathrm{K} \Omega)$ & $\Delta \mathrm{R}_{\bmod }(\mathrm{K} \Omega)$ \\
\hline 0.01 & 23.2 & - & 18.9 & - \\
\hline 0.05 & 23.2 & 0.0 & 18.9 & 0.0 \\
\hline 0.1 & 23.3 & 0.1 & 19.0 & 0.1 \\
\hline 0.5 & 23.5 & 0.3 & 19.3 & 0.4 \\
\hline 1.0 & 23.9 & 0.7 & 19.6 & 0.7 \\
\hline 5.0 & 26.7 & 3.5 & 22.5 & 3.6 \\
\hline 10.0 & 30.3 & 7.1 & 26.1 & 7.2 \\
\hline 15.0 & 33.9 & 10.7 & 29.7 & 10.8 \\
\hline
\end{tabular}

\begin{tabular}{|c||c|c|c|c|}
\hline \multicolumn{5}{|c|}{$\mathrm{C}_{\mathrm{L}}=1 \mathrm{pf} \quad \frac{\mathrm{W}}{\mathrm{L}}=\frac{8}{3}$} \\
\hline \hline $\mathrm{T}(\mathrm{ns})$ & $\mathrm{R}_{\mathrm{spc} 2}(\mathrm{~K} \Omega)$ & $\Delta \mathrm{R}_{\mathrm{spc} 2}(\mathrm{~K} \Omega)$ & $\mathrm{R}_{\bmod }(\mathrm{K} \Omega)$ & $\Delta \mathrm{R}_{\bmod }(\mathrm{K} \Omega)$ \\
\hline 0.01 & 5.0 & - & 2.4 & - \\
\hline 0.05 & 5.0 & 0.0 & 2.4 & 0.0 \\
\hline 0.1 & 5.0 & 0.0 & 2.4 & 0.0 \\
\hline 0.5 & 5.3 & 0.3 & 2.7 & 0.3 \\
\hline 1.0 & 5.6 & 0.6 & 3.1 & 0.7 \\
\hline 5.0 & 8.2 & 3.2 & 5.9 & 3.5 \\
\hline 10.0 & 11.5 & 6.5 & 9.2 & 6.8 \\
\hline 15.0 & 14.7 & 9.7 & 12.3 & 9.9 \\
\hline
\end{tabular}

\begin{tabular}{|c||c|c|c|c|}
\hline \multicolumn{5}{|c|}{$C_{\mathrm{L}}=1 \mathrm{pf} \quad \frac{\mathrm{W}}{\mathrm{L}}=\frac{16}{3}$} \\
\hline \hline $\mathrm{T}(\mathrm{ns})$ & $\mathrm{R}_{\mathrm{spc} 2}(\mathrm{~K} \Omega)$ & $\Delta \mathrm{R}_{\mathrm{spc} 2}(\mathrm{~K} \Omega)$ & $\mathrm{R}_{\bmod }(\mathrm{K} \Omega)$ & $\Delta \mathrm{R}_{\bmod }(\mathrm{K} \Omega)$ \\
\hline 0.01 & 2.5 & - & 1.2 & - \\
\hline 0.05 & 2.5 & 0.0 & 1.2 & 0.0 \\
\hline 0.1 & 2.6 & 0.1 & 1.3 & 0.1 \\
\hline 0.5 & 2.8 & 0.3 & 1.5 & 0.3 \\
\hline 1.0 & 3.2 & 0.7 & 1.9 & 0.7 \\
\hline 5.0 & 5.8 & 3.3 & 4.6 & 3.4 \\
\hline 10.0 & 8.9 & 6.4 & 7.6 & 6.4 \\
\hline 15.0 & 11.7 & 9.2 & 10.4 & 9.2 \\
\hline
\end{tabular}




\begin{tabular}{|c||c|c|c|c|}
\hline \multicolumn{5}{|c|}{$\mathrm{C}_{\mathrm{L}}=1 \mathrm{pf} \quad \frac{\mathrm{W}}{\mathrm{L}}=\frac{5}{5}$} \\
\hline \hline $\mathrm{T}(\mathrm{ns})$ & $\mathrm{R}_{\mathrm{spc} 2}(\mathrm{~K} \Omega)$ & $\Delta \mathrm{R}_{\mathrm{spc} 2}(\mathrm{~K} \Omega)$ & $\mathrm{R}_{\text {mod }}(\mathrm{K} \Omega)$ & $\Delta \mathrm{R}_{\text {mod }}(\mathrm{K} \Omega)$ \\
\hline 0.01 & 10.0 & - & 6.3 & - \\
\hline 0.05 & 10.1 & 0.1 & 6.3 & 0.0 \\
\hline 0.1 & 10.1 & 0.1 & 6.4 & 0.1 \\
\hline 0.5 & 10.4 & 0.4 & 6.6 & 0.3 \\
\hline 1.0 & 10.7 & 0.7 & 7.0 & 0.7 \\
\hline 5.0 & 13.4 & 3.4 & 9.9 & 3.6 \\
\hline 10.0 & 16.8 & 6.8 & 13.4 & 7.1 \\
\hline 15.0 & 20.2 & 10.2 & 16.9 & 10.6 \\
\hline
\end{tabular}

$$
\mathrm{C}_{\mathrm{L}}=1 \mathrm{pf} \quad \frac{\mathrm{W}}{\mathrm{L}}=\frac{5}{10}
$$

\begin{tabular}{|c||c|c|c|c|}
\hline \hline $\mathrm{T}(\mathrm{ns})$ & $\mathrm{R}_{\mathrm{spc} 2}(\mathrm{~K} \Omega)$ & $\Delta \mathrm{R}_{\mathrm{spc} 2}(\mathrm{~K} \Omega)$ & $\mathrm{R}_{\mathrm{mod}}(\mathrm{K} \Omega)$ & $\Delta \mathrm{R}_{\mathrm{mod}}(\mathrm{K} \Omega)$ \\
\hline 0.01 & 15.7 & - & 12.6 & - \\
\hline 0.05 & 15.8 & 0.1 & 12.7 & 0.1 \\
\hline 0.1 & 15.8 & 0.1 & 12.7 & 0.1 \\
\hline 0.5 & 16.1 & 0.4 & 13.0 & 0.4 \\
\hline 1.0 & 16.4 & 0.7 & 13.3 & 0.7 \\
\hline 5.0 & 19.3 & 3.6 & 16.2 & 3.6 \\
\hline 10.0 & 22.8 & 7.1 & 19.8 & 7.2 \\
\hline 15.0 & 26.3 & 10.6 & 23.4 & 10.8 \\
\hline
\end{tabular}

\begin{tabular}{|c||c|c|c|c|}
\hline \multicolumn{5}{|c|}{$\mathrm{C}_{\mathrm{L}}=1 \mathrm{pf} \quad \frac{\mathrm{W}}{\mathrm{L}}=\frac{10}{5}$} \\
\hline \hline $\mathrm{T}(\mathrm{ns})$ & $\mathrm{R}_{\mathrm{spc} 2}(\mathrm{~K} \Omega)$ & $\Delta \mathrm{R}_{\mathrm{spc} 2}(\mathrm{~K} \Omega)$ & $\mathrm{R}_{\mathrm{mod}}(\mathrm{K} \Omega)$ & $\Delta \mathrm{R}_{\mathrm{mod}}(\mathrm{K} \Omega)$ \\
\hline 0.01 & 4.9 & - & 3.2 & - \\
\hline 0.05 & 5.0 & 0.1 & 3.2 & 0.0 \\
\hline 0.1 & 5.0 & 0.1 & 3.2 & 0.0 \\
\hline 0.5 & 5.3 & 0.4 & 3.5 & 0.3 \\
\hline 1.0 & 5.6 & 0.7 & 3.9 & 0.7 \\
\hline 5.0 & 8.3 & 3.4 & 6.7 & 3.5 \\
\hline 10.0 & 11.7 & 6.8 & 10.1 & 6.9 \\
\hline 15.0 & 15.1 & 10.2 & 13.3 & 10.1 \\
\hline
\end{tabular}




\begin{tabular}{|c||c|c|c|c|}
\hline \multicolumn{5}{|c|}{$\mathrm{C}_{\mathrm{L}}=1 \mathrm{pf} \quad \frac{\mathrm{W}}{\mathrm{L}}=\frac{10}{10}$} \\
\hline \hline $\mathrm{T}(\mathrm{ns})$ & $\mathrm{R}_{\mathrm{spc} 2}(\mathrm{~K} \Omega)$ & $\Delta \mathrm{R}_{\mathrm{spc} 2}(\mathrm{~K} \Omega)$ & $\mathrm{R}_{\bmod }(\mathrm{K} \Omega)$ & $\Delta \mathrm{R}_{\bmod }(\mathrm{K} \Omega)$ \\
\hline 0.01 & 7.7 & - & 6.4 & - \\
\hline 0.05 & 7.7 & 0.0 & 6.4 & 0.0 \\
\hline 0.1 & 7.7 & 0.0 & 6.4 & 0.0 \\
\hline 0.5 & 8.0 & 0.3 & 6.7 & 0.3 \\
\hline 1.0 & 8.3 & 0.6 & 7.1 & 0.7 \\
\hline 5.0 & 11.2 & 3.5 & 9.9 & 3.5 \\
\hline 10.0 & 14.7 & 7.0 & 13.5 & 7.1 \\
\hline 15.0 & 18.2 & 10.5 & 17.0 & 10.6 \\
\hline
\end{tabular}

\begin{tabular}{|c||c|c|c|c|}
\hline \multicolumn{5}{|c|}{$C_{L}=1 \mathrm{pf} \quad \frac{\mathrm{W}}{\mathrm{L}}=\frac{16}{16}$} \\
\hline \hline $\mathrm{T}(\mathrm{ns})$ & $\mathrm{R}_{\mathrm{spc} 2}(\mathrm{~K} \Omega)$ & $\Delta \mathrm{R}_{\mathrm{spc} 2}(\mathrm{~K} \Omega)$ & $\mathrm{R}_{\bmod }(\mathrm{K} \Omega)$ & $\Delta \mathrm{R}_{\bmod }(\mathrm{K} \Omega)$ \\
\hline 0.01 & 7.0 & - & 6.5 & - \\
\hline 0.05 & 7.0 & 0.0 & 6.5 & 0.0 \\
\hline 0.1 & 7.1 & 0.1 & 6.5 & 0.0 \\
\hline 0.5 & 7.3 & 0.3 & 6.8 & 0.3 \\
\hline 1.0 & 7.7 & 0.7 & 7.2 & 0.7 \\
\hline 5.0 & 10.5 & 3.5 & 10.1 & 3.6 \\
\hline 10.0 & 14.1 & 7.1 & 13.6 & 7.1 \\
\hline 15.0 & 17.7 & 10.7 & 17.1 & 10.6 \\
\hline
\end{tabular}

\begin{tabular}{|c||c|c|c|c|}
\hline \multicolumn{5}{|c|}{$\mathrm{C}_{\mathrm{L}}=1 \mathrm{pf} \quad \frac{\mathrm{W}}{\mathrm{L}}=\frac{16}{32}$} \\
\hline \hline $\mathrm{T}(\mathrm{ns})$ & $\mathrm{R}_{\mathrm{spc} 2}(\mathrm{~K} \Omega)$ & $\Delta \mathrm{R}_{\mathrm{spc} 2}(\mathrm{~K} \Omega)$ & $\mathrm{R}_{\bmod }(\mathrm{K} \Omega)$ & $\Delta \mathrm{R}_{\bmod }(\mathrm{K} \Omega)$ \\
\hline 0.01 & 13.2 & - & 13.3 & - \\
\hline 0.05 & 13.3 & 0.1 & 13.4 & 0.1 \\
\hline 0.1 & 13.3 & 0.1 & 13.4 & 0.1 \\
\hline 0.5 & 13.6 & 0.4 & 13.7 & 0.4 \\
\hline 1.0 & 14.0 & 0.8 & 14.0 & 0.7 \\
\hline 5.0 & 16.8 & 3.6 & 16.9 & 3.6 \\
\hline 10.0 & 20.4 & 7.2 & 20.5 & 7.2 \\
\hline 15.0 & 24.0 & 10.8 & 24.1 & 10.8 \\
\hline
\end{tabular}




\begin{tabular}{|c||c|c|c|c|}
\hline \multicolumn{5}{|c|}{$\mathrm{C}_{\mathrm{L}}=1 \mathrm{pf} \quad \frac{\mathrm{W}}{\mathrm{L}}=\frac{32}{16}$} \\
\hline \hline $\mathrm{T}(\mathrm{ns})$ & $\mathrm{R}_{\mathrm{spc} 2}(\mathrm{~K} \Omega)$ & $\Delta \mathrm{R}_{\mathrm{spc} 2}(\mathrm{~K} \Omega)$ & $\mathrm{R}_{\bmod }(\mathrm{K} \Omega)$ & $\Delta \mathrm{R}_{\bmod }(\mathrm{K} \Omega)$ \\
\hline 0.01 & 3.6 & - & 3.3 & - \\
\hline 0.05 & 3.6 & 0.0 & 3.4 & 0.1 \\
\hline 0.1 & 3.6 & 0.0 & 3.4 & 0.1 \\
\hline 0.5 & 3.9 & 0.3 & 3.7 & 0.4 \\
\hline 1.0 & 4.2 & 0.6 & 4.0 & 0.7 \\
\hline 5.0 & 7.1 & 3.5 & 6.9 & 3.6 \\
\hline 10.0 & 10.6 & 7.0 & 10.3 & 7.0 \\
\hline 15.0 & 14.2 & 10.6 & 13.5 & 10.2 \\
\hline
\end{tabular}

\begin{tabular}{|c||c|c|c|c|}
\hline \multicolumn{5}{|c|}{$\mathrm{C}_{\mathrm{L}}=1 \mathrm{pf} \quad \frac{\mathrm{W}}{\mathrm{L}}=\frac{32}{32}$} \\
$\mathrm{~T}(\mathrm{~ns})$ & $\mathrm{R}_{\mathrm{spc} 2}(\mathrm{~K} \Omega)$ & $\Delta \mathrm{R}_{\mathrm{spc} 2}(\mathrm{~K} \Omega)$ & $\mathrm{R}_{\bmod }(\mathrm{K} \Omega)$ & $\Delta \mathrm{R}_{\bmod }(\mathrm{K} \Omega)$ \\
\hline 0.01 & 6.6 & - & 7.1 & - \\
\hline 0.05 & 6.7 & 0.1 & 7.1 & 0.0 \\
\hline 0.1 & 6.7 & 0.1 & 7.1 & 0.0 \\
\hline 0.5 & 7.0 & 0.4 & 7.4 & 0.3 \\
\hline 1.0 & 7.4 & 0.8 & 7.8 & 0.7 \\
\hline 5.0 & 10.2 & 3.6 & 10.6 & 3.5 \\
\hline 10.0 & 13.8 & 7.0 & 14.2 & 7.1 \\
\hline 15.0 & 17.4 & 10.8 & 17.7 & 10.9 \\
\hline
\end{tabular}

\begin{tabular}{|c||c|c|c|c|}
\hline \multicolumn{5}{|c|}{$\mathrm{C}_{\mathrm{L}}=1 \mathrm{pf} \quad \frac{\mathrm{W}}{\mathrm{L}}=\frac{50}{50}$} \\
\hline \hline $\mathrm{T}(\mathrm{ns})$ & $\mathrm{R}_{\mathrm{spc} 2}(\mathrm{~K} \Omega)$ & $\Delta \mathrm{R}_{\mathrm{spc} 2}(\mathrm{~K} \Omega)$ & $\mathrm{R}_{\bmod }(\mathrm{K} \Omega)$ & $\Delta \mathrm{R}_{\bmod }(\mathrm{K} \Omega)$ \\
\hline 0.01 & 6.6 & - & 8.2 & - \\
\hline 0.05 & 6.7 & 0.1 & 8.2 & 0.0 \\
\hline 0.1 & 6.7 & 0.1 & 8.2 & 0.0 \\
\hline 0.5 & 7.0 & 0.4 & 8.5 & 0.3 \\
\hline 1.0 & 7.3 & 0.7 & 8.9 & 0.7 \\
\hline 5.0 & 10.2 & 3.6 & 11.8 & 3.6 \\
\hline 10.0 & 13.8 & 7.2 & 15.4 & 7.2 \\
\hline 15.0 & 17.4 & 10.8 & 18.8 & 10.6 \\
\hline
\end{tabular}




\begin{tabular}{|c||c|c|c|c|}
\hline \multicolumn{5}{|c|}{$\mathrm{C}_{\mathrm{L}}=1 \mathrm{pf} \quad \frac{\mathrm{W}}{\mathrm{L}}=\frac{50}{100}$} \\
\hline \hline $\mathrm{T}(\mathrm{ns})$ & $\mathrm{R}_{\mathrm{spc} 2}(\mathrm{~K} \Omega)$ & $\Delta \mathrm{R}_{\mathrm{spc} 2}(\mathrm{~K} \Omega)$ & $\mathrm{R}_{\bmod }(\mathrm{K} \Omega)$ & $\Delta \mathrm{R}_{\mathrm{mod}}(\mathrm{K} \Omega)$ \\
\hline 0.01 & 13.1 & - & 20.1 & - \\
\hline 0.05 & 13.1 & 0.0 & 20.2 & 0.1 \\
\hline 0.1 & 13.2 & 0.1 & 20.2 & 0.1 \\
\hline 0.5 & 13.5 & 0.4 & 20.5 & 0.4 \\
\hline 1.0 & 13.8 & 0.7 & 20.8 & 0.7 \\
\hline 5.0 & 17.8 & 4.7 & 23.7 & 3.6 \\
\hline 10.0 & 20.3 & 7.2 & 27.3 & 7.2 \\
\hline 15.0 & 24.9 & 11.8 & 31.0 & 10.9 \\
\hline
\end{tabular}

\begin{tabular}{|c||c|c|c|c|}
\hline \multicolumn{5}{|c|}{$\mathrm{C}_{\mathrm{L}}=1 \mathrm{pf} \quad \frac{\mathrm{W}}{\mathrm{L}}=\frac{100}{50}$} \\
\hline \hline $\mathrm{T}(\mathrm{ns})$ & $\mathrm{R}_{\mathrm{spc} 2}(\mathrm{~K} \Omega)$ & $\Delta \mathrm{R}_{\mathrm{spc} 2}(\mathrm{~K} \Omega)$ & $\mathrm{R}_{\bmod }(\mathrm{K} \Omega)$ & $\Delta \mathrm{R}_{\bmod }(\mathrm{K} \Omega)$ \\
\hline 0.01 & 3.5 & - & 5.0 & - \\
\hline 0.05 & 3.5 & 0.0 & 5.1 & 0.1 \\
\hline 0.1 & 3.6 & 0.1 & 5.1 & 0.1 \\
\hline 0.5 & 3.8 & 0.3 & 5.4 & 0.4 \\
\hline 1.0 & 4.2 & 0.7 & 5.7 & 0.7 \\
\hline 5.0 & 7.3 & 3.8 & 8.7 & 3.7 \\
\hline 10.0 & 10.9 & 7.4 & 11.9 & 6.9 \\
\hline 15.0 & 14.2 & 10.7 & 14.8 & 9.8 \\
\hline
\end{tabular}

\begin{tabular}{|c||c|c|c|c|}
\hline \multicolumn{5}{|c|}{$\mathrm{C}_{\mathrm{L}}=1 \mathrm{pf} \quad \frac{\mathrm{W}}{\mathrm{L}}=\frac{100}{100}$} \\
\hline \hline $\mathrm{T}(\mathrm{ns})$ & $\mathrm{R}_{\mathrm{spc} 2}(\mathrm{~K} \Omega)$ & $\Delta \mathrm{R}_{\mathrm{spc} 2}(\mathrm{~K} \Omega)$ & $\mathrm{R}_{\bmod }(\mathrm{K} \Omega)$ & $\Delta \mathrm{R}_{\bmod }(\mathrm{K} \Omega)$ \\
\hline 0.01 & 6.8 & - & 13.9 & - \\
\hline 0.05 & 6.9 & 0.1 & 13.9 & 0.0 \\
\hline 0.1 & 6.9 & 0.1 & 13.9 & 0.0 \\
\hline 0.5 & 7.2 & 0.4 & 14.2 & 0.3 \\
\hline 1.0 & 7.6 & 0.8 & 14.6 & 0.7 \\
\hline 5.0 & 10.4 & 3.6 & 17.4 & 3.5 \\
\hline 10.0 & 14.1 & 7.3 & 21.3 & 7.4 \\
\hline 15.0 & 17.7 & 10.9 & 24.5 & 10.6 \\
\hline
\end{tabular}


APPENDIX B

LIST OF SPICE DECKS 


\section{M61R SPICE PARAMETERS}

MODEL CMOSN NMOS LEVEL $=2.00000 \quad$ LD $=0.462600 \mathrm{U}$ TOX $=488.000 \mathrm{E}-10 \mathrm{NSUB}=1.125000 \mathrm{E}+16 \mathrm{VTO}=0.662329 \mathrm{KP}=4.736000 \mathrm{E}-$ 05 GAMMA $=0.863200 \mathrm{PHI}=0.600000 \mathrm{UO}=669.320 \mathrm{UEXP}=4.154398 \mathrm{E}-02$ $\mathrm{UCRIT}=31427.8 \quad$ DELTA $=1.0 \mathrm{E}-06 \quad \mathrm{VMAX}=57839.1 \quad \mathrm{XJ}=0.400000 \mathrm{U}$ $\mathrm{LAMBDA}=1.829628 \mathrm{E}-02 \quad \mathrm{NFS}=1.037274 \mathrm{E}+12 \quad \mathrm{NEFF}=1.001000 \mathrm{E}-02$ $\mathrm{NSS}=0.000000 \mathrm{E}+00 \quad \mathrm{TPG}=1.00000 \quad \mathrm{RSH}=19.41 \quad \mathrm{CGSO}=3.3 \mathrm{E}-10$ $\mathrm{CGDO}=3.3 \mathrm{E}-10 \mathrm{CJ}=4.5 \mathrm{E}-4 \mathrm{MJ}=0.5 \mathrm{CJSW}=6.0 \mathrm{E}-10 \mathrm{MJSW}=0.33$ MODEL CMOSP PMOS LEVEL $=2.00000 \quad \mathrm{LD}=0.560000 \mathrm{U}$ TOX $=488.000 \mathrm{E}-10 \mathrm{NSUB}=1.894000 \mathrm{E}+15 \mathrm{VTO}=-0.740527 \mathrm{KP}=1.837000 \mathrm{E}-$ 05 GAMMA $=0.354100 \quad \mathrm{PHI}=0.600000 \quad \mathrm{UO}=259.600 \quad \mathrm{UEXP}=0.100882$ UCRIT $=14960.3 \quad$ DELTA $=1.0 \mathrm{E}-06 \quad \mathrm{VMAX}=10000.0 \quad \mathrm{XJ}=0.400000 \mathrm{U}$ LAMBDA $=2.459510 \mathrm{E}-02 \quad \mathrm{NFS}=3.195973 \mathrm{E}+12 \quad \mathrm{NEFF}=1.001000 \mathrm{E}-02$ $\mathrm{NSS}=0.000000 \mathrm{E}+00 \quad \mathrm{TPG}=-1.00000 \quad \mathrm{RSH}=79.19 \quad \mathrm{CGSO}=3.96 \mathrm{E}-10$ $\mathrm{CGDO}=3.96 \mathrm{E}-10 \mathrm{CJ}=3.6 \mathrm{E}-4 \mathrm{MJ}=0.5 \mathrm{CJSW}=6.0 \mathrm{E}-10 \mathrm{MJSW}=0.33$

\section{M72M SPICE PARAMETERS}

MODEL CMOSN NMOS LEVEL $=2$ LD $=0.255300 \mathrm{U}$ TOX $=500.000 \mathrm{E}-10$ NSUB $=1.108241 \mathrm{E}+16 \quad \mathrm{VTO}=0.753588 \quad \mathrm{KP}=4.477000 \mathrm{E}-05$ GAMMA $=0.910100 \quad \mathrm{PHI}=0.600000 \quad \mathrm{UO}=669.208 \quad \mathrm{UEXP}=1.001000 \mathrm{E}-03$ UCRIT $=1.000000 \mathrm{E}+06$ DELTA $=4.04010$ VMAX $=22985.4 \quad \mathrm{XJ}=0.400000 \mathrm{U}$ LAMBDA $=7.356002 \mathrm{E}-02 \quad \mathrm{NFS}=4.975581 \mathrm{E}+11 \quad \mathrm{NEFF}=1.001000 \mathrm{E}-02$ $\mathrm{NSS}=0.000000 \mathrm{E}+00 \quad \mathrm{TPG}=1.00000 \quad \mathrm{RSH}=18.9 \quad \mathrm{CGSO}=2.12 \mathrm{E}-10$ $\mathrm{CGDO}=2.12 \mathrm{E}-10 \quad \mathrm{CJ}=2.773 \mathrm{E}-04 \quad \mathrm{MJ}=0.4479 \quad \mathrm{CJSW}=4.53 \mathrm{E}-10$ MJSW $=0.2719 \mathrm{~PB}=0.7$

MODEL CMOSP PMOS LEVEL $=2$ LD $=0.335150 \mathrm{U}$ TOX $=500.000 \mathrm{E}-10$ 
NSUB $=1.880559 \mathrm{E}+15$

$\mathrm{VTO}=-0.762310$

$\mathrm{KP}=1.717000 \mathrm{E}-05$

GAMMA $=0.374900 \quad \mathrm{PHI}=0.600000 \quad \mathrm{UO}=256.652 \quad \mathrm{UEXP}=0.162916$ UCRIT $=13006.7 \quad$ DELTA $=1.13910 \quad \mathrm{VMAX}=25951.8 \quad \mathrm{XJ}=0.400000 \mathrm{U}$ LAMBDA $=4.483024 \mathrm{E}-02 \quad \mathrm{NFS}=2.694968 \mathrm{E}+11 \quad \mathrm{NEFF}=1.001000 \mathrm{E}-02$ $\mathrm{NSS}=0.000000 \mathrm{E}+00 \quad \mathrm{TPG}=-1.00000 \quad \mathrm{RSH}=79.64 \quad \mathrm{CGSO}=2.79 \mathrm{E}-10$ $\mathrm{CGDO}=2.79 \mathrm{E}-10 \quad \mathrm{CJ}=1.538 \mathrm{E}-04 \quad \mathrm{MJ}=0.4308 \quad \mathrm{CJSW}=4.038 \mathrm{E}-10$ MJSW $=0.2041 \mathrm{~PB}=0.7$

\section{M72N SPICE PARAMETERS}

MODEL CMOSN NMOS LEVEL $=2$ LD $=0.154500 U$ TOX $=526.000 E-10$ $\mathrm{NSUB}=1.282623 \mathrm{E}+16$ VTO $=0.869800$ $\mathrm{KP}=4.181000 \mathrm{E}-05$ GAMMA $=1.03000 \quad \mathrm{PHI}=0.600000 \quad \mathrm{UO}=657.461 \quad \mathrm{UEXP}=1.001000 \mathrm{E}-03$ $\mathrm{UCRIT}=1.000000 \mathrm{E}+06$ DELTA $=1.06772 \mathrm{VMAX}=41989.1 \mathrm{XJ}=0.400000 \mathrm{U}$ LAMBDA $=7.268573 \mathrm{E}-04 \quad \mathrm{NFS}=1.338913 \mathrm{E}+12 \quad \mathrm{NEFF}=1.001000 \mathrm{E}-02$ $\mathrm{NSS}=0.000000 \mathrm{E}+00 \quad \mathrm{TPG}=1.00000 \quad \mathrm{RSH}=18.38 \quad \mathrm{CGSO}=1.01 \mathrm{E}-10$ $\mathrm{CGDO}=1.01 \mathrm{E}-10 \quad \mathrm{CJ}=2.944 \mathrm{E}-4 \quad \mathrm{MJ}=0.4502 \quad \mathrm{CJSW}=3.958 \mathrm{E}-10$ MJSW $=0.2067 \mathrm{~PB}=0.7$

MODEL CMOSP PMOS LEVEL $=2$ LD $=0.222250 \mathrm{U}$ TOX $=526.000 \mathrm{E}-10$ $\mathrm{NSUB}=1.743034 \mathrm{E}+15$

VTO $=-0.709473$ $\mathrm{KP}=1.671000 \mathrm{E}-05$ GAMMA $=0.379700 \quad \mathrm{PHI}=0.600000 \quad \mathrm{UO}=262.764 \quad \mathrm{UEXP}=0.166129$ UCRIT $=15705.6 \quad$ DELTA $=1.16196 \quad$ VMAX $=41912.8 \quad \mathrm{XJ}=0.400000 \mathrm{U}$ LAMBDA $=4.424773 \mathrm{E}-02 \quad \mathrm{NFS}=6.798740 \mathrm{E}+11 \quad \mathrm{NEFF}=1.001000 \mathrm{E}-02$ $\mathrm{NSS}=0.000000 \mathrm{E}+00 \quad \mathrm{TPG}=-1.00000 \quad \mathrm{RSH}=82.57 \quad \mathrm{CGSO}=1.46 \mathrm{E}-10$ $\mathrm{CGDO}=1.46 \mathrm{E}-10 \quad \mathrm{CJ}=1.217 \mathrm{E}-4 \quad \mathrm{MJ}=0.4171 \quad \mathrm{CJSW}=3.753 \mathrm{E}-10$ MJSW $=0.2042 \mathrm{~PB}=0.7$ 


\section{M72Q SPICE PARAMETERS}

MODEL CMOSN NMOS LEVEL $=2.00000 \quad$ LD $=0.3088000$ $\mathrm{TOX}=560.000 \mathrm{E}-10 \mathrm{NSUB}=2.007836 \mathrm{E}+16 \mathrm{VTO}=0.942848 \mathrm{KP}=4.294000 \mathrm{E}-$ 05 GAMMA $=1.37200$ PHI $=0.600000$ UO=718.876 UEXP $=1.001000 \mathrm{E}-03$ UCRIT $=1.000000 \mathrm{E}+06$ DELTA $=5.46347$ VMAX $=27561.9 \mathrm{XJ}=0.400000 \mathrm{U}$ LAMBDA $=9.000512 \mathrm{E}-02 \quad \mathrm{NFS}=7.832465 \mathrm{E}+11 \quad \mathrm{NEFF}=1.001000 \mathrm{E}-02$ $\mathrm{NSS}=0.000000 \mathrm{E}+00 \mathrm{TPG}=1.00000 \mathrm{RSH}=20 \mathrm{CGSO}=5.2 \mathrm{E}-10 \mathrm{CGDO}=5.2 \mathrm{E}-$ $10 \mathrm{CJ}=4.5 \mathrm{E}-4 \mathrm{MJ}=0.5 \mathrm{CJSW}=6.0 \mathrm{E}-10 \mathrm{MJSW}=0.33$

MODEL CMOSP PMOS LEVEL $=2.00000 \quad$ LD $=0.160450 \mathrm{U}$ $\mathrm{TOX}=560.000 \mathrm{E}-10 \mathrm{NSUB}=3.464315 \mathrm{E}+15 \mathrm{VTO}=-0.776821 \mathrm{KP}=1.654000 \mathrm{E}-$ $05 \quad$ GAMMA $=0.569900 \quad \mathrm{PHI}=0.600000 \quad \mathrm{UO}=276.903 \quad \mathrm{UEXP}=0.162848$ UCRIT $=18521.0 \quad$ DELTA $=1.21786 \quad$ VMAX $=74213.1 \quad \mathrm{XJ}=0.400000 \mathrm{U}$ LAMBDA $=3.739351 \mathrm{E}-02 \quad \mathrm{NFS}=1.618943 \mathrm{E}+12 \quad \mathrm{NEFF}=1.001000 \mathrm{E}-02$ $\mathrm{NSS}=0.000000 \mathrm{E}+00 \mathrm{TPG}=-1.00000 \mathrm{RSH}=55 \mathrm{CGSO}=4 \mathrm{E}-10 \mathrm{CGDO}=4 \mathrm{E}-10$ $\mathrm{CJ}=3.6 \mathrm{E}-4 \mathrm{MJ}=0.5 \mathrm{CJSW}=6.0 \mathrm{E}-10 \mathrm{MJSW}=0.33$

\section{M73W SPICE PARAMETERS}

MODEL CMOSN NMOS LEVEL $=2 \quad$ LD $=0.3355 \mathrm{U} \quad$ TOX $=425 \mathrm{E}-10$ $\mathrm{NSUB}=2.455 \mathrm{E}+16 \mathrm{VTO}=0.9954 \mathrm{KP}=4.348 \mathrm{E}-05 \mathrm{GAMMA}=1.108 \mathrm{PHI}=0.6$ $\mathrm{UO}=543.5$ UEXP=3.205439E-02 UCRIT $=13297.2$ DELTA $=1.950344 \mathrm{E}-05$ VMAX $=62889.8 \quad \mathrm{XJ}=0.4 \quad$ LAMBDA $=7.543926 \mathrm{E}-03 \quad \mathrm{NFS}=2.567312 \mathrm{E}+12$ NEFF $=1.001 \mathrm{E}-02 \quad \mathrm{NSS}=0.0 \quad \mathrm{TPG}=1.0 \quad \mathrm{RSH}=28.97 \quad \mathrm{CGDO}=3.28 \mathrm{E}-10$ $\mathrm{CGSO}=3.28 \mathrm{E}-10 \mathrm{CJ}=3.805 \mathrm{E}-04 \mathrm{MJ}=0.5016 \mathrm{CJSW}=5.25 \mathrm{E}-10 \mathrm{MJSW}=0.2911$ $\mathrm{PB}=0.74$

MODEL CMOSP PMOS LEVEL $=2 \quad$ LD $=0.2433 \mathrm{U} \quad$ TOX $=425 \mathrm{E}-10$ $\mathrm{NSUB}=5.366480 \mathrm{E}+15 \quad \mathrm{VTO}=-0.855 \quad \mathrm{KP}=1.8952 \mathrm{E}-05 \quad \mathrm{GAMMA}=0.518$ 
$\mathrm{PHI}=0.6 \mathrm{UO}=236.9 \quad \mathrm{UEXP}=1.02358 \mathrm{UCRIT}=193182.0 \quad \mathrm{DELTA}=3.3814$ VMAX $=33990.6 \quad \mathrm{XJ}=0.4 \quad \mathrm{LAMBDA}=8.48968 \mathrm{E}-04 \quad \mathrm{NFS}=1.0 \mathrm{E}+12$ $\mathrm{NEFF}=1.001 \mathrm{E}-02 \quad \mathrm{NSS}=0.0 \quad \mathrm{TPG}=-1.0 \quad \mathrm{RSH}=106.1 \quad \mathrm{CGDO}=2.34 \mathrm{E}-10$ $\mathrm{CGSO}=2.34 \mathrm{E}-10 \mathrm{CJ}=2.462 \mathrm{E}-04 \mathrm{MJ}=0.5093 \mathrm{CJSW}=2.765 \mathrm{E}-10 \mathrm{MJSW}=0.131$ $\mathrm{PB}=0.77$

\section{M74Y SPICE PARAMETERS}

MODEL CMOSN NMOS LEVEL $=2 \quad \mathrm{LD}=0.606 \mathrm{U} \quad \mathrm{TOX}=493 \mathrm{E}-10$ $\mathrm{NSUB}=1.528 \mathrm{E}+16 \mathrm{VTO}=0.8531 \mathrm{KP}=4.02 \mathrm{E}-05 \mathrm{GAMMA}=1.014 \mathrm{PHI}=0.6$ $\mathrm{UO}=582.9 \quad \mathrm{UEXP}=4.155837 \mathrm{E}-02 \quad \mathrm{UCRIT}=72546.9 \quad \mathrm{DELTA}=1.0 \mathrm{E}-06$ $\mathrm{VMAX}=56103.1 \quad \mathrm{XJ}=0.4 \mathrm{U} \quad \mathrm{LAMBDA}=1.829946 \mathrm{E}-02 \quad \mathrm{NFS}=1.037035 \mathrm{E}+12$ $\mathrm{NEFF}=1.001 \mathrm{E}-02 \quad \mathrm{NSS}=0.0 \quad \mathrm{TPG}=1.0 \quad \mathrm{RSH}=14.76 \quad \mathrm{CGDO}=5.09 \mathrm{E}-10$ $\mathrm{CGSO}=5.09 \mathrm{E}-10 \quad \mathrm{CJ}=3.794 \mathrm{E}-04 \quad \mathrm{MJ}=0.4567 \quad \mathrm{CJSW}=6.218 \mathrm{E}-10$ $\mathrm{MJSW}=0.3175 \mathrm{~PB}=0.74$

MODEL CMOSP PMOS LEVEL $=2 \quad \mathrm{LD}=0.5905 \mathrm{U}$ TOX $=493 \mathrm{E}-10$ $\mathrm{NSUB}=1.672015 \mathrm{E}+15 \mathrm{VTO}=-0.955075 \mathrm{KP}=1.6638 \mathrm{E}-05 \quad \mathrm{GAMMA}=0.3354$ $\mathrm{PHI}=0.6 \mathrm{UO}=241.251 \mathrm{UEXP}=1.09559 \mathrm{UCRIT}=162059.0 \mathrm{DELTA}=0.486241$ VMAX $=100000.0 \mathrm{XJ}=0.4 \mathrm{U}$ LAMBDA $=9.497504 \mathrm{E}-05 \mathrm{NFS}=3.116837 \mathrm{E}+12$ $\mathrm{NEFF}=1.001 \mathrm{E}-02 \quad \mathrm{NSS}=0.0 \quad \mathrm{TPG}=-1.0 \quad \mathrm{RSH}=31.86 \quad \mathrm{CGDO}=4.96 \mathrm{E}-10$ $\mathrm{CGSO}=4.96 \mathrm{E}-10 \quad \mathrm{CJ}=1.375 \mathrm{E}-04 \quad \mathrm{MJ}=0.4033 \quad \mathrm{CJSW}=5.003 \mathrm{E}-10$ MJSW $=0.2432 \mathrm{~PB}=0.66$

\section{M74Z SPICE PARAMETERS}

MODEL CMOSN NMOS LEVEL $=2 \quad$ LD $=0.3943 U$ TOX $=502 E-10$ $\mathrm{NSUB}=1.22416 \mathrm{E}+16 \mathrm{VTO}=0.756 \mathrm{KP}=4.224 \mathrm{E}-05 \mathrm{GAMMA}=0.9241 \mathrm{PHI}=0.6$ $\mathrm{UO}=623.661 \mathrm{UEXP}=8.328627 \mathrm{E}-02 \mathrm{UCRIT}=54015.0 \mathrm{DELTA}=5.218409 \mathrm{E}-03$ 
$\mathrm{VMAX}=50072.2 \mathrm{XJ}=0.4 \mathrm{U} \quad \mathrm{LAMBDA}=2.975321 \mathrm{E}-02 \quad \mathrm{NFS}=4.909947 \mathrm{E}+12$ NEFF $=1.001 \mathrm{E}-02 \quad \mathrm{NSS}=0.0 \quad$ TPG $=1.0 \quad \mathrm{RSH}=20.37 \quad \mathrm{CGDO}=3.1 \mathrm{E}-10$ $\mathrm{CGSO}=3.1 \mathrm{E}-10 \mathrm{CJ}=3.205 \mathrm{E}-04 \mathrm{MJ}=0.4579 \mathrm{CJSW}=4.62 \mathrm{E}-10 \mathrm{MJSW}=0.2955$ $\mathrm{PB}=0.7$

MODEL CMOSP PMOS LEVEL $=2$ LD $=0.2875 \mathrm{U}$ TOX=502E-10 NSUB $=1.715148 \mathrm{E}+15 \quad \mathrm{VTO}=-0.7045 \quad \mathrm{KP}=1.686 \mathrm{E}-05 \quad$ GAMMA $=0.3459$ $\mathrm{PHI}=0.6 \mathrm{UO}=248.933$ UEXP $=1.02652$ UCRIT $=182055.0 \mathrm{DELTA}=1.0 \mathrm{E}-06$ VMAX $=100000.0 \quad \mathrm{XJ}=0.4 \mathrm{U} \quad \mathrm{LAMBDA}=1.25919 \mathrm{E}-02 \quad \mathrm{NFS}=1.0 \mathrm{E}+12$ NEFF $=1.001 \mathrm{E}-02 \quad \mathrm{NSS}=0.0 \quad \mathrm{TPG}=-1.0 \quad \mathrm{RSH}=79.10 \quad \mathrm{CGDO}=2.89 \mathrm{E}-10$ $\mathrm{CGSO}=2.89 \mathrm{E}-10 \mathrm{CJ}=1.319 \mathrm{E}-04 \mathrm{MJ}=0.4125 \mathrm{CJSW}=3.421 \mathrm{E}-10 \mathrm{MJSW}=0.198$ $\mathrm{PB}=0.66$

\section{M75A SPICE PARAMETERS}

MODEL CMOSN NMOS LEVEL $=2 \quad$ LD $=0.3317 \mathrm{U} \quad$ TOX $=434 \mathrm{E}-10$ $\mathrm{NSUB}=2.358802 \mathrm{E}+16 \mathrm{VTO}=0.8706 \mathrm{KP}=4.34 \mathrm{E}-05 \mathrm{GAMMA}=1.109 \mathrm{PHI}=0.6$ $\mathrm{UO}=553.988 \quad \mathrm{UEXP}=4.15439 \mathrm{E}-02 \quad \mathrm{UCRIT}=157748.0 \quad$ DELTA $=1.0 \mathrm{E}-06$ VMAX $=75850.8 \quad \mathrm{XJ}=0.4 \mathrm{U} \quad$ LAMBDA $=1.829483 \mathrm{E}-02 \quad \mathrm{NFS}=1.036802 \mathrm{E}+12$ NEFF $=1.001 \mathrm{E}-02 \quad \mathrm{NSS}=0.0 \quad \mathrm{TPG}=1.0 \quad \mathrm{RSH}=30.08 \quad \mathrm{CGDO}=3.78 \mathrm{E}-10$ $\mathrm{CGSO}=3.78 \mathrm{E}-10 \quad \mathrm{CJ}=3.838 \mathrm{E}-04 \quad \mathrm{MJ}=0.5017 \quad \mathrm{CJSW}=5.304 \mathrm{E}-10$ MJSW=0.2997 PB=0.74

MODEL CMOSP PMOS LEVEL $=2 \quad$ LD $=0.2651 \mathrm{U} \quad$ TOX $=434 \mathrm{E}-10$ $\mathrm{NSUB}=5.926819 \mathrm{E}+15 \mathrm{VTO}=-0.879441 \mathrm{KP}=1.8826 \mathrm{E}-05$ GAMMA $=0.5559$ $\mathrm{PHI}=0.6 \mathrm{UO}=240.308$ UEXP $=1.06435$ UCRIT $=206582.0$ DELTA $=0.727743$ VMAX $=100000.0 \quad \mathrm{XJ}=0.4 \mathrm{U} \quad$ LAMBDA $=1.0 \mathrm{E}-06 \quad \mathrm{NFS}=3.708259 \mathrm{E}+12$ NEFF $=1.001 \mathrm{E}-02 \quad \mathrm{NSS}=0.0 \quad$ TPG $=-1.0 \quad \mathrm{RSH}=106.4 \quad \mathrm{CGDO}=2.91 \mathrm{E}-10$ $\mathrm{CGSO}=2.91 \mathrm{E}-10 \quad \mathrm{CJ}=2.499 \mathrm{E}-04 \quad \mathrm{MJ}=0.4887 \quad \mathrm{CJSW}=3.002 \mathrm{E}-10$ 
MJSW=0.1373 PB $=0.7$

\section{M75D SPICE PARAMETERS}

MODEL CMOSN NMOS LEVEL $=2$ LD=0.611100U TOX=452.000014E$10 \mathrm{NSUB}=1.42394 \mathrm{E}+16 \mathrm{VTO}=0.782883 \mathrm{KP}=4.152 \mathrm{E}-05 \quad \mathrm{GAMMA}=0.907$ $\mathrm{PHI}=0.6 \mathrm{UO}=543.5 \mathrm{UEXP}=0.198348 \mathrm{UCRIT}=133524 \quad \mathrm{DELTA}=3.34174$ VMAX $=59251.5 \mathrm{XJ}=0.400000 \mathrm{U}$ LAMBDA $=0.0385668 \mathrm{NFS}=5.10113 \mathrm{E}+12$ $\mathrm{NEFF}=1.001 \mathrm{NSS}=0 \mathrm{TPG}=1.000000 \mathrm{RSH}=15.860000 \mathrm{CGDO}=4.66843 \mathrm{E}-10$ $\mathrm{CGSO}=4.66843 \mathrm{E}-10 \quad \mathrm{CJ}=0.0003897 \quad \mathrm{MJ}=0.461700 \quad \mathrm{CJSW}=0.000601$ MJSW $=0.317500 \mathrm{~PB}=0.730000$

MODEL CMOSP PMOS LEVEL $=2 \mathrm{LD}=0.503450 \mathrm{U}$ TOX $=535.000028 \mathrm{E}-10$ $\mathrm{NSUB}=2.03639 \mathrm{E}+15 \quad \mathrm{VTO}=-0.901643 \quad \mathrm{KP}=1.6962 \mathrm{E}-05 \quad \mathrm{GAMMA}=0.343$ $\mathrm{PHI}=0.6 \quad \mathrm{UO}=221.484 \quad \mathrm{UEXP}=0.276693 \quad \mathrm{UCR} \mathrm{UT}=79352.5$ DELTA $=0.000116196 \quad \mathrm{VMAX}=19574.5 \quad \mathrm{XJ}=0.40000 \mathrm{U}$ LAMBDA $=0.0971642 \mathrm{NFS}=2.63666 \mathrm{E}+12 \quad \mathrm{NEFF}=0.01001 \mathrm{NSS}=0 \quad \mathrm{TPG}=-$ $1.000000 \quad \mathrm{RSH}=31.830000 \quad \mathrm{CGDO}=3.24937 \mathrm{E}-10 \quad \mathrm{CGSO}=3.24937 \mathrm{E}-10$ $\mathrm{CJ}=0.0001419 \quad \mathrm{MJ}=0.405300 \quad \mathrm{CJSW}=0.0004923 \quad \mathrm{MJSW}=0.240200$ $\mathrm{PB}=0.600000$

\section{M76L SPICE PARAMETERS}

MODEL CMOSN NMOS LEVEL $=2 \quad$ LD $=0.6865 U$ TOX $=535 E-10$ $\mathrm{NSUB}=2.106653 \mathrm{E}+16 \quad \mathrm{VTO}=1.05499 \mathrm{KP}=3.843749 \mathrm{E}-05 \quad \mathrm{GAMMA}=1.318$ $\mathrm{PHI}=0.6 \mathrm{UO}=595.517 \mathrm{UEXP}=0.196776 \mathrm{UCRIT}=113854 . \mathrm{DELTA}=0.338246$ VMAX $=61223.4 \quad \mathrm{XJ}=0.4 \mathrm{U} \quad \mathrm{LAMBDA}=3.182768 \mathrm{E}-02 \quad \mathrm{NFS}=1.136274 \mathrm{E}+12$ $\mathrm{NEFF}=1.001 \mathrm{E}-02 \quad \mathrm{NSS}=0.0 \quad \mathrm{TPG}=1.0 \quad \mathrm{RSH}=12.14 \quad \mathrm{CGDO}=4.4308 \mathrm{E}-10$ $\mathrm{CGSO}=4.4308 \mathrm{E}-10 \quad \mathrm{CJ}=3.819 \mathrm{E}-04 \quad \mathrm{MJ}=0.4161 \quad \mathrm{CJSW}=5.527 \mathrm{E}-10$ 
$\mathrm{MJSW}=0.3085 \mathrm{~PB}=0.73$

MODEL CMOSP PMOS LEVEL $=2 \quad$ LD $=0.4564 \mathrm{U} \quad$ TOX $=535 \mathrm{E}-10$ $\mathrm{NSUB}=4.28184 \mathrm{E}+15 \quad \mathrm{VTO}=-0.798734 \mathrm{KP}=1.4928 \mathrm{E}-05 \quad \mathrm{GAMMA}=0.5887$ $\mathrm{PHI}=0.6 \mathrm{UO}=231.29 \mathrm{UEXP}=0.383116 \mathrm{UCRIT}=89015.8$ DELTA $=1.0 \mathrm{E}-06$ $\mathrm{VMAX}=51840.0 \mathrm{XJ}=0.4 \mathrm{U} \quad \mathrm{LAMBDA}=4.977096 \mathrm{E}-02 \quad \mathrm{NFS}=2.162284 \mathrm{E}+09$ $\mathrm{NEFF}=1.001 \mathrm{E}-02 \quad \mathrm{NSS}=0.0 \quad \mathrm{TPG}=-1.0 \quad \mathrm{RSH}=38.10 \quad \mathrm{CGDO}=2.946 \mathrm{E}-10$ $\mathrm{CGSO}=2.946 \mathrm{E}-10 \quad \mathrm{CJ}=2.309 \mathrm{E}-04 \quad \mathrm{MJ}=0.4449 \quad \mathrm{CJSW}=3.345 \mathrm{E}-10$ MJSW=0.1613 $\mathrm{PB}=0.71$ 
APPENDIX C

PROGRAM CODE OF BISECTION METHOD 
${ }^{*}$ Initialize variables before using bisection method.*/

pretmpval $=0.0$;

tmpval = LARGENUMBER;

lowt $=$ toff;

upt $=$ toff;

/* Newton method */

do \{

pretmpval $=$ tmpval;

midt $=0.5 *($ lowt + upt $)$;

lowval = Value(W,L,T,CL,pt,lowt,toff);

upval = Value(W,L,T,CL,pt,upt,toff);

midval = Value(W,L,T,CL,pt,midt,toff);

if $(($ lowval<0.0) \&\& (upval<0.0) \& \& (midval<0.0))

$\{$ midt = LARGENUMBER; break; $\}$

if $($ lowval $==0.0)\{$ midt $=$ lowt; break; $\}$

if (upval $==0.0)\{$ midt $=$ upt; break; $\}$

if ( midval $==0.0$ ) break;

if $(($ lowval<0.0) \&\& (upval>0.0) \&\& (midval<0.0))

$\{$ tmpval $=$ midval; lowt $=$ midt; $\}$

if $(($ lowval<0.0) \&\& (upval>0.0) \&\& (midval $>0.0))$

$\{$ tmpval = midval; upt $=$ midt; $\}$

check = tmpval - pretmpval;

if $($ check<0.0) check $*=-1.0$;

\} while (check $>$ SMALLNUMBER);

return (midt); 